\title{
METHODOLOGY DEVELOPMENT AND LOCAL CALIBRATION OF MEPDG PERMANENT DEFORMATION MODELS FOR ONTARIO'S FLEXIBLE PAVEMENTS
}

\author{
by \\ Afzal Waseem, \\ Bachelor of Science in Civil Engineering \\ University of Engineering \& Technology, Lahore, 2011
}

\author{
A thesis \\ presented to Ryerson University \\ in partial fulfillment of the \\ requirements for the degree of \\ Master of Applied Science \\ in the Program of \\ Civil Engineering
}

Toronto, Ontario, Canada, 2013

(C)Afzal Waseem 2013 


\section{Author's Declaration}

\section{AUTHOR'S DECLARATION FOR ELECTRONIC SUBMISSION OF A THESIS}

I hereby declare that I am the sole author of this thesis. This is a true copy of the thesis, including any required final revisions as accepted by my examiners.

I authorize Ryerson University to lend this thesis to other institutions or individuals for the purpose of scholarly research.

I further authorize Ryerson University to reproduce this thesis by photocopying or by other means, in total or in part, at the request of other institutions or individuals for the purpose of scholarly research.

I understand that my thesis may be electronically available to the public. 


\title{
METHODOLOGY DEVELOPMENT AND LOCAL CALIBRATION OF MEPDG PERMANENT DEFORMATION MODELS FOR ONTARIO'S FLEXIBLE PAVEMENTS \\ by
}

Afzal Waseem

Master of Applied Science in Civil Engineering, 2013

Department of Civil Engineering, Ryerson University

Toronto, Canada

\begin{abstract}
The AASHTO-supported interim Mechanistic-Empirical Pavement Design Guide (MEPDG) was published in 2008 for trial use. However, local calibration of the empirical distress models in the design guide has been an essential exercise for any transportation agency before it formally adopts the MEPDG for practical design use. Nevertheless, a universally agreed upon local calibration methodology using historical pavement performance data from field evaluation has not been available. This research focuses on permanent deformation or rutting models in MEPDG and presents a layer-by-layer longitudinal local calibration process at the DARWin$\mathrm{ME}^{\mathrm{TM}}$ platform coupled with Excel Macros. Using the best input data available, many of Level 3 accuracy, the study performs local calibration for 10 reconstructed and 19 rehabilitated flexible pavement sections. Further, this thesis statistically evaluated the level-3 pre-overlay rut value for rehabilitated flexible pavements in Ontario. A comparison of the longitudinal calibration and pooled local calibration demonstrated the importance of the longitudinal calibration in the quantification of uncertainties involved in local calibration.
\end{abstract}




\section{Acknowledgements}

My deepest gratitude goes to my mentor and supervisor Dr. Arnold (Xian-Xun) Yuan, who expertly guided me through my graduate studies, since my first day at Ryerson University. His consistent mentoring developed my ethics of scientific research and motivated me to indulge in his fascinating domain of civil engineering research.

I would like to extend my gratitude to Dr. Medhat Shehata for his sincere and valuable guidance. I would also like to extend my thanks to Mr. Desmond Rogan the Network Administrator of the Department of Civil Engineering for his help in keeping the computer program running.

Finally, I would like to express my gratitude to my family, specially my mother and father for their unceasing encouragement and support. 


\section{Table of Contents}

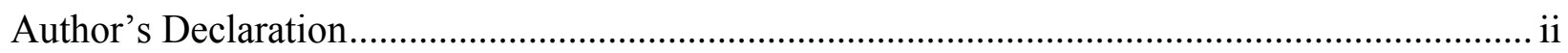

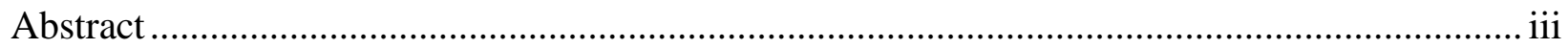

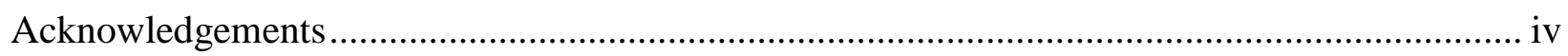

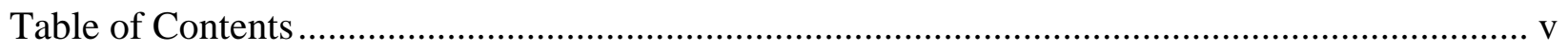

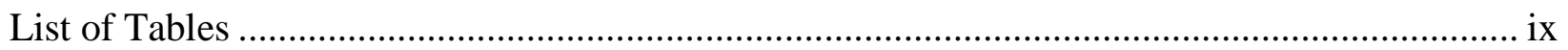

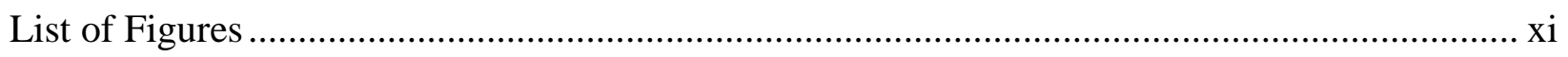

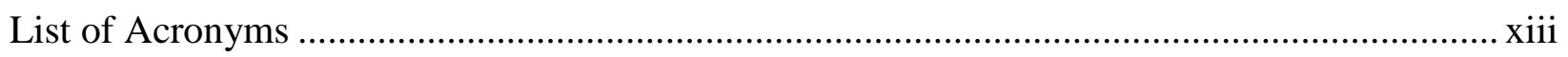

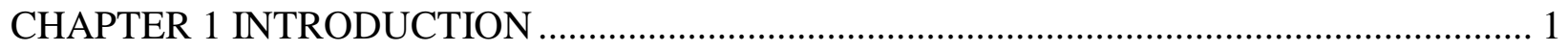

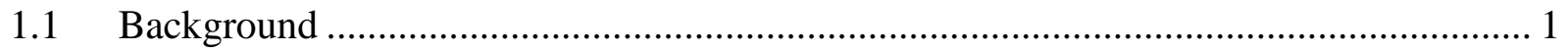

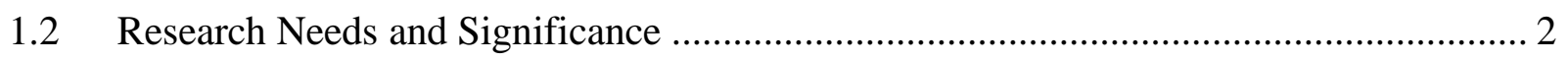

1.3 Research Objective and Scope …………………..................................................... 3

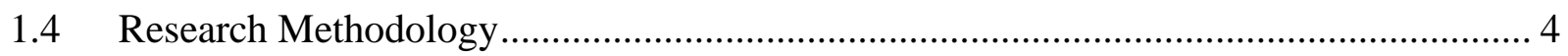

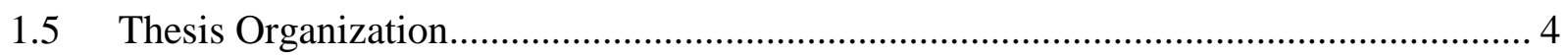

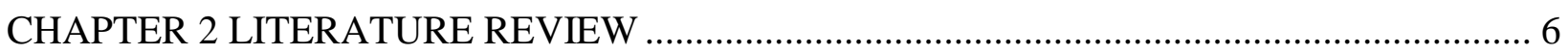

2.1 Historical Developments of Pavement Design Methods................................................. 6

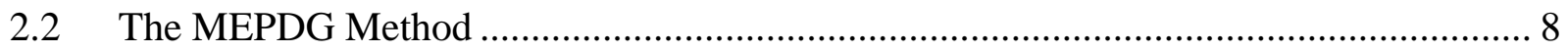

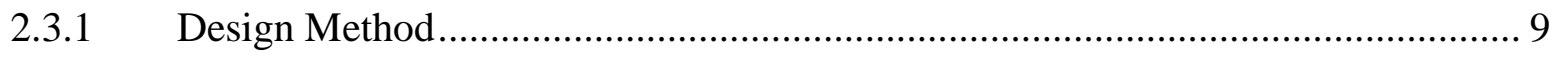

2.3.2 Hierarchical Design Input Levels …………………………………………..... 12

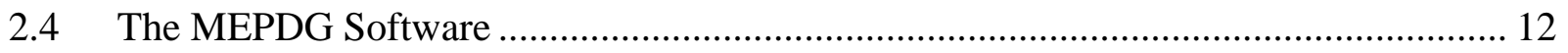

2.4.1 Computational Methodology …………....................................................... 13

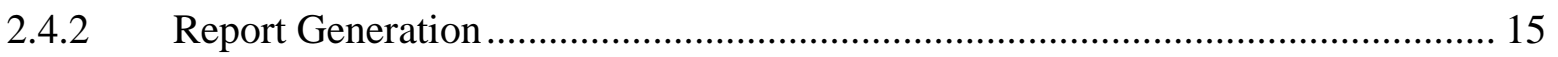

2.5 Permanent Deformation: Mechanism and Models .......................................................... 15 


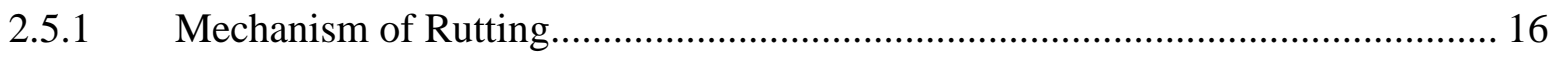

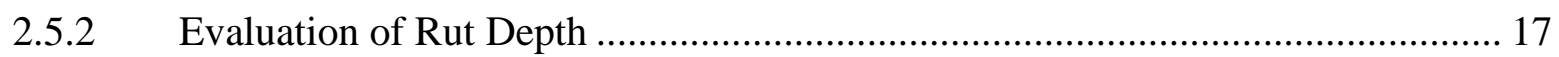

2.5.3 Existing Permanent Deformation Models............................................................. 17

2.5.4 MEPDG Rutting Distress Model for Flexible Pavements ................................... 20

2.5.4.1 HMA Rutting Model ............................................................................. 21

2.5.4.2 Unbound Granular and Subgrade Rutting Model........................................... 22

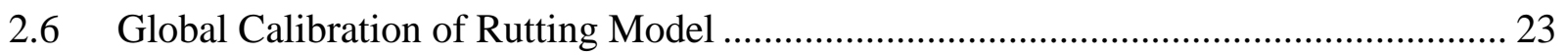

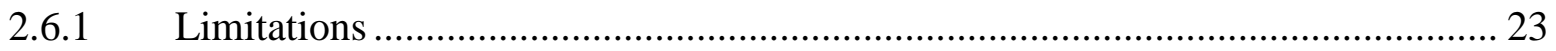

2.6.2 MEPDG Software Simulation Runs …………................................................ 24

2.6.3 Sensitivity Analysis for Permanent Deformation …………………………....... 26

2.7 Former Local Calibration Studies .......................................................................... 27

$2.8 \quad$ Local Calibration Methodology Guide ………………................................................ 33

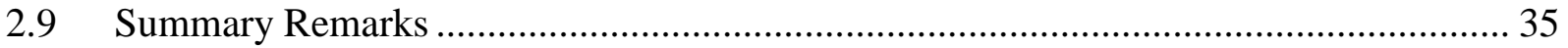

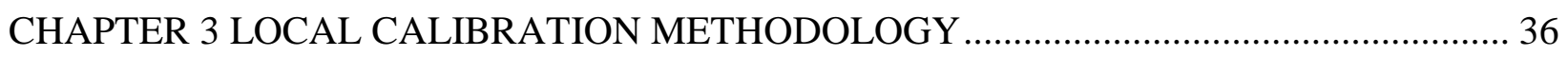

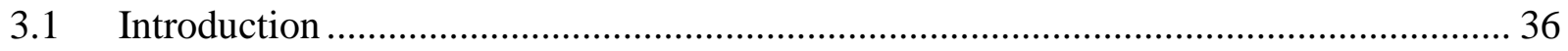

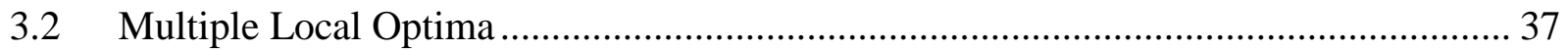

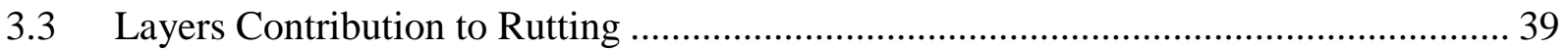

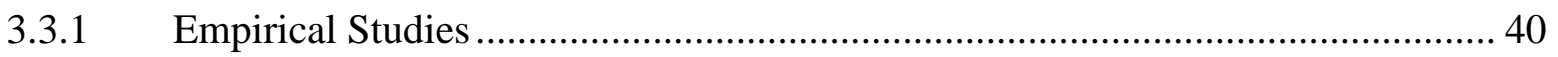

3.3.2 Layers Contribution to Rutting from Software Packages ..................................... 43

3.3.3 Findings from DARWin-ME ${ }^{\mathrm{TM}}$ Global Models .............................................. 43

3.4 Local Calibration Methodology ………………….................................................... 46

CHAPTER 4 LOCAL CALIBRATION OF RECONSTRUCTED FLEXIBLE PAVEMENTS. 51

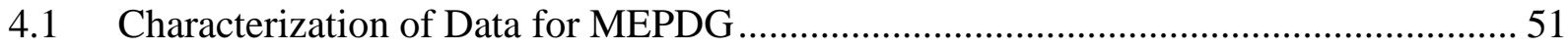

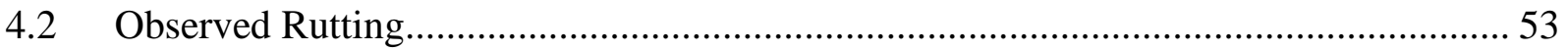


4.3 Local Calibration Results of Reconstructed Flexible Pavement Sections

4.3.1 Locally Calibrated Parameters ................................................................. 55

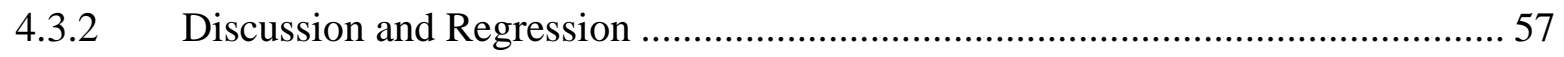

4.3.3 Comparison with Pooled and Global Calibration ........................................... 61

CHAPTER 5 LOCAL CALIBRATION OF REHABILITATED FLEXIBLE PAVEMENTS ... 67

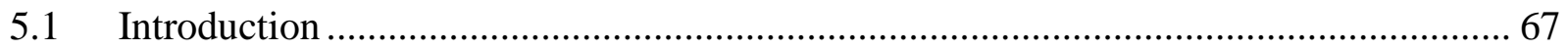

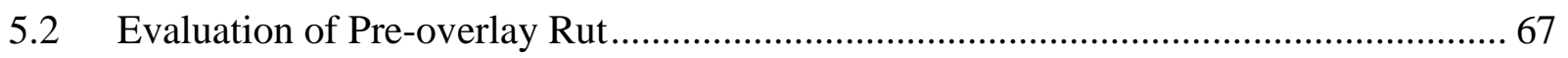

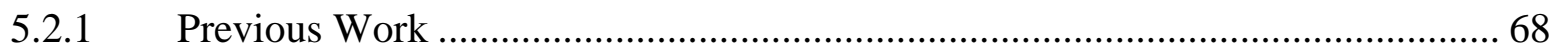

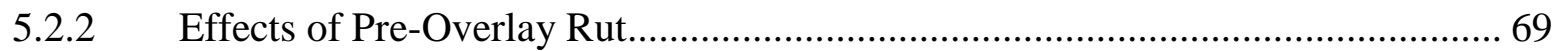

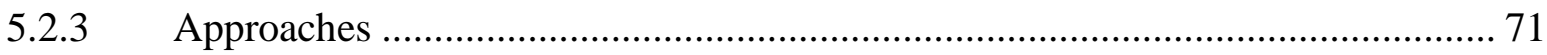

5.2.4 Statistical Estimation of Pre-overlay Rut Depth........................................ 72

5.2.4.1 Criteria for Identification of Pre-overlay rut ........................................ 72

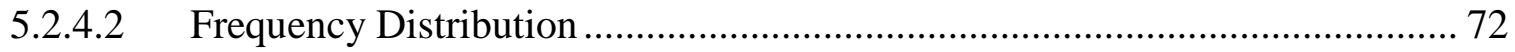

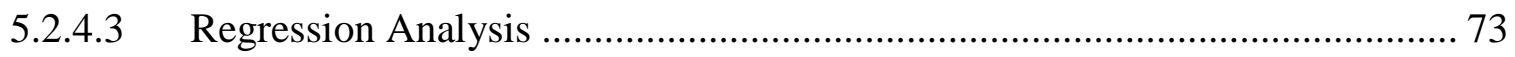

S.2.5 Scenario Analyses ............................................................................ 74

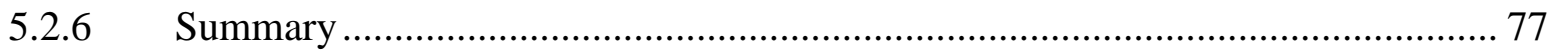

5.3 Local Calibration Results of Rehabilitated Flexible Pavement Sections ...................... 77

5.3.1 Locally Calibrated Parameters ................................................................ 77

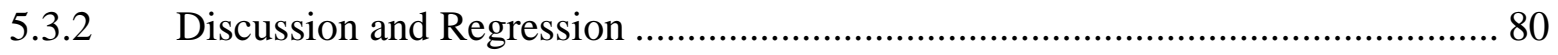

5.3.3 Comparison with Pooled and Global Calibration ............................................ 83

CHAPTER 6 SUMMARY, CONCLUSIONS AND RECOMENDATIONS .......................... 89

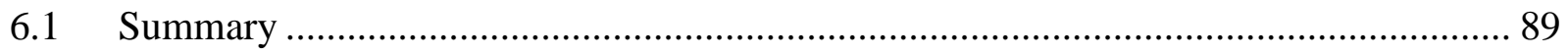

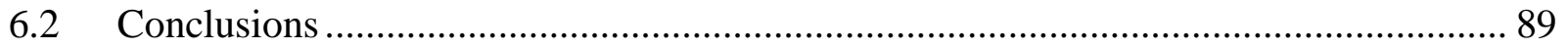

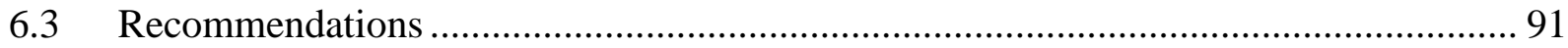




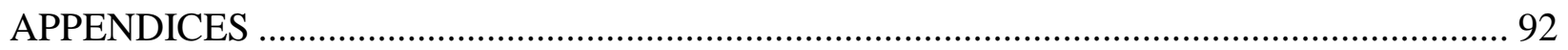

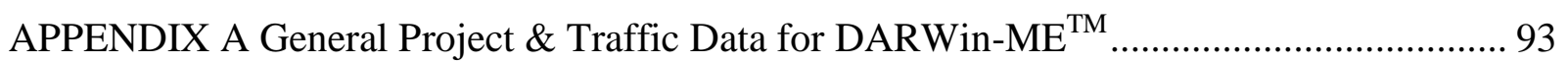

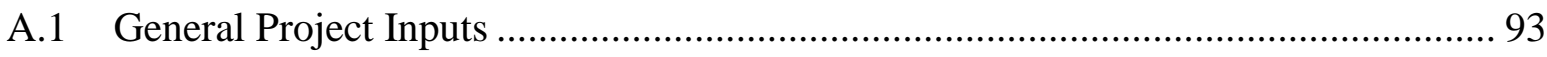

A.2 Annual Average Daily Truck Traffic ........................................................... 94

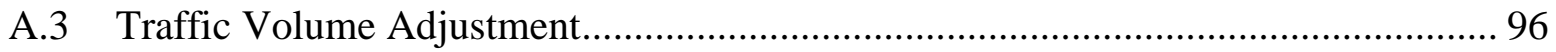

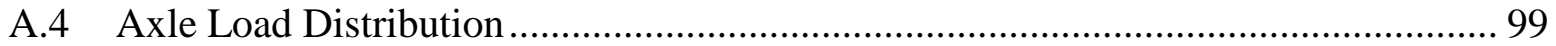

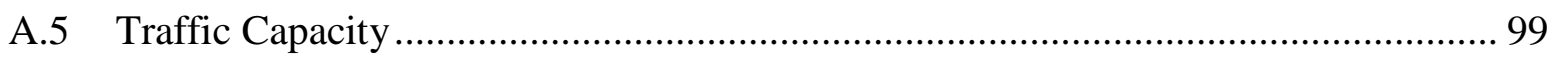

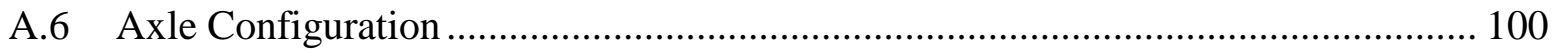

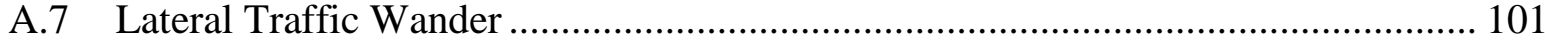

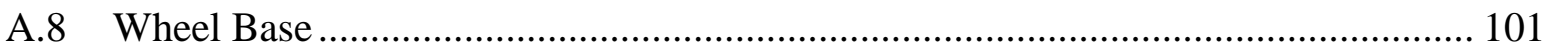

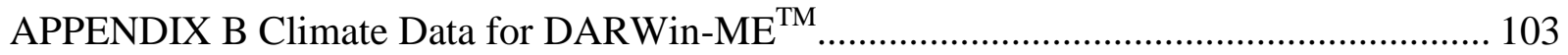

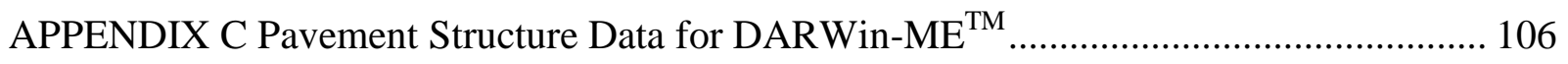

C.1 Asphalt Concrete Material Inputs …........................................................ 106

C.2 Unbound Granular and Fine/Subgrade Material Inputs ................................... 108

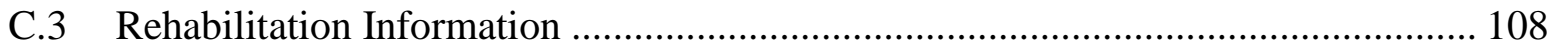

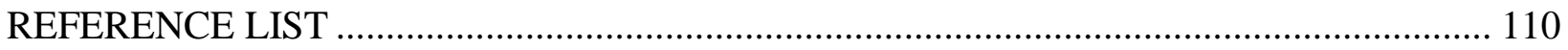




\section{List of Tables}

Table 2-1: The MEPDG HMA Rutting Models used in the DARWin-ME ${ }^{\mathrm{TM}}$ 21

Table 2-2: The MEPDG Unbound and Subgrade Rutting Models used in the DARWin-ME ${ }^{\mathrm{TM}} .22$ Table 2-3: Calibration Factors of Rutting Model obtained from Former Local Calibration studies 32

Table 3-1: Average Percentage of Surface Rutting for different Pavement layers and Subgrade.

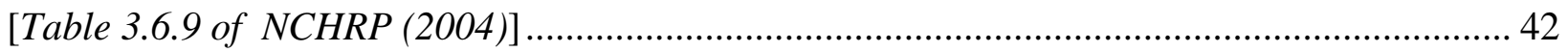

Table 3-2: Layers contribution to Rutting from Software Packages ...................................... 43

Table 4-1: Comparison of RSS from Original Observed Rutting and Smoothed Observed Rutting 55

Table 4-2: First stage Section-by-section Local Calibration results for Reconstructed Pavements. 56

Table 4-3: Second stage Section-by-section Longitudinal Local Calibration results for Reconstructed Pavements. 57

Table 4-4: Statistics of $\beta_{A C 1}{ }^{(0)}$ regressed equation for reconstructed section............................ 58

Table 4-5: Statistics of $\beta_{\mathrm{GB}}$ regressed equation for reconstructed section.............................. 59

Table 4-6: Statistics of $\beta_{\mathrm{SB}}$ regressed equation for reconstructed section................................ 59

Table 4-7: Major Input Characteristics of Reconstructed pavement sections. .......................... 60

Table 4-8: RSS of Reconstructed sections based on the Pooled local calibration results. .......... 61

Table 4-9: Comparison of Statistics of Global calibration and Local calibration. ..................... 66

Table 5-1: Parameters of Frequency distribution for Pre-overlay rut.................................... 74

Table 5-2: Regression Statistics of Rut depth with RCI and DMI ...................................... 74

Table 5-3: Regression analysis results for multiple Pre-overlay Rut values. .......................... 77

Table 5-4: First stage Section-by-section Local calibration results for Rehabilitated pavements 78 
Table 5-5: Second stage Section-by-section Longitudinal Local calibration results for

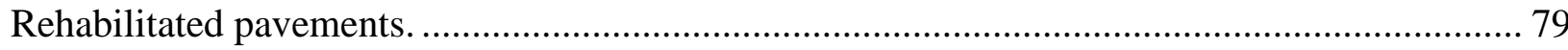

Table 5-6: Major Input Characteristics of Rehabilitated pavement sections........................... 81

Table 5-7: Statistics of $\beta_{\mathrm{AC} 1}{ }^{(0)}$ regressed equation for rehabilitated section............................ 82

Table 5-8: Statistics of $\beta_{\mathrm{GB}}$ regressed equation for rehabilitated section. ............................. 83

Table 5-9: RSS of Rehabilitated sections based on the Pooled local calibration results............. 84

Table A-1: General Project Input's Requirement for DARWin-ME ${ }^{\mathrm{TM}} \quad \ldots \ldots \ldots \ldots \ldots \ldots \ldots . . . . . . .63$

Table A-2: Ontario Recommended Percentage of Trucks in Design Lane (MTO 2012) ............ 94

Table A-3: Classification of operational speed on highway type .......................................... 95

Table A-4: Truck Traffic classification (AASHTOWare Pavement ME Design) ....................... 96

Table A-5: TTC group description and corresponding vehicle (truck) class distribution (percentages) available in DARWin-ME ${ }^{\mathrm{TM}}$ (AASHTOWare Pavement ME Design) ................. 97

Table A-6: Functions used in forecasting AADTT over pavement age. ................................. 98

Table A-7: Southern Ontario Typical Axle Per Trucks Table (MTO 2012) ............................ 98

Table A-8: Northern Ontario Typical Axle Per Trucks Table (MTO 2012) ............................. 99

Table A-9: Traffic Inputs with level and source used for DARWin-ME ${ }^{\mathrm{TM}}$ projects of Ontario. 102

Table B-1: Climate Inputs with level and source used in DARWin-ME ${ }^{\mathrm{TM}}$ projects in Ontario.104 


\section{List of Figures}

Figure 2.1: Philosophy of development of NCHRP Guide................................................... 8

Figure 2.2: Major components of MEPDG methodology. .............................................. 10

Figure 2.3: DARWin-ME ${ }^{\mathrm{TM}}$ Software components......................................................... 14

Figure 2.4: $(\mathrm{a}, \mathrm{b})$ Flowchart of global calibration procedures for MEPDG rutting model .......... 25

Figure 3.1: RSS contours against $\beta_{\mathrm{AC} 1}$ and $\beta_{\mathrm{SG}}$ showing multiple local minima..................... 38

Figure 3.2: RSS contour against $\beta_{\mathrm{GB}}$ and $\beta_{\mathrm{SG}}$ plotted at constant value $\beta_{\mathrm{AC} 3}=\beta_{\mathrm{AC} 3}=1.0 \ldots \ldots \ldots . .38$

Figure 3.3: Comparison of Predicted total rut depth curves with different combinations of

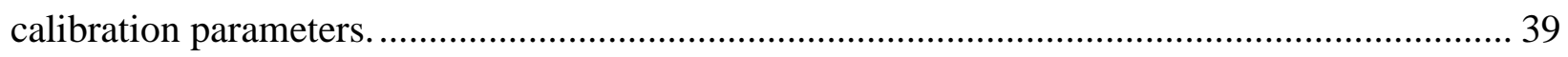

Figure 3.4: Variation of layers percentage contributions with TxMLS load repetitions............ 41

Figure 3.5: Summary of layers contribution to rutting (New Pavement Sections).................... 42

Figure 3.6: Percentage layer contribution of rutting for new or reconstructed sections along

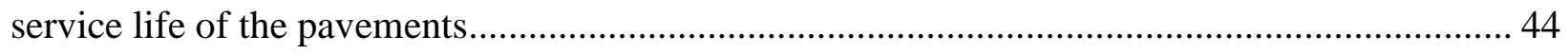

Figure 3.7: Percentage layer contribution of rutting for rehabilitated sections along service life of

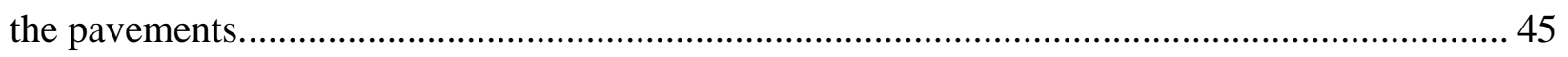

Figure 3.8: Flowchart for Section-by-section longitudinal local calibration based on layers rutting

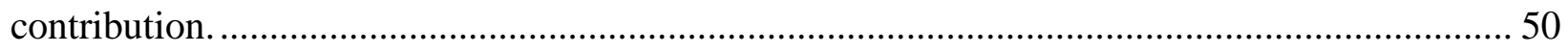

Figure 4.1: Locations of the 51 flexible pavement sections on Google Maps........................... 52

Figure 4.2: Visual representation of basic MEPDG inputs in typical DARWin-ME ${ }^{\mathrm{TM}}$ project... 52 Figure 4.3: Observed rutting, Predicted rutting and smoothed rutting comparison graph. ......... 55 Figure 4.4: Residual Errors for total predicted rut depth after calibration for reconstructed

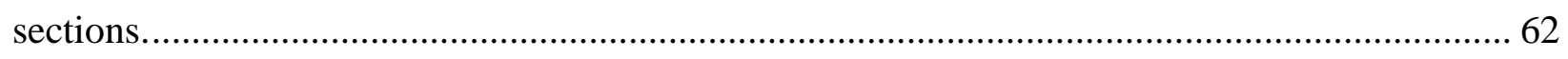

Figure 4.5: After-calibration prediction versus observation plots. (a) section-by-section

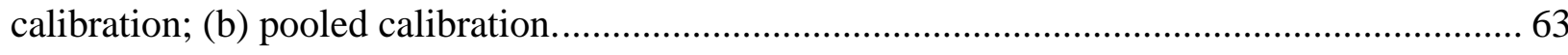


Figure 4.6: After- section-by-section calibration prediction versus observation plots. (a) Asphalt concrete layer; (b) Granular layer (c) Subgrade layer. 64 Figure 4.7: Longitudinal comparison of section-by-section and pooled calibration of section 376.

Figure 5.1: Effect of pre-overlay traffic on accumulation of rutting (after NCHRP (2004)) ....... 69

Figure 5.2: Sensitivity of permanent deformation to pre-overlay rut value (ranging from $4 \mathrm{~mm}$ at the top to $12 \mathrm{~mm}$ at the bottom) for a typical rehabilitated flexible pavement.......................... 71

Figure 5.3: Histogram of the life-cycle maximum rut depth from PMS-2 database .................. 73

Figure 5.4: Comparison of predicted with observed rut depth ........................................... 76

Figure 5.5: AC Layer RSS of Optimized Combinations obtained during Second stage of

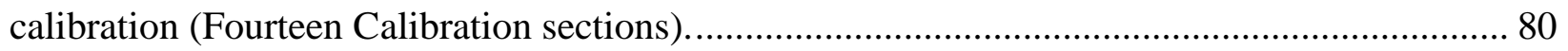

Figure 5.6: Residual Errors for total predicted rut depth after calibration for rehabilitated sections 85

Figure 5.7: Prediction versus observation comparison plots after calibration of rehabilitated sections 86

Figure 5.8: After-section-by-section calibration prediction versus observation plots for rehabilitated sections 87

Figure 5.9: Longitudinal comparison of section-by-section and pooled calibration of section 358. 88

Figure A-1: Dual tire spacing in single axle with dual tire. .100

Figure A-2: Tandem, Tridem, Quad axle spacing. 101 


\section{List of Acronyms}

$\begin{array}{ll}\text { AADT } & \text { Annual Average Daily Traffic } \\ \text { AADTT } & \text { Annual Average Daily Truck Traffic } \\ \text { AASHO } & \text { American Association of State Highway Officials, the predecessor of } \\ \text { AASHTO } & \text { AASHTO } \\ \text { AC } & \text { Asphalt Concrete } \\ \text { AI } & \text { Asphalt Institute } \\ \text { ARA } & \text { Applied Research Associates } \\ \text { ARAN } & \text { Automatic Road Analyzer } \\ \text { ARE } & \text { Austin Research Engineers ARS } \\ \text { ASU } & \text { Arizona State University } \\ \text { ASU-TMI } & \text { Arizona State University - Thornthwaite Moisture Index } \\ \text { BRRC } & \text { Belgian Road Research Center } \\ \text { Caltrans } & \text { California Department of Transportation } \\ \text { CBR } & \text { California Bearing Ratio } \\ \text { DMI } & \text { Distress Manifestation Index } \\ \text { DOT } & \text { Department of Transportation } \\ \text { EICM } & \text { Enhanced Integrated Climatic Model } \\ \text { ESALs } & \text { Equivalent Single-Axle Loads } \\ \text { FHWA } & \text { Federal Highway Administration } \\ \text { GA } & \text { Genetic Algorithm } \\ \text { GRG } & \text { Generalized Reduced Gradient } \\ \text { GWT } & \text { Ground Water Table } \\ \text { HMA } & \text { Hot Mix Asphalt } \\ \text { HRB } & \text { Highway Research Board } \\ \text { HVS } & \text { Heavy Vehicle Simulators } \\ \text { IRI } & \text { International Roughness Index } \\ \text { JULEA } & \text { Jacob Uzan Layered Elastic Analysis } \\ \text { LL } & \text { Liquid Limit } \\ \text { LRRB } & \text { Local Road Research Board } \\ \text { LTPP } & \text { Long Term Pavement Performance } \\ \text { MAAT } & \text { Mean Average Annual Temperature } \\ \text { ME } & \text { Mechanistic-Empirical } \\ \text { MEPDG } & \text { Mechanistic-Empirical Pavement Design Guide } \\ \text { MnDOT } & \text { Minnesota Department of Transportation } \\ \text { MnRoad } & \text { Minnesota Road } \\ & \end{array}$




$\begin{array}{ll}\text { MoDOT } & \text { Missouri Department of Transportation } \\ \text { MTO } & \text { Ministry of Transportation, Ontario } \\ \text { NCDOT } & \text { North Carolina Department of Transportation } \\ \text { NCHRP } & \text { National Cooperative Highway Research Program } \\ \text { NO } & \text { Northern Ontario } \\ \text { ODOT } & \text { Oregon Department of Transportation } \\ \text { PCC } & \text { Portland Cement Concrete } \\ \text { PCI } & \text { Pavement Condition Index } \\ \text { PCR } & \text { Pavement Condition Rating } \\ \text { PI } & \text { Plasticity Index } \\ \text { PMIS } & \text { Pavement Management Information System } \\ \text { PMS } & \text { Pavement Management Systems } \\ \text { PR } & \text { Public Roads } \\ \text { RCI } & \text { Riding Comfort Index } \\ \text { RCR } & \text { Ride Comfort Rating } \\ \text { SHRP } & \text { Strategic Highway Research Program } \\ \text { SMA } & \text { Stone Matrix Asphalt } \\ \text { SO } & \text { Southern Ontario } \\ \text { SPS } & \text { Specific Pavement Studies } \\ \text { SWCC } & \text { Soil-Water Characteristic Curves } \\ \text { TDC } & \text { Top-Down Cracking } \\ \text { TTC } & \text { Truck Traffic Classification } \\ \text { TxMLS } & \text { Texas Mobile Load Simulator } \\ \text { U.S. DOT } & \text { U.S. Department of Transportation } \\ \text { UCPRC } & \text { University of California Pavement Research Center } \\ \text { UGM } & \text { Unbound Granular Material } \\ \text { USCE } & \text { U.S. Corps of Engineers } \\ \text { VMA } & \text { Voids in Mineral Aggregate } \\ \text { WASHO } & \text { Western Association of State Highway Officials } \\ \text { WSDOT } & \text { Washington State Department of Transportation } \\ \text { XML } & \text { Extensible Markup Language } \\ & \end{array}$




\section{CHAPTER 1 INTRODUCTION}

\subsection{Background}

Three major road tests under controlled conditions were conducted by the Highway Research Board starting from the mid-1940s to the early 1960s (Huang 2004). These tests include Maryland Road Test, WASHO Road Test and AASHO Road Test. Among those, the AASHO Road Test is considered as the most important research in the history of pavement design as it for the first time through field tests, determined empirical relationships between axle loads and performance of pavements with different structural design. Another major contribution of the test was development of the serviceability concept, which channelled subsequent pavement researches into a focus on performance-based, rather than stress-based, design. Based on results from the Road Test, AASHO published its first Interim Guide for the Design of Rigid and Flexible Pavements in 1961. Thickness of structural layers of a flexible pavement would be determined by a series of empirical equations among present serviceability index (PSI), traffic axle loading, pavement material characteristics, subgrade modulus, and drainage conditions.

The strong need to develop a mechanistic empirical design approach was clearly noticed in 1986 when the official AASHTO Guide for Design of Pavement Structures was first adopted with 'interim' removed from its title. A major update in the AASHTO guide was done in 1993, mainly to expand the inference space of the empirical design equations and enhance the overlay design.

In March 1996, a workshop on pavement design sponsored by AASHTO Joint Task Force on Pavements, NCHRP and FHWA recommended developing an M-E guide by the year 2002. As a result, an NCHRP project 1-37A was created to develop the M-E design guide. In 2004, a draft guide, named the AASHTO Mechanistic Empirical Pavement Design Guide (MEPDG), was developed. The new design guide represents a major shift in method of pavement structural design. In a MEPDG design a preliminary design is needed with thickness of all layers. This design method requires inputs of materials, traffic, climate and type of rehabilitation activities. With the inputs, MEPDG performs the pavement analysis in two stages. The first stage comprises engineering mechanics analysis that calculates stress, strain and deformation at 
different points of the pavement structure. The second stage calculates pavement distresses and IRI using empirical transfer models that relate the pavement distresses to the previously calculated stresses, strains and deformations. The MEPDG delivers a strong interaction between materials, structural design, construction, climatic conditions, traffic inputs and PMS practices.

The transfer models or functions in the second stage analysis of the MEPDG have been globally calibrated with three sets of data (LTPP, MnRoad and Vandalia). Hence, the prediction models do not represent locally utilized material, traffic stream, climatic conditions, subgrade soil, and construction and maintenance practices. This means that the global models in MEPDG does not necessary give accurate results when used for pavement sections in Ontario. Therefore, the MEPDG distress models may require adjustment of calibration parameters before they can be used by designers; this adjustment is called local calibration. In 2011 a Guide for local calibration of the MEPDG (AASHTO 2010) was published to facilitate the regional local calibration studies.

\subsection{Research Needs and Significance}

The Ministry of Transportation of Ontario (MTO) decided to adopt the MEPDG for possible future pavement design. Although LTPP data included pavement sections from Ontario but a recent study by Jannat (2012), concluded that the default global models over-predict distresses, particularly the permanent deformation, or rutting. Therefore there was an urgent need to calibrate the local parameters in the transfer models in MEPDG for design conditions of Ontario. This research is the first full-scale local calibration of MEPDG rutting models for pavements in Ontario.

Although the MEPDG Local Calibration Guide suggests a stepwise methodology, but the exact approach to adjust the calibration parameters in permanent deformation models is vague. The local calibration methodology of previous researches differs with each other. The unavailability of a universally agreed upon local calibration methodology required further studies, which prompted this research.

This thesis is also significant as this local calibration was carried out using the pavement performance data collected from MTO's $2^{\text {nd }}$ generation Pavement Management System (PMS-2) database. A majority of previous local calibration studies were done using LTPP database or other road test data, which has higher accuracy due to the comprehensiveness of database. When 
the PMS data are used in local calibration, there will be many challenges to be addressed in developing a detailed calibration procedure ready for implementation. For example, pre-overlay rut depth is a sensitive parameter for prediction of permanent deformation of rehabilitated pavement sections. But this parameter is unavailable in PMS database. Similarly, historical performance database for rutting was only limited to total rutting in a pavement section. The rutting in individual layers was not available. All these issues are to be addressed in this thesis study.

\subsection{Research Objective and Scope}

The principal research objective of this thesis is to develop a local calibration methodology for the permanent deformation models in MEPDG for flexible pavements, including both reconstructed and rehabilitated sections, with consideration of the availability of MTO's historical pavement performance data. The secondary objective is to calibrate the MEPDG rutting model for the design of new and rehabilitated flexible pavements in Ontario using PMS-2 database.

A local calibration database including performance history, material, traffic data was developed by Jannat (2012) and MTO staff. The pavement sections used in the study are selected from the local calibration database. The structural and construction data of the sections are taken from the database while material, traffic and climatic data are mainly based on the MEPDG Default Values Guide for Ontario, a document recently developed by the MTO staff (MTO 2012).

For calibrating the global performance models, the scope of this research is limited to permanent deformation (rutting). Distress models for longitudinal (bottom-up cracking) and alligator cracking (top-down cracking) were not calibrated due to limitations in historical performance database like difference in measuring units between software and observed distresses, as reported by Jannat (2012). Although Ontario PMS-2 database has significant amount of IRI data available still, the IRI model was are not to be calibrated because IRI is the combination of other distresses. It cannot be calibrated until the component distress models have all been calibrated. 


\section{$1.4 \quad$ Research Methodology}

The research is an in depth study, with implementation and improvement of a single step in a multi-step local calibration methodology. This single step is the adjustment of local calibration parameters. The local calibration methodology should be developed within the limitation of the PMS-2 database of MTO. Hence, this research follows the basic principle set out in the AASHTO local calibration guide, but focuses on special issues that met in implementation of local calibration of in Ontario. First of all, the behaviour of local calibration of rutting models was studied against total rutting, which raised the issue of the multiple local optima. The issue of multiple local optima found in the local calibration was resolved by incorporating layer contributions to total rutting or in other words individual calibration of rutting models. Then an iterative optimization procedure was developed using DARWin-ME ${ }^{\mathrm{TM}}$ as the pavement analysis platform and Microsoft Excel Macro as the iteration engine. The proposed local calibration methodology was applied to 10 reconstructed sections and 19 rehabilitated sections. For rehabilitated sections, the pre-overlay rut depth, an important input variable for DARWin-ME, was studied using statistical analysis.

\subsection{Thesis Organization}

The thesis is comprised of six chapters including this first Chapter.

Chapter 2 provides a comprehensive review of literature related to local calibration. It reviews historical developments in design methods, the AASHTO M-E pavement design method and corresponding design software (DARWin-ME ${ }^{\mathrm{TM}}$ ), permanent deformation models, former local calibration studies and their implemented methodology for local calibration.

Chapter 3 presents the local calibration methodology developed by the author for the calibration of rutting models for Ontario's roads. Several challenges in rutting local calibration are discussed. These include the multiple local optima nature and unavailability of rutting for individual layers in historical database. With a fine selected set of percentage layer contributions, an iterative, response-surface-based, layer-by-layer and section-by-section local calibration is proposed. 
Chapter 4 discusses the implementation of local calibration methodology for local calibration and presents the results of locally calibrated parameters for reconstructed flexible pavement sections for Ontario.

The same local calibration methodology is used for the local calibration of rehabilitated sections. The results are presented in Chapter 5. But before the calibration, a special issue in the case of rehabilitated sections is discussed at first, which is the uncertain pre-overlay rut value in historical database. The variations and applicability of these locally calibrated parameters are also discussed.

Finally, Chapter 6 summarizes the research with conclusions and recommendations.

Appendix A, B and C describes the traffic, climate and material input data, input level and sources of these input parameters used in DARWin-ME ${ }^{\mathrm{TM}}$. 


\section{CHAPTER 2 LITERATURE REVIEW}

\subsection{Historical Developments of Pavement Design Methods}

The AASHTO MEPDG is a result of century long engineering evolution of pavement design methods. Its development was built upon a long history of professional practices, engineering trials and errors, and scientific investigation. This section provides a brief review on historical developments of pavement design methods.

Similar to many other civil engineering fields, pavements were constructed before a scientific design method was developed. They were built mainly based on constructor's courage and experience from other projects. Slowly, experiences were accumulated; failure lessons learned. For a better road, smart engineers started to identify important design factors and then attempted to establish some relationship between those design factors and pavement performance. Actual measurement techniques of pavement performance and quantitative empirical design equations had yet to wait for decades to develop.

Modern pavement design started from soil classification. Public Roads (PR) soil classification method was proposed in 1920's by Terzaghi and Hogentogler (1929). In those days, due to low traffic loadings, thicknesses of layers were only assigned to protect pavements from the shear failure of subgrade. Highway Research Board (HRB) improved PR method by grouping it into 7 groups (A-1 to A-7). In 1928 California Bearing Ratio (CBR) method was developed by California Divisions of Highways to evaluate the bearing capacity and mechanical properties (shear strength) of subgrade ad base materials of flexible pavements. It was made for classifying the suitability of a soil for use as a subgrade, subbase or base material in highway. Later it was adopted and improved by U.S. Corps of Engineers (USCE) and became the most widely used method in the world due to its simplicity.

From 1954 to 1969, Asphalt Institute published eight editions of Manual Series No.1 (MS-1) for the design of thickness of asphalt pavements (Huang 2004). The AI method up to the eight editions was based on empirical relations.

The American Association of State Highway Officials (AASHO) Road Test, a \$27 million scientific endeavor from 1956 to 1961 is one of the most significant researches done in pavement 
structural design history. This research took place on a road test section in Ottawa, Illinois which eventually become a part of Interstate-80 highway. This primary purpose of this study was to observe the structural performance of the pavement due to truck traffic. An important outcome from this study was the "AASHO Interim Guide for the Design of Rigid and Flexible Pavements" published in 1961 by the AASHO Committee of Design.

AASHTO design guide was built on findings of AASHO Road Test which makes it purely empirical design method. Regression equations were developed from the results gathered during road test. However, it was obvious from the start that the applicability of these empirical relations is limited in region other than the AASHO Road Test site. Hence, to make these regression models more compatible with diverse interactions of traffic, soil and climate with pavements, updates were needed. The major updates in AASHTO design guide were done in 1972, 1986 and 1993 based on additional road tests. A few of the major updates done after the first issue are discussed below in more details.

In the 1986 revision, CBR and R-value were replaced with resilient modulus as the main strength defining property of pavement materials. The revision also for the first time included the concept of reliability of design, drainage factors, enhanced environmental effects and refined input parameters. The 1993 edition of the AASHTO Pavement Design Guide included major changes mainly focused in the area of rehabilitation design using overlays (AASHTO, 1993). It emphasized more on non-destructive testing for evaluation of existing pavements. These improvements, which were based on physical principles as well as engineering experiences, have tried to make the design method to be applicable to design conditions other than those of AASHO Road Test.

AASHTO design guide was globally practiced due to simplicity of its design method. Overall serviceability of a pavement is measured in terms of Present Serviceability Index (PSI). PSI is more an objective measure of pavement condition than distress like cracking, patching, rut depth, distortion etc. in flexible pavements. Traffic loadings or ESAL's $\left(W_{18}\right)$ and terminal serviceability $\left(P_{\mathrm{t}}\right)$ are input into empirical equations to get a Structural Number $(S N)$. Thickness of pavements layers are selected on the basis of this calculated structural number, layer coefficients $\left(a_{1}, a_{2}, a_{3}\right)$ and drainage coefficients $\left(m_{2}, m_{3}\right)$. These layer coefficients are selected based upon the strength of different pavement layer materials. Although this design method 
incorporated major interactions of pavements to its surrounding, many input parameters with long term effects on pavements cannot be incorporated in an empirical design method.

Entering into the twenty-first century, pavement engineers started to seek a real integration of results from highway road research over the past many decades to develop a rational pavement design method with solid theoretical or mechanistic underpinnings.

\subsection{The MEPDG Method}

The major achievement of NCHRP Project 1-37A was development of the Guide for Mechanistic-Empirical Design of New and Rehabilitated Pavement Structures released in 2004. As the name Mechanistic-Empirical suggests this method is the result of integration of mechanistic theories of engineering with experimental results. The basic philosophy of the development of NCHRP guide can be understood by Figure 2.1. The objective of this guide was to develop a rational pavement design method which uses state of the art mechanistic models for the design of pavements. It was the first highly developed design established on existing validated M-E technologies. It incorporated different types of inputs in three hierarchical levels of design inputs. Global calibration of the distress models were also performed in this document using mainly the long-term pavement performance (LTPP) database. It will be discussed in more detail in this chapter.

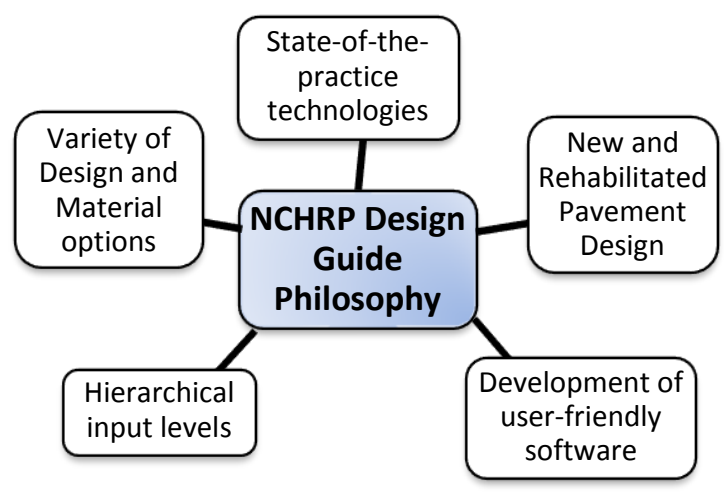

Figure 2.1: Philosophy of development of NCHRP Guide.

An independent review of NCHRP (2004) was done under NCHRP project 1-40A (Brown et al. 2006). It raised a number of issues that need to be resolved before effective implementation of design guide. These issues were addressed in NCHRP project 1-40D and reported in Research 
Results Digest 308 (NCHRP 2006). One of these suggestions resulted in inclusion of mixturespecific plastic deformation coefficients to be entered for individual HMA layers. Some major changes include recalibration of distress transfer functions. HMA transfer functions of NCHRP Project 1-37A were revised and recalibrated in future studies.

Database was developed under NCHRP Project 9-30 and used in the recalibration of HMA transfer function. In NCHRP Project 9-30A (VonQuintus et al. 2012), comparison of rut depth transfer functions were performed and possibility of including them as alternative models for end users to select was also evaluated. These rut depth transfer functions include Asphalt Institute, Modified Leahy, Verstraeten and WesTrack rut depth transfer functions. Other enhancements include fixing of local calibration parameters for unbound aggregate base layer and incorporation of a normal distribution of truck traffic rather than a uniform distribution between limits of truck wander. Extensive improvements in sampling template were recommended to refine the calibration of rut depth transfer functions.

The AASHTO interim Mechanistic-Empirical Pavement Design Guide (MEPDG), was adopted as the first design guide which was based on Mechanistic-Empirical method (AASHTO 2008). This guide presents detailed M-E based design procedure for evaluating existing pavements and designing pavements using the MEPDG software. A Few of the other topics discussed in this guide includes the strategies to evaluate material properties for new and rehabilitated pavements. The MEPDG pavement design method represents a major change from conventional AASHTO method.

\subsubsection{Design Method}

A typical MEPDG pavement design involves material, traffic and climate inputs. The MEPDG has highly increased the number of inputs (over 100) of a proposed project unlike conventional AASHTO method, which generally involved very few inputs. In MEPDG effect of many small factors like vehicular inputs and seasonal climatic changes are taken in account during pavement designs which were otherwise not considered in historical pavement design methods. As the level of influence changes with service life/time these factors could only be defined by incorporating a mechanistic part. However, due to technological constraints these heavy computative mechanistic portions could not be incorporated in previous pavement design methods. 
In mechanistic part of the MEPDG, multi-layered elastic theory is used to predict stresses in pavements layers from these inputs. Further mechanistic relationships are used to calculate strains of these stresses. These responses are used in response models to calculate the accumulated damage over time. An empirical part relates the design process to the characterization of materials, traffic and environment. Empirical relations are used to correlate accumulated damage to all distress in pavements. In MEPDG these empirical models are already calibrated with distress predictions of sections from PMS and LTPP databases. These regressed distress models needs adjustments of calibration coefficients to synchronize distress predictions based on the regional material, climate, traffic data and DOT guidelines. These calibration coefficients in distress models are changed unless distress accumulation of pavement models are synchronized with observed distresses, this process is also called local calibration. This thesis presents the local calibration of permanent deformation models for flexible pavement sections in Ontario. Major component of a MEPDG method is shown in Figure 2.2.

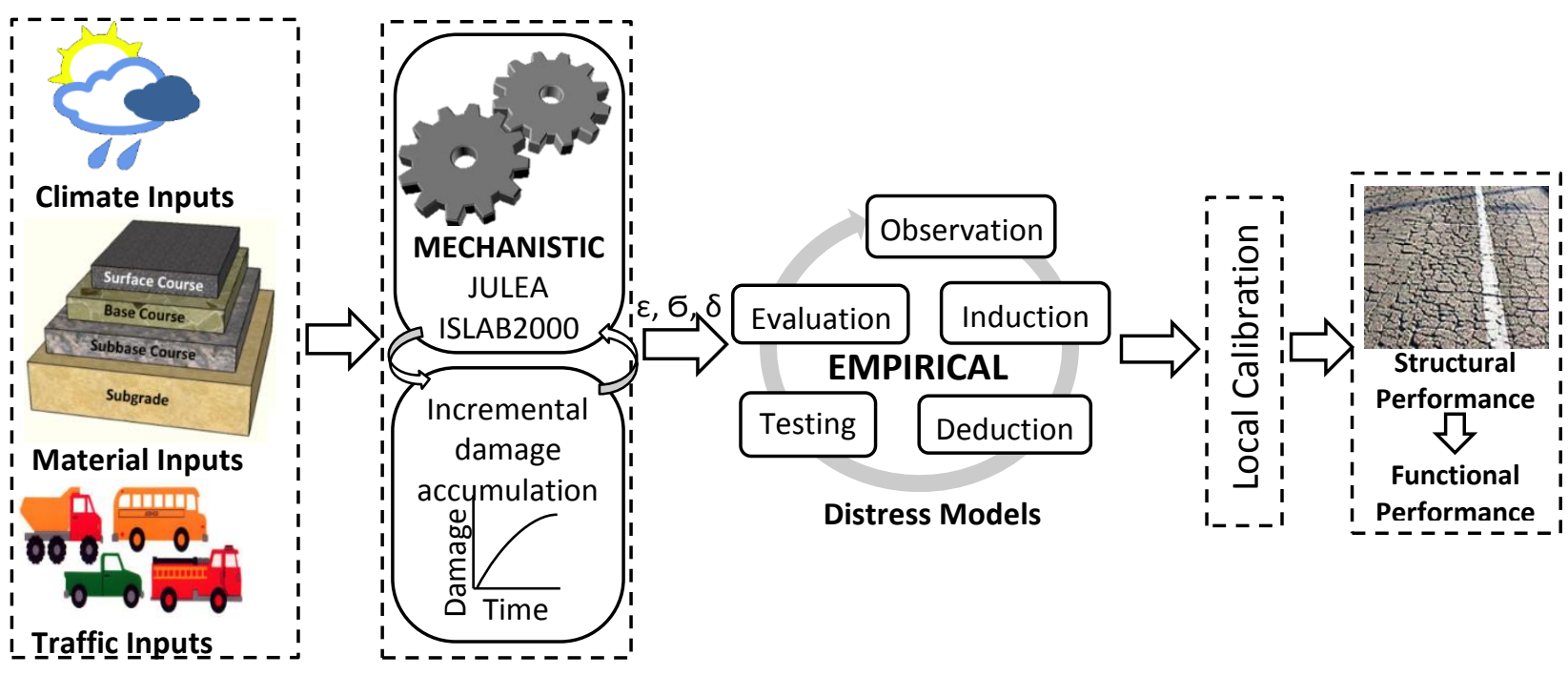

Figure 2.2: Major components of MEPDG methodology.

Pavement design with MEPDG is evaluated with the predicted distress. Pavement distress can be classified into structural and functional distress depending upon features represented by the predicted distress. Performance of a pavement is generated along its service life in terms of structural and functional distresses and roughness. Pavements are designed to keep their distresses within a pre-established limit. These limits are considered as failure criteria for 
pavements, which also controls initiation of a rehabilitation or reconstruction activities in pavements. These limits of distresses are dictated by regional transport agencies guidelines. In the design of pavement with MEPDG, the pavement section is revised until all pre-established distress design criteria are satisfied. In a flexible pavement following performance prediction indicators can be obtained from MEPDG method.

1. AC bottom-up fatigue cracking

2. AC top-down fatigue cracking

3. AC thermal facture

4. Total Cracking (Reflective + Alligator)

5. International Roughness Index (IRI)

\section{Permanent deformation}

AC bottom-up fatigue cracking are load-related cracks which is also called alligator cracking. Fatigue cracking is one of the major distress types occurring in flexible pavements. These cracks initiate at the bottom of the AC layer and propagate to the surface of the pavement as fine longitudinal cracks which spread into form a chicken wired pattern. AC top-down fatigue cracking's (TDC) are load related surface cracking, which is also known as longitudinal cracking. Top-down cracking are the most common type of cracking in flexible pavement distresses. Repetition of heavy loads with the combination of thermal stresses is considered to be the major cause of fine longitudinal cracking. AC thermal cracking is non-load related cracking. Thermal cracks occur in transverse direction of the road, which could of full or half lane width. Thermal cracks mostly occur in cold regions, when asphalt layers become brittle and high tensile stresses develop that lead to cracking of the pavement. Reflective cracking only occurs in a rehabilitated pavement. When a flexible pavement is overlaid over jointed or severely cracked existing pavement, cracks will reflect to the surface of the new overlay. They contribute in deteriorating functional performance and allow water to percolate in to the interior layers, which further deteriorate the pavement structure. IRI is the measure of functional performance indicator, which is the measure of the smoothness of a pavement surface. It is defined as "the deviations of a pavement surface from a true planar surface with characteristic dimensions that 
affect vehicle dynamics and ride quality" (The Transtec Group, Inc Smooth Pavements). Permanent deformation will be discussed in-detail, later in this chapter.

\subsubsection{Hierarchical Design Input Levels}

The hierarchical design input levels in MEPDG provides flexibility to obtain design inputs based on criticality of the project and the available resources. Traffic, materials and pavement condition are classified in three hierarchical input levels.

Level 1 represents highest level of accuracy of inputs. These input parameters are directly measured on site and thus, would have the lowest level of uncertainty. Level 1 input is used for site features, materials or traffic conditions that are different from the inference space of available correlations. Calculation of these input involve expensive experimentation, therefore they are only calculated when early project failure would result high economical risks.

Level 2 provide an intermediate level of accuracy. These inputs are calculated through correlations or regression equations which are built on high quality experimental Level 1 database. Input Level 2 also represent regional data provided by regional DOT's.

Level 3 represents the lowest level of accuracy in input parameters. It is employed where there are minimal consequences of early failure (NCHRP 2004). These are the regional or global default values. This level should only be used for low volume roads.

\subsection{The MEPDG Software}

MEPDG is a computation intensive design method; therefore it was not practical to develop this method without development of computer software which can handle these computations. MEPDG design guide was also supplemented with user friendly computational software (MEPDG Version 0.7) which was based on design guide procedure. It was updated many times from 2005 to 2006. NCHRP project 1-40D, further updated this software and made it more user friendly by development of version 0.9 and 1.0 of MEPDG software. This MEPDG software version 1.0 were further improved in 2012 under NCHRP Project 9-30A (VonQuintus et al. 2012), improved version is named MEPDG version 9-30A. 
Last version of this MEPDG software (Version 1.10, September 2009) was available till 2011. Recently in 2011, AASHTO have developed user-friendly MEPDG software (AASHTO DARWin-ME ${ }^{\mathrm{TM}}$ ) for commercial purposes.

\subsubsection{Computational Methodology}

AASHTO DARWin-ME ${ }^{\mathrm{TM}}$ provides an interactive interface to handle large input data for material, traffic and climate. The objective of this design software is to perform all mechanistic and empirical computations in a limited time. The mechanistic part is more computation intensive and hence takes much longer time than solving empirical equations. Software processes involve differential equations solutions employed by various analysis models (NCHRP 2004).

It provides flexibility to select inputs from within three earlier defined hierarchical input levels. This indirectly helps in reducing cost of material testing during field investigation of pavement site. Input levels can be selected and inputted depending upon the economic importance of the pavement structure.

The AASHTO DARWin-ME ${ }^{\mathrm{TM}}$ contains 9 years of hourly data of over 851 whether stations across US and Canada. MEPDG subdivides the structural and subgrade of the trial design into sublayers. Enhanced integrated climatic model (EICM) with many other minor models (Suction, ASU-TMI, SWCC, Moisture content, Specific gravity and Hydraulic conductivity) is used to simulate internal pavement temperature, moisture, and freeze-thaw conditions in each sublayer as a function of time.

The DARWin-ME ${ }^{\mathrm{TM}}$ uses structural response models to calculate critical pavement responses (stresses, deflections and strains) in sublayers of pavement. The Jacob Uzan Layered Elastic Analysis (JULEA) for flexible pavements and Finite element analysis program ISLAB2000 for rigid pavements is the structural response model used in DARWin-ME ${ }^{\mathrm{TM}}$ computations. Pavement responses are used in distresses transfer function for each distress to compute actual distress. These distress transfer functions were recalibrated under NCHRP 1-40D. The recalibration results and various other changes done in MEPDG software under NCHRP 1-40D can be found in Research Results Digest 308 (NCHRP 2006).

The software provides flexibility to change the calibration factor of all distress functions to match the regional performance. The output of the software is in terms of pavement structural 
and functional performance. On demand, it can also produce the structural response to the designer. Flowchart in Figure 2.3 shows the basic components of DARWin-ME ${ }^{\mathrm{TM}}$ software.

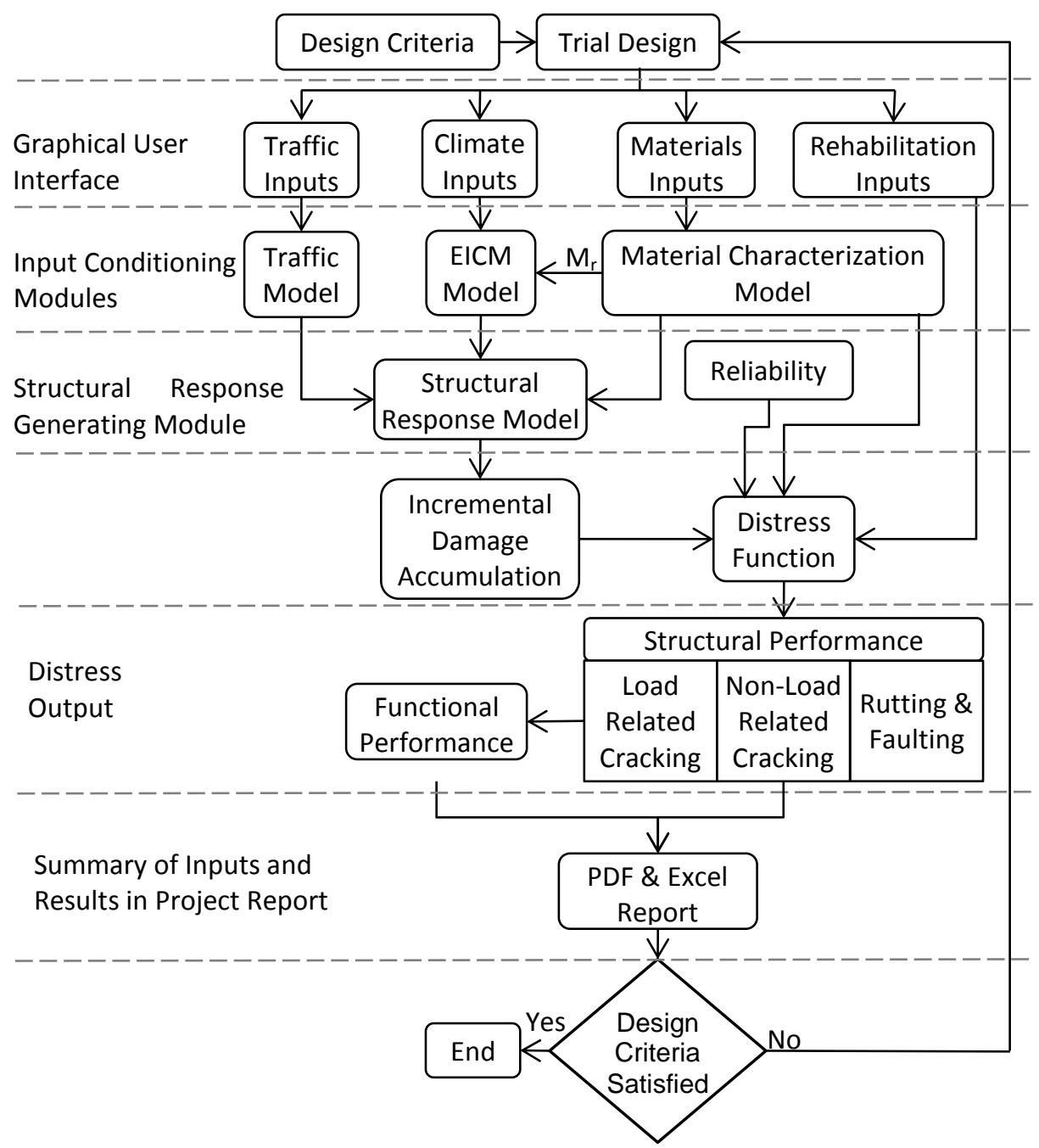

Figure 2.3: DARWin-ME ${ }^{\mathrm{TM}}$ Software components.

Some other features of DARWin-ME ${ }^{\mathrm{TM}}$ include archiving projects, saving projects and inputs in library, exporting and importing input data files, batch running option for inputting all projects at same time to running them sequentially. It has the capability to run as many project at a time as many cores are there in the computer system. DARWin-ME ${ }^{\mathrm{TM}}$ saves the project in an extension of .dgpx, which is coded in a markup language Extensible Markup Language (XML) so it is both human-readable and machine-readable. XML coded documents gives designer the flexibility to understand the project files and hence, gives the designer ability to make and apply 
Macros to edit the project files. Macros can be very useful in saving time especially for local calibration, when software is needed to run same project hundreds of times with different set of calibration coefficients. For more information and help defining inputs in different types of pavement consult AASTOWare ${ }^{\circledR}$ DARWin-ME ${ }^{\mathrm{TM}}$ Software help manual (AASHTO 2011).

\subsubsection{Report Generation}

DARWin-ME generates a report in Pdf as well as in Excel format. This report includes summary data and plots of detailed material inputs, traffic inputs, climate inputs, sublayer modulus and total predicted distress with distress for each month for entire pavement life. The report also summarizes the calibration coefficients used in the analysis of the project. In addition to these final reports it can also generate .txt extension files for intermediate responses (stress and strains) in structural response model in all sublayers of pavement.

\subsection{Permanent Deformation: Mechanism and Models}

According to SP-024 Manual for Condition Rating for Flexible Pavements: Distress Manifestations (Chong et al. 1989), permanent deformations can be defined as a combination of transverse undulations, longitudinal depressions or pavement surface distortions like dishing, bumps, dips, tenting or stepping at cracks etc. Rutting is a basic type of permanent deformation which is loosely defined as single or multiple longitudinal depressions, left in the wheel track accompanied by small upheavals to the side after repeated loadings. In addition to variations it also results in roughness which affects the functional serviceability or IRI. Generally rutting takes place on a pavement surface due to distortion on bituminous layer as a result of continuous traffic loadings. It can be cause due to many other reasons like poor subgrade compaction, unstable HMA mixture, base layers, poor water proofing layers, improper structural design and poor construction practices.

Rutting in roads affects the drainage characteristics of the road which is dangerous for the drivers because of: 1) the ruts would be filled with water and will result in hydroplaning phenomena and 2) it becomes extremely difficult to drive through a road filled with ruts. Therefore due to safety concerns, DOT's of a region specify certain limits of ruts after which pavement would require a rehabilitation. 
The FHA (1979) has categorized rutting into 4 levels of severity: hydroplaning (0.2-0.25 in. or 5.08-6.35mm), low (0.25-0.5 in. or $6.35-12.7 \mathrm{~mm})$, medium $(0.5-1$ in. or $12.7-25.4 \mathrm{~mm})$ and high (1.0 in. or 25.4mm) (Sousa et al. 1991).

HMA mixture of surface layer is more critical for protection against rutting as it is in direct contact to traffic and climate effects. Suitable construction quality control during the construction is necessary under heavy traffic loads to ensure that the placed material has desired rut resistance properties. In an HMA layer many factors are responsible for affecting rutting including stiffness, binder content air void, VMA, temperature, stress and strains, moisture content and traffic loadings.

Unbound Granular material are considered as linear elastic materials, where rutting is produced due to accumulation of permanent deformation with time. The intensity of permanent deformation in an unbound granular depends upon water content, density, shape of aggregates and crushed materials. Under repeated traffic loads on pavement, UGM response is generalized in four categories 1) Purely elastic 2) Elastic shakedown 3) Plastic shakedown 4) Incremental collapse (Werkmeister et al. 2005).

Subgrade should be made dense by compaction to prevent consolidation or settlement that could possible lead to rutting in subgrade at a later stage. Subgrade rutting depends upon density, moisture content, traffic, shrinkage and swelling. Soil density is the main factor in contributing towards rutting in a pavement. Subgrade rutting depends upon several other factors including climate, soil gradation, strength, SWCC, PI, and LL.

\subsubsection{Mechanism of Rutting}

Rutting occurs due to repeated traffic load which produce densification (decrease in volume hence increase in density) and shear deformation (displacement of material with constant deformation) of in all layers of pavement.

Hofstra (1972) pointed that shear deformation rather than densification is the major cause of rutting mechanism (Sousa et al. 1991). Eisenmann (1987) also concluded that rutting is caused by deformation flow without volume change. He verified that if a pavement is already compacted to higher density then, further densification would be unlikely. Pavement rutting is 
mostly followed by upheaval along the surrounding area of longitudinal rut. A two-stage mechanism of rutting is described below.

1. In the initial stage of loadings the depression (rutting) in pavement is more than the increase of upheaval zone. Showing that, most of the rutting in this stage is due to densification due traffic loading in this initial stage.

2. After the initial stage, the increase deformation in pavement becomes equal to increase of upheaval. Showing that the densification is completed and that further rutting is caused by displacement at the same volume (shear flow).

\subsubsection{Evaluation of Rut Depth}

Evaluation of rut depth can be done by both manually as well as using modern automated methods. Conventionally permanent deformations in a flexible pavement were measured using $3 \mathrm{~m}$ straight edge. However, due to subjective nature of measurement process results obtained are error-prone. Automatic Road Analyzer (ARAN) an advanced pavement data collection vehicles is another method to measure surface profile including rutting, roughness and texture. ARAN is equipped with Laser Transverse Profiler for accurately measuring the permanent deformation on the surface of the pavements.

\subsubsection{Existing Permanent Deformation Models}

The concept of integration mechanistic and empirical pavement design principles was not an abstract notion. M-E design methods are available, where pavements were designed by limiting permanent deformation on the surface of subgrade. Further, other performance models have been developed by different agencies for the accurate prediction of these distresses. These types of design require the capability to accurately predict functional or structural distresses over a longer period of time. There are two types of design models 1) response models and 2) performance models. Response models predict stress, strain and deflection on the basis of modulus of elasticity, poison ratio, layer thickness and traffic loadings. These response models include JULEA, WESLEA, VESYS, CIRCLY etc. Performance models are empirical relations which are used to calculate incremental damage accumulation in terms of pavement responses (structural and functional distress) from results of response models e.g. stress, strain and deflections. 
Asphalt Institute pavement design method shifted from empirical based design to an M-E design method. The ninth edition of AI manual was published in 1991 and it was based on integration of mechanistic empirical methodologies. The AI methods were based on two main design criteria fatigue and permanent deformation criteria. Due to mechanistic nature of design method and need for heavy computations subsequently, design software SW-1 Thickness Design Software for Asphalt Pavements (2005) was developed on the basis of mechanistic empirical principles. SW-1 software includes DAMA module to analyse a multi-layered elastic pavement structure and generate stresses, strain, and deflections at the interface of each layer. The permanent deformation criteria to predict failure based on vertical compressive subgrade strain is given by:

$$
N_{f}=\beta_{0} \varepsilon_{v}^{-\beta_{1}}
$$

where,

$$
\begin{aligned}
& \beta_{0,} \beta_{1}=\text { Empirical coeficients } \\
& N_{f}=\text { Load repetitions to failure Load } \\
& \varepsilon_{v}=\text { Vertical compressive subgrade strain }
\end{aligned}
$$

Another non-linear elastic model DRESDEN was developed to calculate stress in unbound granular layer (Werkmeister 2002). Repeated Loading Triaxial Test (RLTT) results were used to determine the resistance against rutting of unbound granular materials (UGM). Permanent deformation behaviour was predicted in 3 ranges of permanent strain. Huurman-Model which is a stress dependent model served as the basis for the new model. The Technical Research Center of Finland (VTT) has also studied multiple aspects of permanent deformations with accelerated pavement tests. VTT model for prediction of permanent deformations in conventional pavements was developed by Korkiala-Tanttu (2005).

Mathematical Model of Pavement Performance (MMOPP) is another pavement design model, developed by Danish road authorities (Hildebrand et al. 2006). The MMOPP model is used to simulate increase in distresses of pavement structure due to traffic load, climate impact and selection of materials. In MMOPP permanent deformation prediction is described separately for 
asphalt concrete and granular layer. The permanent deformation in AC materials is predicted by Kirk's formula.

$$
\varepsilon_{h}=-0.000230\left(\frac{N}{10^{6}}\right)^{-0.191}
$$

For unbound granular layer, although the permanent deformation is divided into primary, secondary, and tertiary phases, the tertiary stage was not considered in MMOPP. Hence, the permanent deformation in unbound granular layer is predicted by the following two equations:

Phase 1 (primary):

$$
\varepsilon_{p}=A N^{B}\left(\frac{\sigma_{1}}{\sigma}\right)^{C} \quad \text { for } \varepsilon_{\mathrm{p}}<\varepsilon_{0}
$$

Phase 2 (secondary):

$$
\varepsilon_{p}=\varepsilon_{0}+\left(N-N_{0}\right) A^{\frac{1}{B}} B \varepsilon_{0}^{1-\frac{1}{B}}\left(\frac{\sigma_{1}}{\sigma}\right)^{-\frac{C}{B}} \text { for } \varepsilon_{\mathrm{p}}>\varepsilon_{0}
$$

where

$$
N_{0}=\varepsilon_{0} \frac{1}{B} A^{\frac{-1}{B}}\left(\frac{\sigma_{1}}{\sigma}\right)^{-\frac{C}{B}}
$$

and

$$
\begin{aligned}
& \left.\varepsilon_{0}=\text { Limit of plastic shakedown (phase } 1\right) \\
& \varepsilon_{p}=\text { Plastic strain } \\
& N=\text { Number of load repetetions } \\
& \sigma_{1}=\text { Major principal stress } \\
& \sigma=\text { Reference stress (Atmospheric pressure, } 0.1 \mathrm{MPa} \text { ), and } \\
& A, B, C=\text { Calibration constants. }
\end{aligned}
$$

VESYS is another series of highly developed mechanistic-empirical models for pavement design, developed during a long period of time. Its rutting models relates plastic strain $\left(\varepsilon_{\mathrm{p}}\right)$ to the elastic strains $\left(\varepsilon_{\mathrm{e}}\right)$ through permanent deformation parameters $\mu$ and $\alpha$. Its rutting model predicts 
permanent deformations in each layer as a product of elastic compression and permanent deformation law for that layer.

$$
\varepsilon_{p}(n)=\mu \varepsilon_{\mathrm{e}} n^{-\alpha}
$$

where

$$
n=\text { number of load repetitions. }
$$

A model developed in UK similar to MMOPP is called Whole-Life Pavement Performance Model (WLPMM) (Cebon 1995). In this method vehicle simulation is used to generate dynamic tyre forces as function of time along the pavement. These dynamic tyre forces are used in

response influence functions to generate pavement primary responses (stress, strain and deflections). These primary responses are used in pavement damage models to generate damage (rutting and fatigue as a function of distance along the pavement.

In California another model for prediction of permanent deformation was employed in the Caltrans mechanistic-empirical software known as CalME. In this software mechanisticempirical modelling is done on linear elastic multi-layer theory whose results are used in permanent deformation distress functions. Incremental analysis of damage is done and results of each increment are used in the analysis of next increment. It is also called an incrementalrecursive mechanistic-empirical model. CalME has some similarity to the methodology used in MEPDG.

\subsubsection{MEPDG Rutting Distress Model for Flexible Pavements}

The MEPDG design is based on accumulation of incremental damage. The permanent deformation is calculated at the mid depth of each pavement sublayer for each sub-season. Dissimilar models are available for different materials to compute plastic strain in each layer. Total permanent deformation for a season is calculated by sum of permanent deformation in each layer. It can be mathematically expresses by the following equation:

$$
\mathrm{PR}=\sum_{i=1}^{\text {nsublayers }} \varepsilon_{p}^{i} h^{i}
$$


where

$$
\begin{aligned}
& \mathrm{PR}=\text { Pavement permanent deformation } \\
& n=\text { Number of sublayers } \\
& \varepsilon_{p}^{i}=\text { Total plastic strain in sublayer } i \\
& h^{i}=\text { Thickness of sublayer } \mathrm{i}
\end{aligned}
$$

The predicted rutting of each layer is the function of time and number of traffic. These rutting models contain local calibration coefficients or transfer functions that need adjustment to reduce the bias between the predicted and observed rut depth.

\subsubsection{HMA Rutting Model}

A default globally calibrated model for HMA or AC (asphalt concrete) has been included in the software, which contains three calibration coefficients $\left(\beta_{\mathrm{r} 1}, \beta_{\mathrm{r} 2}, \beta_{\mathrm{r} 3}\right.$, ) that are calibrated for local calibration. In globally calibrated models there values is 1 . The HMA rutting model used in computation inside DARWin-ME ${ }^{\mathrm{TM}}$ is shown in in Table 2-1.

Table 2-1: The MEPDG HMA Rutting Models used in the DARWin-ME ${ }^{\mathrm{TM}}$

\begin{tabular}{|cc|l|}
\hline \multicolumn{2}{|c|}{ Mathematical Equations } & Notations \\
\hline & & $\varepsilon_{\mathrm{p}}=$ Accumulated Permanent or Plastic strain \\
& & $\varepsilon_{\mathrm{r}}=$ Resilient or elastic strain \\
$\frac{\varepsilon_{\mathrm{p}}}{\varepsilon_{\mathrm{r}}}=k_{\mathrm{z}} \beta_{\mathrm{AC} 1} 10^{k_{1}} T^{k_{2} \beta_{\mathrm{AC} 2} N^{k_{3} \beta_{\mathrm{AC} 3}}}$ & $(8)$ & $T=$ Mix or Pavement layer temperature $\left({ }^{0} \mathrm{~F}\right)$ \\
& & $N=$ Number of Load Repetitions \\
& & $k_{\mathrm{z}}=$ Depth confinement factor \\
\hline$k_{\mathrm{z}}=\left(C_{1}+C_{2} \times\right.$ Depth $) \times 0.328196^{\text {Depth }}$ & $(9)$ & $D=$ Depth below the surface (in) \\
$C_{1}=-0.1039 H_{A C}{ }^{2}+2.4868 H_{A C}-17.342$ & $(10)$ & $H_{\mathrm{AC}}=$ Total AC Thickness (in) \\
$C_{2}=0.0172 H_{A C}{ }^{2}-1.7331 H_{A C}+27.428$ & $(11)$ & \\
\hline
\end{tabular}




\section{Calibration Coefficients}

$\mathrm{k}_{1}, \mathrm{k}_{2}, \mathrm{k}_{3}=$ Global field calibration parameters (from the NCHRP 1-40 recalibration)

$$
\mathrm{K}_{1}=-3.3541, \mathrm{k}_{2}=1.5606, \mathrm{k}_{3}=0.4791
$$

$\beta_{\mathrm{AC} 1}, \beta_{\mathrm{AC} 2}, \beta_{\mathrm{AC} 3}=$ Local or mixture field calibration constants; for the global calibration these constants are given below

$$
\beta_{\mathrm{AC} 1}=1, \beta_{\mathrm{AC} 2}=1, \beta_{\mathrm{AC} 3}=1
$$

\subsubsection{Unbound Granular and Subgrade Rutting Model}

Different rutting model is used to predict rutting in unbound layer (base and subbase) or foundation layer (subgrade). This model consist of only one calibration coefficient $\left(\beta_{s 1}\right)$ that needs to be locally calibrated; its default value is 1 for globally calibrated model. MEPDG Unbound and Foundation Rutting Model used in DARWin-ME ${ }^{\mathrm{TM}}$ are shown in in Table 2-2. To avoid confusion between two calibration constant $\left(\beta_{\mathrm{s} 1}\right)$ in this thesis, $\beta_{\mathrm{s} 1}$ for granular base can be referred as $\beta_{\mathrm{GB}}$ and $\beta_{\mathrm{s} 1}$ for subgrade/fine layer can be referred as $\beta_{\mathrm{SB}}$.

\begin{tabular}{|c|c|c|}
\hline Mathematical Equations & & Notations \\
\hline$\delta_{a}(N)=\beta_{s_{1}} k_{1} \varepsilon_{v} h\left(\frac{\varepsilon_{o}}{\varepsilon_{r}}\right) e^{-\left(\frac{\rho}{N}\right)^{\beta}}$ & $(14)$ & $\begin{array}{l}\delta_{\mathrm{a}}=\text { Permanent deformation for th layer } \\
N=\text { Number of axle }- \text { load applications } \\
\varepsilon_{\mathrm{v}}=\text { Average vertical strain } \\
\varepsilon_{0}, \beta, \rho=\text { Material properties } \\
\varepsilon_{\mathrm{r}}=\text { Resilient strain } \\
h=\text { Thickness of the unbound layer (in) }\end{array}$ \\
\hline $\log \beta=-0.61119-0.017638\left(W_{c}\right)$ & (15) & $W_{\mathrm{c}}=$ Water content $(\%)$ \\
\hline$\rho=10^{9}\left(\frac{C_{o}}{\left(1-\left(10^{9}\right)^{\beta}\right)}\right)^{\frac{1}{\beta}}$ & (16) & $M_{\mathrm{r}}=$ Resilient modulus of the unbound layer (in) \\
\hline$C_{o}=\ln \left(\frac{a_{1} M_{r}^{b_{1}}}{a_{9} M_{r}^{b_{9}}}\right)=0.0075$ & (17) & $\begin{array}{l}a_{1,9}=\text { Regression const. } ; a_{1}=0.15 \text { and } a_{9}=0.15 \\
b_{1,9}=\text { Regression const. } ; b_{1}=0 \text { and } b_{9}=0\end{array}$ \\
\hline
\end{tabular}

Table 2-2: The MEPDG Unbound and Subgrade Rutting Models used in the DARWin-ME ${ }^{\mathrm{TM}}$ 


\begin{tabular}{|c|c|}
\hline \multicolumn{2}{|c|}{ Calibration Coefficients } \\
\hline Granular Layer & Fine Layer \\
\hline$k_{1}=$ Global field calibration parameters, $k_{1}=1.673$ & $k_{1}=$ Global field calibration parameters, $k_{1}=1.35$ \\
\hline $\begin{aligned} \beta_{\mathrm{s} 1}= & \text { Local or mixture field calibration constants; for } \\
& \text { the global calibration this constants is } \beta_{\mathrm{s} 1}=1\end{aligned}$ & $\begin{array}{c}\beta_{\mathrm{s} 1}=\text { Local or mixture field calibration constants; for } \\
\text { the global calibration this constants is } \beta_{\mathrm{s} 1}=1\end{array}$ \\
\hline
\end{tabular}

\subsection{Global Calibration of Rutting Model}

The MEPDG software DARWin-ME ${ }^{\mathrm{TM}}$ includes the globally calibrated distress prediction models, which were calibrated from the pavement sections located throughout North America. Mainly pavement sections from LTPP database was selected, while sections from MnRoad and Vandalia, were also included in the global calibration process. Calibration is a systematic process to eliminate bias and minimize the residual error between observed real word distress and results predicted by models. This global calibration is done by modifying the calibration parameters or transfer functions in the simulation model. Accuracy of calibration model is dependent upon both precision (reproducibility) and bias. Brief procedure of global calibration with complete results are given in Appendices GG Calibration of Permanent Deformation Model (NCHRP 2004). Following sections summarize the global calibration procedure described in NCHRP (2004) global regarding calibration of rutting model.

LTPP was the main source of data for global calibration of all models in MEPDG. Calibration included 136 LTPP test sections from 28 states of USA, from which 94 were new sections and 42 were overlays. During the development of the database it was insured that all factors that are part of the distress model are included in the database.

\subsubsection{Limitations}

1. MEPDG models include assumption of zero permanent deformation in chemically stabilized materials, bedrock and PCC fractured slab material. 
2. Standard error of the predicted rut depth within each layer was based on estimation by proportioning of total rut depth. Field trench studies were neither available nor performed for the LTPP sections selected for use in global calibration, which could accurately give the measured rut depth in each layer (AASHTO 2008). Therefore rut in sublayers (base, subbase and subgrade) was estimated by multiplying the percentage from the predicted sublayer rutting by the average total rutting to approximate the true field rutting in each layer.

3. The rut prediction methodology does not consider the rutting due to long term plastic (shear) deformations. Since, permanent deformation prediction test that reach this stage are particularly time consuming and there is lack of methodology that can efficiently implement this type of rutting (NCHRP 2004).

\subsubsection{MEPDG Software Simulation Runs}

Rutting models have 5 calibration factors (three for HMA layer $\left(\beta_{\mathrm{AC} 1}, \beta_{\mathrm{AC} 2}, \beta_{\mathrm{AC} 3}\right)$, one for unbound granular $\left(\beta_{\mathrm{GB}}\right)$ and one for subgrade $\left(\beta_{\mathrm{SG}}\right)$. The flowchart of global calibration procedure for MEPDG rutting model is shown in Figure 2.4 (a) and (b). The procedure consisted of calibration in three stages. The first stage is the calibration of $\beta_{\mathrm{AC} 2}$ (Temperature) and $\beta_{\mathrm{AC} 3}$ (Load Repetitions) coefficients using LTPP database pavement sections. 11 unique combinations of $\beta_{\mathrm{AC} 2}$ and $\beta_{\mathrm{AC} 3}$ were run in MPEDG for each pavement section to observe RSS (Residual Sum of Squares) and error. Optimization was done on the basis of the results of simulations, which resulted in selection of same set of coefficients using two different optimization approaches.

Calibration of $\beta_{\mathrm{GB}}$ (Granular), $\beta_{\mathrm{SB}}$ (Subgrade) Layers is done using the results from 1993 AASHTO Design Guide method using 38 AASHTO pavement sections. This calibration approach used constant $\beta_{\mathrm{AC} 2}, \beta_{\mathrm{AC} 3}$ calculated from the first stage. Further calibration was performed with LTPP pavement sections using the previously found coefficients. The previously calculated coefficients were used with modified $\beta_{\mathrm{AC} 1}$. Two different optimization approaches were adopted to optimize the value of $\beta_{\mathrm{GB}}$ and $\beta_{\mathrm{SB}}$. The final model transfer functions were selected by optimization by minimization of error square of the total rut through simultaneously varying three factors $\left(\beta_{\mathrm{AC} 1}, \beta_{\mathrm{GB}}\right.$ and $\left.\beta_{\mathrm{SB}}\right)$. 


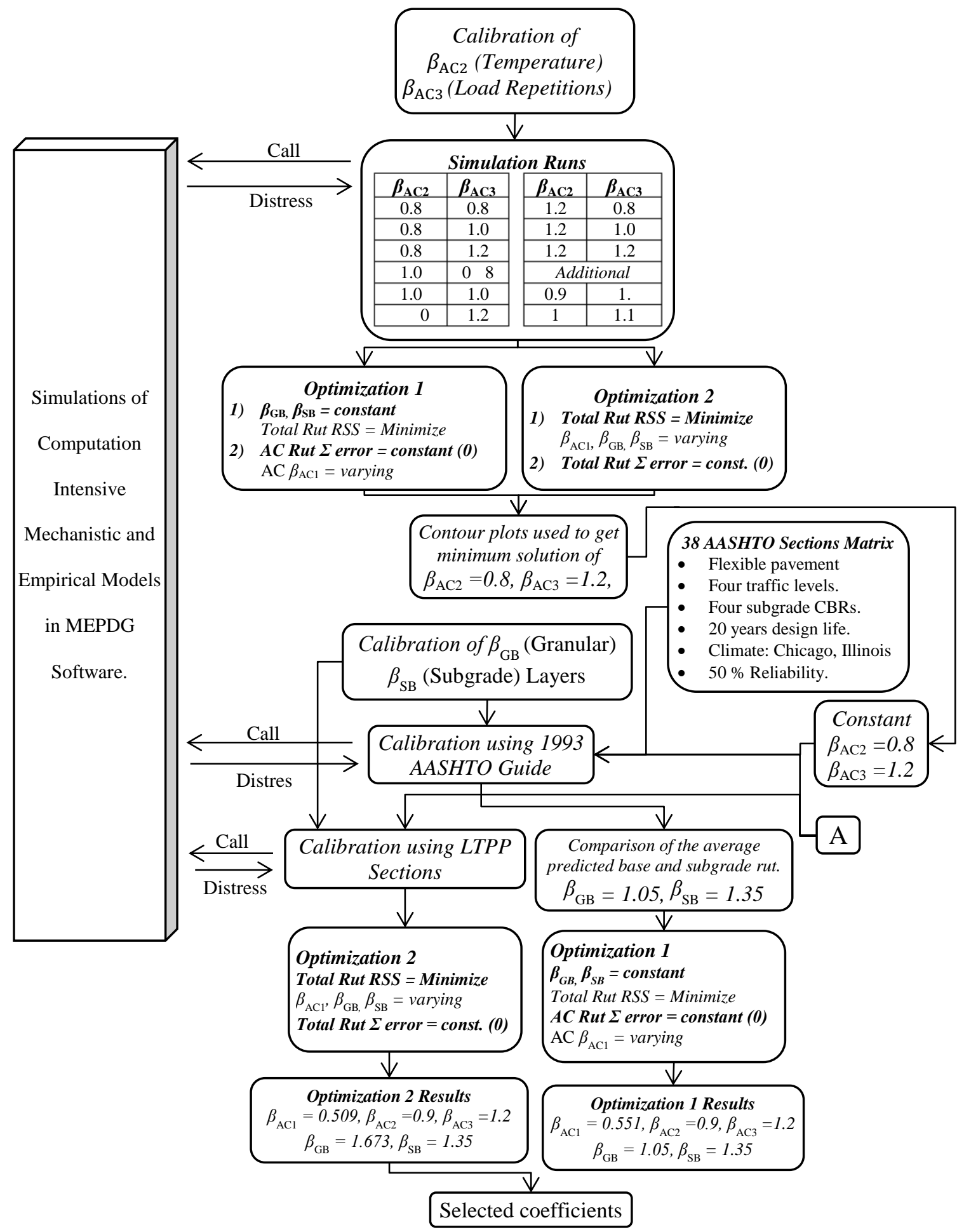

Figure 2.4: (a) Flowchart of global calibration procedures for MEPDG rutting model 


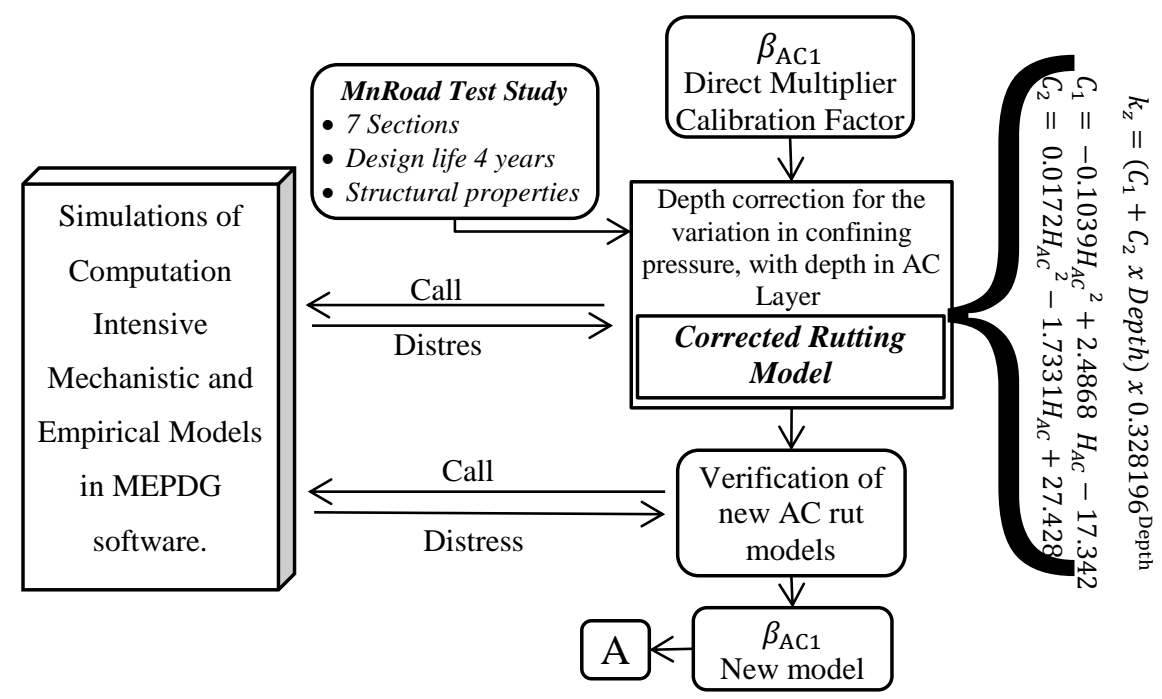

Figure 2.4: (b) Flowchart of global calibration procedures for MEPDG rutting model.

\subsubsection{Sensitivity Analysis for Permanent Deformation}

The objective of this general sensitivity study (Appendix GG-2 of NCHRP (2004)) was to investigate how some major design input parameters effect the permanent deformation. This study included individual reports associated with influence of AC Mix stiffness (Thin Layer), AC Mix Stiffness (Thick Layer), AC Mix as a function of traffic repetitions, AC thickness as function of depth, AC mix air voids, asphalt content, mean average annual temperature (MAAT), base thickness, subgrade modulus, truck traffic volume, traffic speed, traffic analysis level, traffic wander, bedrock depth and depth of GWT upon permanent deformation. Following conclusions can be drawn from this sensitivity study.

1. Permanent deformation in HMA layer will decrease with increase of HMA stiffness. However, variation in HMA AC mix stiffness has relatively smaller effect on permanent deformation.

2. Traffic loading and vehicular operating speed have larger influence on AC layer while granular and subgrade layer has relatively minor effect. 
3. Maximum rutting in $\mathrm{AC}$ layer is achieved at an optimum thickness while further increasing thickness lead to decrease in rutting. Thin HMA layers would lead to greater permanent deformation in granular and subgrade layers due to less protection against traffic loadings as compared to thick HMA layers.

4. Distribution of rutting in AC layer was measured as a function of depth. It showed that smaller portion of rutting will occur in top $1 \mathrm{inch}(25.4 \mathrm{~mm})$. Maximum portion of rutting would occur in 2-4 in or (50.8 - 101.6 mm) depth of AC layer. Air voids, amount of binder and geographical location (environmental temperature) in mixture will directly influence the amount of rutting in AC layer.

5. Increase in thickness of granular layer has non-existence effect in AC layer however it protects subgrades from further rutting. Increasing modulus of granular layer has very small effect in rutting in other layers. However, change in subgrade modulus and presence of bedrock will have larger effect in AC layer than in granular or subgrade layer.

Local calibration should include pavement section with these parameters with all ranges of values. Implications of locally calibrated models would also be for wider range of parameters.

\subsection{Former Local Calibration Studies}

Throughout U.S and Canada many state or regional transportation agencies have initiated local calibration for their regional conditions. Although, the main objective of all calibration is to reduce the bias and standard error, these calibration approaches differ from each other in its processes. Studies particularly related to calibration or verification of rutting model is summarized.

Kang and Adams (2007) calibrated longitudinal and alligator fatigue cracking models for Midwest Region (Michigan, Ohio and Wisconsin). Database from three DOT`s were collected for the calibration. Pooled calibration with hit and trail method was done. Comparison was done to determine the recommended calibrated coefficient values for Wisconsin.

In Montana, local calibration models for all distresses except top-down longitudinal cracking were validated by VonQuintus and Moulthrop (2007). Research used 34 LTPP and 13 non- 
LTPP pavements sections located in Montana, while 55 LTPP sections and structural information for sections located in adjacent US States and Canadian provinces were used. Calibration was done in a heuristic iterative approach or trial and error. For rutting under the assumption that granular and subgrade layer has negligible rutting $\beta_{\mathrm{GB}}=\beta_{\mathrm{SG}}=0.2$ for granular and subgrade layer.

For Missouri, local calibration of HMA pavements was done by Donahue (2008) using MoDOT and LTPP database. For California, local calibration of CalME rutting model for each layer was done by Ullidtz et al. (2008) using California heavy vehicle simulators (HVS). Calibration of rutting models was done along entire life of pavement.

For Texas, local calibration of AC Permanent deformation model for MEPDG was performed by Banerjee et al. (2009). Texas was divided into 5 different regions, and average calibration coefficients these regions are used as the calibration coefficient of Texas. Texas specific data from SPS-1 and SPS-3 experiments of LTPP database were used in the calibration. In AC rutting model only $\beta_{\mathrm{AC} 1}$ and $\beta_{\mathrm{AC} 3}$ were varied while, $\beta_{\mathrm{AC} 2}$ was kept constant at 1 , under assumption that the temperature dependency of the specific material should be determined in the laboratory for a given mix. Subgrade permanent deformation calibration factors values were derived from expert knowledge. Simultaneous joint optimization (pooled calibration) routine was applied because it was theoretically sound. Five regional level 2 calibrations were performed and their average coefficients were selected as a Texas state default coefficients (level 3).

For Washington, Li et al. (2009) performed local calibration for pavement sections under WSDOT. The calibration procedure involved (a) bench testing (b) model analysis (c) calibration (d) validation, and (e) iteration. In bench testing sensitivity of various input parameters on distresses were observed. Subgrade rutting calibration factor $\left(\beta_{\mathrm{SG}}\right)$ was set at zero, as very small rutting was observed in subgrades on WSDOT. Typically calibration was performed by categorizing pavement section in 18 possible subgroups based on 3 traffic ranges, 2 subgrade soil types with different resilient modulus and 3 different climates $(3 \times 2 \times 3=18)$. However, many of these subgroups had no section available, leaving eight actual subgroups. Pavement sections were calibrated (Table 2-3) by an iterative method.

For the state of Ohio, Mallela et al. (2009) performed validation and recalibration of MEPDG rutting models. SPS projects in LTPP and MnRoad database were used, with approximately 10 
years distress/IRI data. Recalibration of all three models (HMA, base and subgrade) significantly improved the model accuracy but not the bias. The recalibration was done only for multiplier calibration parameters $\beta_{r 1}, \beta_{G B}$ and $\beta_{S B}$, emphasizing than $\beta_{r 2}$ and $\beta_{r 3}$ should only be adjusted after laboratory investigation of accumulation of permanent deformation with repeated loadings.

Verification of distress and roughness of MEPDG for the state of New Jersey was done by Siraj et al. (2009). Study used combination of LTPP and non-LTPP pavement sections with level-3 material inputs and level-2 traffic inputs. The analysis results showed that difference between measured rutting and the average predicted rutting was insignificant. Other predicted distress and IRI were also quite similar to observed distress and roughness.

Jadoun (2011) wrote his dissertation on Calibration of flexible pavement distress prediction models in the Mechanistic Empirical Pavement Design Guide (MEPDG) for North Carolina. Material properties and permanent deformation performance characterization were developed for all 12 asphalt mix used in North Carolina before local calibration. Conversion model was developed by Corley-Lay et al. (2010) to convert subjective rut depth and alligator cracking ratings to equivalent LTPP ratings. They used two approaches, approach I the generalized reduced gradient (GRG) method and approach II genetic algorithm (GA) optimization technique to calibrate material specific HMA models. In approach-I, for each section, 110 combinations of $\beta_{\mathrm{AC} 2}$ and $\beta_{\mathrm{AC} 3}$ yielding were analyzed and $\beta_{\mathrm{AC} 1}, \beta_{\mathrm{GB}}$ and $\beta_{\mathrm{SG}}$ were optimized for least RSS using generalized reduced gradient (GRG) of MS Excel solver. In Approach-II, genetic algorithm (GA)

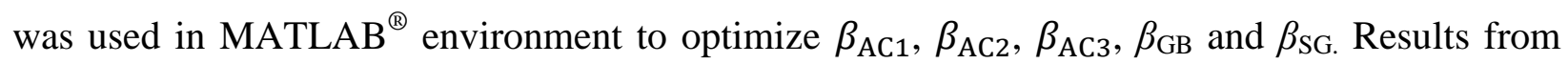
Approach-II were selected (Table 2-3). Only pavement sections from LTPP database were used in the local calibration while PMS sections of NCDOT were only used for validation.

Calibration of the MEPDG for flexible pavement design was done in Arkansas by Hall et al. (2011) using LTPP and PMS database. Alligator cracking and rutting models were improved by this initial calibration. Like in many other calibrations, default values of many parameters were used due to lack of data. Paper concluded by recommending data collection from more sites before full implementation of the MEPDG in Arkansas. Paper strongly stressed on the need of collection of transverse cracking distress data.

For Alberta, He et al. (2011) evaluated rutting models using Alberta's PMS data. In this preliminary study, average rut depths of inventory sections for the network were organized in 
groups. These rut depths were plotted against the pavement age for each group. The objective was to analyses the predicted rut depths for each of the groups and compares them at the network level.

Recently a thorough research was done by Jannat (2012) on the topic of Database Development for Ontario`s local calibration of MEPDG distress models. She developed a database of 101 section cycles from Ontario; with high quality section specific material, pavement performance and traffic data. Here the term section cycle refers to the life of a section from its construction year (or the time of reconstruction or rehabilitation) to the year before the next major rehabilitation. She further did calibration and validation for IRI and rutting of around 79 section cycles with globally calibrated models using DARWin-ME ${ }^{\mathrm{TM}}$ software. Her study concluded that DARWin-ME ${ }^{\mathrm{TM}}$ generally over predicts rutting for Ontario pavement sections using globally calibrated models.

For Missouri, local calibration of HMA pavements was done by Donahue (2008) using MoDOT and LTPP database. In South Korea (Le et al. 2009), Korean Pavement Design Guide (KPDG) was developed based on M-E approach. Rutting model for AC was developed and then calibrated with accelerated pavement test (APT) and LTPP database for KPDG. For Jiangsu, China (Li and Kuai 2010) local calibration practice for permanent deformation model has been published. The optimum combination of $\beta_{\mathrm{AC} 2}$ and $\beta_{\mathrm{AC} 3}$ were found, while optimized $\beta_{\mathrm{AC} 1}$ is found by least square method. Ahmmed et al. (2011) used MEPDG with regional data on Manitoba pavement section. Sensitivity of MEPDG with variation of truck traffic distributions, AADTT and axle load spectra was examined. Comparison of design with MEPDG and conventional AASHTO 93 design method were also performed.

In Italy (Caliendo 2012) rutting models was calibrated (Table 2-3) from the percentage rutting reported by AASHO Report (1962). Italian designers are required to verify total rutting is less than $15-20 \mathrm{~mm}$ at the end of the service life of pavements. Calibration was started with default factors. Trial runs for $\beta_{\mathrm{AC} 1}, \beta_{\mathrm{AC} 2}$ and $\beta_{\mathrm{AC} 3}$ were conducted and interrupted when rutting of approximately 65, 25 and 10\% were observed in AC (surface + binder + base), subbase and foundation soil while total rut was still $\leq 15-20 \mathrm{~mm}$.

Williams and Shaidur (2013) calibrated rutting distress model for rehabilitated pavements for Oregon. Calibration parameters for granular and subgrade layer were set to zero, due to 
negligible rutting in these layers. However for AC layer, the two steps iterative calibration approach was adopted, where initially $\beta_{\mathrm{AC} 2}$ and $\beta_{\mathrm{AC} 3}$ were calibrated and in the next stage $\beta_{\mathrm{AC} 1}$ were adjusted using Excel Solver to reduce SSE. Calibration factors of rutting model obtained from former local calibration studies are present in Table 2-3.

These calibration studies can be broadly summarized on the basis of calibration process and accuracy of their calibration approach. Most agencies performed a pooled calibration, also referred to as joint optimization in literature, where all sections were analysed with multiple sets of calibration parameters to find the parameters with minimized RSS. This is usually considered as the poorest form of local calibration due to their poor correlation. Another calibration is referred as "level-3" which also takes in account all pavement sections but the process is more comprehensive than pooled calibration. The "level-3" calibration is obtained from average of region specific "level-2" local calibration parameters. The "level-2" calibration is the average of "level-1" calibration for a region, where "level-1" are site specific calibration parameters. This "level-1" calibration can also be termed as section-by-section calibration.

The accuracy of the calibration approach depends on the process of optimization or selection of final calibrated coefficient. Generally the approaches used in literature for this purpose are as follows:

1) Exhaustive search: multiple combinations of calibration parameters are analyzed and the calibration parameter corresponding to residuals error or RSS is selected.

2) Iterative Methods without Numerical Optimization: multiple combinations of calibration parameters are analyzed in batch and then rationale judgment are used to determine next iterations combinations until desired accuracy is obtained.

3) Iterative Method with Numerical Optimization: multiple combinations of calibration parameters are analyzed and new calibration parameters for next iteration are determined using some numerical optimization tool as:

a) Excel Solver (Generalized Reduced Gradient (GRG))

b) $\operatorname{MATLAB}^{\circledR}$ (Genetic Algorithm $(G A)$ ) 
Table 2-3: Calibration Factors of Rutting Model obtained from Former Local Calibration studies

\begin{tabular}{|c|c|c|c|c|c|c|c|c|}
\hline \multirow{2}{*}{ S.No } & \multirow{2}{*}{ Reference } & \multirow{2}{*}{ Location } & \multirow{2}{*}{ Data } & \multicolumn{5}{|c|}{ Calibration factors } \\
\hline & & & & $\beta_{\mathrm{AC} 1}$ & $\beta_{\mathrm{AC} 2}$ & $\beta_{\mathrm{AC} 3}$ & $\beta_{\mathrm{GB}}$ & $\beta_{\mathrm{SG}}$ \\
\hline 1 & (Li et al. 2009) & Washington, USA & $\begin{array}{l}\text { Washington State DOT } \\
\text { PMS (WSDOT) }\end{array}$ & 1.05 & 1.11 & 1.10 & 1.00 & 0.00 \\
\hline 2 & (Banerjee et al. 2009) & Texas, USA & $\begin{array}{l}18 \text { Sections from SPS-1 } \\
\& \text { SPS-3 of LTPP }\end{array}$ & 2.39 & 1.00 & 0.86 & 1.00 & 0.50 \\
\hline 3 & (Mallela et al. 2009) & Ohio, USA & SPS and LTPP database & 0.51 & 1.00 & 1.00 & 0.32 & 0.33 \\
\hline 4 & (Jadoun 2011) & North Carolina, USA & $\begin{array}{l}\text { LTPP, } 41 \text { Sections, } 235 \\
\text { rut depth data points }\end{array}$ & 0.95 & 0.86 & 1.35 & 0.54 & 1.50 \\
\hline 5 & (Hall et al. 2011) & Arkansas, USA & $\begin{array}{l}38 \text { Sections from LTPP } \\
\text { and PMS (ASHTD) }\end{array}$ & 1.20 & 1.00 & 0.80 & 1.00 & 0.50 \\
\hline 6 & (Caliendo 2012) & Italy & 12 Sections from PMS & 1.80 & 1.00 & 1.00 & 0.58 & 0.58 \\
\hline 7 & $\begin{array}{l}\text { (Williams and } \\
\text { Shaidur 2013) }\end{array}$ & Oregon, USA & $\begin{array}{l}44 \text { Sections from PMS of } \\
\text { Oregon DOT }\end{array}$ & 1.48 & 1 & 0.9 & 0 & 0 \\
\hline 8 & (Souliman et al. 2010) & Arizona, USA & 39 LTPP Sections & 3.63 & 1.1 & 0.7 & 0.111 & 1.38 \\
\hline
\end{tabular}


The selection of a method depends on the level of accuracy required in optimizing calibration parameters.

\subsection{Local Calibration Methodology Guide}

The guide was developed for local calibration of distress performance models if default performance models are significantly different from locally observed distresses. Local calibration is a vital step for effective implementation of MEPDG on any region. Therefore, Guide for the Local Calibration of the Mechanical-Empirical Pavement Design Guide was developed by AASHTO (2010). Important terminologies and step-by-step procedure for local calibration has been described in the manual. The accuracy of locally calibrated performance models depends upon the effectiveness of the local calibration process. Hence, calibration process is vital for engineers to have confidence in the design procedure. Eleven steps local calibration procedure has been summarized here.

Step 1: Selection of hierarchical level for each input parameter depending upon the available resources and required accuracy as it has a significant impact on the standard error of each distress prediction model.

Step 2: Development of detailed, statistically sound local experimental plan and sampling template to refine the calibration of the MEPDG distress models. Sampling should be done so that local calibration study contains all primary tiers including pavement type, surface layer type, thickness and subgrade soil type.

Step 3: Estimation of sample size for specific distress prediction models. The numbers of pavement sections are selected to determine local calibration coefficients for a specific distress model.

Step 4: Selection of pavement sections from full-scale pavement section, Accelerated Pavement Testing (APT) pads and combination of these two pavement sections, to obtain maximum benefit from already available information to decrease the sampling and testing cost. This study used MTO-PMS sections in Ontario whose data was already available.

Step 5: Extraction of project specific data e.g distress, material properties, evaluation data including any other missing information in accordance with standard practices. Comparison of 
maximum distress values with their respective design criteria or trigger values. Removing any anomalies in obtained distress data.

Step 6: Conduction of field and forensic investigations in accordance to MEPDG Manual of Practice to obtain missing structural information for selected pavement sections.

Step 7: Validation of global default models in performed by calculating performance indicator for each selected roadway segment. These predicted distresses are compared with field distress in terms of bias and standard error. Null hypothesis are evaluated and if any null hypothesis are rejected models are recalibrated. The null hypothesis is as follow:

$$
H_{0}: \sum\left(y_{\text {Measured }}-x_{\text {predicted }}\right)=0
$$

where

$$
\begin{gathered}
y_{\text {Measured }}=\text { Measured value, and } \\
x_{\text {predicted }}=\text { Predictred using the model. }
\end{gathered}
$$

As previously mentioned validation has been already performed for pavement section in Ontario by Jannat (2012).

Step 8: Elimination of local bias in distress prediction models. Local calibration coefficients are adjusted based on magnitude of bias and residual errors. In permanent deformation rutting models scaling factors $\left(\beta_{\mathrm{GB}}, \beta_{\mathrm{SG}}, \beta_{\mathrm{AC} 1}\right)$ are used to eliminate bias while $\beta_{\mathrm{AC} 2}$ and $\beta_{\mathrm{AC} 3}$ are used to reduce standard error.

Step 9: Comparison of standard error of calibrated pavement sections and global calibration. If the local calibration has a lower standard error then these calibration coefficients should be used.

Step 10: If the standard error is significantly larger than global default models standard error than further adjust calibration coefficients by numerical optimization and other methods.

Step 11: Adequacy of calibration parameters are weighted on the basis of the effect of calibration parameters on designs at different reliability levels. If the design life is too "too short" for regional agency reliability levels, than further work should be done to reduce standard error otherwise the calibrated coefficients are ready to be used in MEPDG software. 
Further, the local calibration guide also provides examples for validation and calibration to account for the local/regional factors that were not considered in the global calibration.

\subsection{Summary Remarks}

Although a few mechanistic methods were developed in literature pavements have been designed mainly using empirical methods. The AASHTO MEPDG stands out as a major step forward for pavement design because of its comprehensive analysis framework. It can predict permanent deformation in each layer using separate rutting models. However, due to the MEPDG's empirical nature, the local calibration of permanent deformation models is unavoidable for Ontario. The AASHTO official guidelines for local calibration and procedure of calibrating default models are available for our convenience. Similarly, experiences of numerous transportation agencies throughout North America also provide guidance and challenges faced during their local calibration effort. The uniqueness in local calibration efforts of several agencies gave us the opportunity to understand their adopted process and motives behind choosing a particular methodology. These motives may include simplicity in calibration process

or higher accuracy of calibrated parameters. The optimization process needs to be compared and selected based on the accuracy required for our local calibration effort. This knowledge of local calibration will be helpful in countering challenges of local calibration of permanent deformation models is Ontario. 


\section{CHAPTER 3 LOCAL CALIBRATION METHODOLOGY}

\subsection{Introduction}

As earlier discussed in the literature review, the MEPDG contains three separate empirical transfer models for prediction of rutting in the HMA, granular base and subgrade layers. The three models contain five local calibration parameters that are to be adjusted in a local calibration practice.

The ultimate goal of local calibration is two-fold: to eliminate the possible bias and to minimize the Residual Sum of Squares (RSS). The two objectives are usually compatible, i.e., reducing the absolute bias often minimizes the RSS and vice versa. Therefore, it is common in local calibration to focus on only the RSS.

For a specific pavement sections with observed total rut depth $d_{j}$ and calculated total permanent deformation $D_{j}$ at different inspection time $t_{j}$, the RSS is defined as

$$
R S S=\sum_{j=1}^{n}\left(D_{j}-d_{j}\right)^{2}
$$

Here $n$ is the total number of rut depth measurements. Note that $D_{j}$ depends on the five local calibration parameters $\beta_{\mathrm{AC} 1}, \beta_{\mathrm{AC} 2}, \beta_{\mathrm{AC} 3}, \beta_{\mathrm{GB}}, \beta_{\mathrm{SG}}$. It has been expected that a unique optimal value of the five parameters could be obtained by simple minimization of the RSS. For this, many people used Excel Solver or other optimization tools to find the numerical optima, as mentioned in Chapter 2. However, our study showed that there were actually multiple local optima in the RSS minimization problem. Using an example, Section 3.2 illustrates this point.

In order to avoid the multiple optima, layers contribution to rutting was studied so that a layer-by-layer local calibration can be performed. Results of the layers contribution are reported in Section 3.3. Finally, Section 3.4 explains the detailed local calibration methods adopted in the study. 


\subsection{Multiple Local Optima}

To understand this, extensive computer iterations of a typical pavement section (PMS-2 Section I.D. 1200) were run in DARWin-ME ${ }^{\mathrm{TM}}$ to plot surfaces between the local calibration parameters and the RSS. For the sake of simplicity, the two exponent parameters $\beta_{\mathrm{AC} 2}$ and $\beta_{\mathrm{AC} 3}$ in these iterations were kept to be the default value of 1 while all possible permutations of $\beta_{\mathrm{AC} 1}, \beta_{\mathrm{GB}}$ and $\beta_{S G}$ from 0.1 to 1.3 at a constant interval of 0.1 were used for analysis. The results of this analysis were used to draw a contour plot of RSS between any two calibration parameters among $\beta_{\mathrm{AC} 1}$, $\beta_{\mathrm{GB}}$ and $\beta_{\mathrm{SG}}$

As shown in Figure 3.1, at least two combinations of $\beta_{\mathrm{AC} 1}$ and $\beta_{\mathrm{SG}}$ provides similar minimized RSS values. Similarly, Figure 3.2, shows multiple local optimums with similar RSS for combinations of $\beta_{\mathrm{GB}}$ and $\beta_{\mathrm{SG}}$. Due to space limit, the other contour plots with different combinations of the three parameters at different levels are not shown here, but they include the similar pattern of contours with multiple local optimal solutions. In fact, when the three scaling parameters are allowed to vary, even between these small ranges, there are more than 17 local optima that resulted in a RSS of less than 4. The Figure 3.3 shows five of these local combinations and the correspondingly predicted total rut depth against the observed values. Although the local calibration parameters are very different as shown in the legend, the predicted rut depth curves and the associated RSS values are very close. The solution of local calibration becomes vague when multiple local optimums exist with a slight difference in RSS. Because of under-determination of the system (multiple solutions with the same value for the RSS), no unique solution is produced. The presence of the multiple local optima makes the local calibration of rutting models very complicated. 


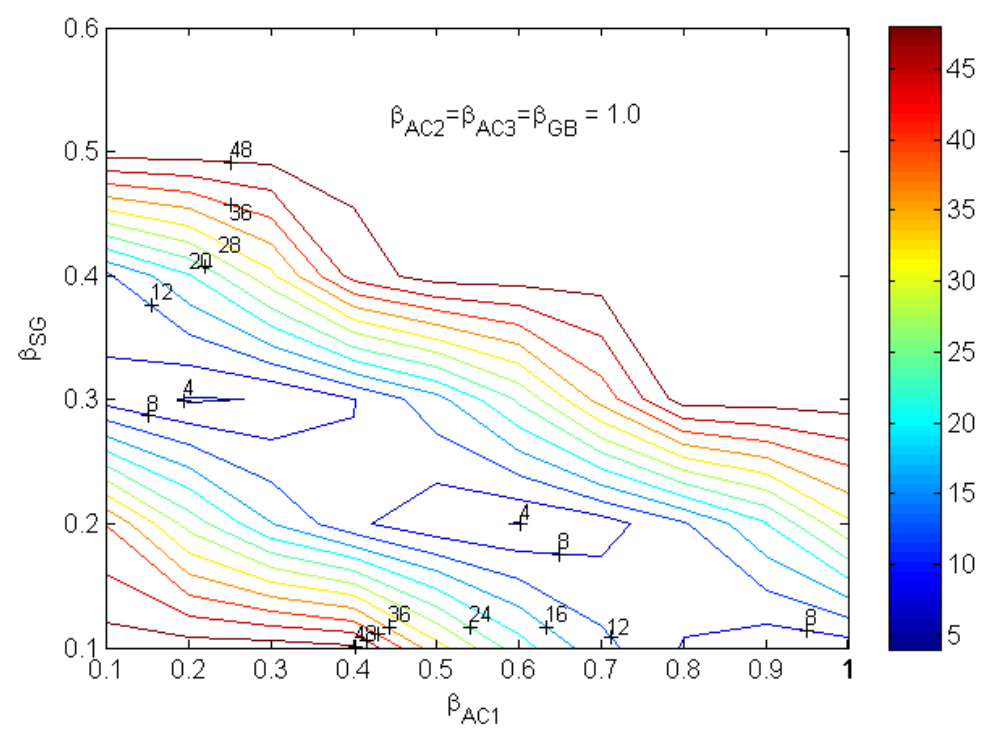

Figure 3.1: RSS contours against $\beta_{\mathrm{AC} 1}$ and $\beta_{\mathrm{SG}}$ showing multiple local minima.

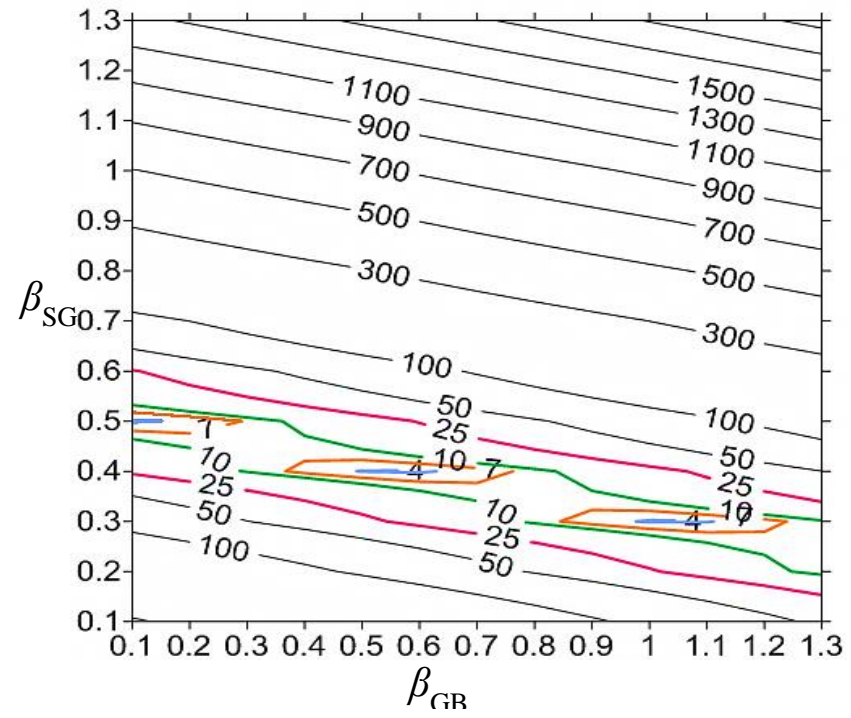

b) $\mathrm{AC} \beta_{\mathrm{AC} 1}=0.2$

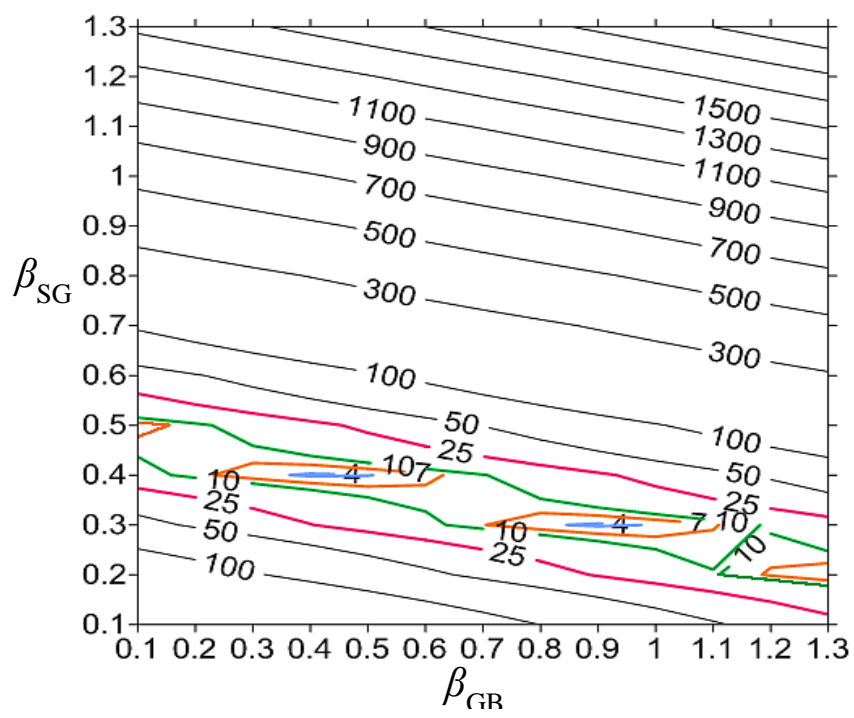

c) $\mathrm{AC} \beta_{\mathrm{AC} 1}=0.3$

Figure 3.2: RSS contour against $\beta_{\mathrm{GB}}$ and $\beta_{\mathrm{SG}}$ plotted at constant value $\beta_{\mathrm{AC} 3}=\beta_{\mathrm{AC} 3}=1.0$. 


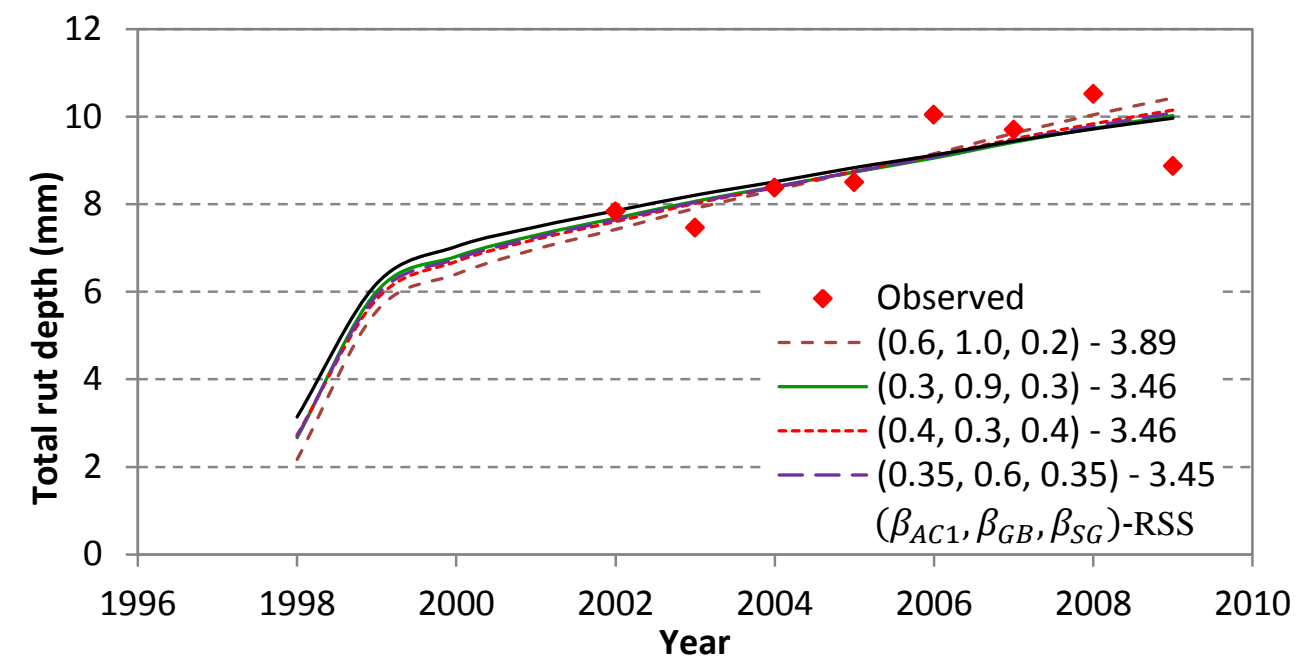

Figure 3.3: Comparison of Predicted total rut depth curves with different combinations of calibration parameters.

\subsection{Layers Contribution to Rutting}

Because of the multiple local optima in the RSS minimization, some researchers used evolutionary optimization algorithms (e.g., the genetic algorithm) trying to get a so-called global optimal solution. This approach blurs the nature of the problem and thus not used in this study. The root cause of the multiple optima is the underdeterminacy of the transfer functions. As discussed in Chapter 2, the three transfer functions collectively determine the total surface rut depth. However, the local calibration is doing the opposite, i.e., use the total surface rut depth to determine the three functions. In order to uniquely determine the five local calibration parameters in the three functions, one needs to reduce the inherent indeterminacy of the permanent deformation models. The only reliable approach to this reduction is through the layer contribution to the total surface rut depth, i.e., how much percentage of the total rutting comes from the AC surface layer, base layer, subbase layer, and the subgrade soil? Hence, integration the element of layer contribution of rutting in the process of calibration will narrow down the number of possible local optimums for section. Once this information is available, unique determination of the five local calibration parameters can be expected. Therefore layers percentage contribution of rutting was included as a component of calibration. The details of the local calibration methodology are explained in the next section. 
Before that, the actual percentages of layer contribution to rutting need to be sorted out. A direct way of determining the layer contribution would be the field trench analysis that the MEPDG research team advocated long time ago. This method is not very practical for local calibration for two reasons. The first one is that the trench analysis is very expensive and time consuming. The second one is that even a dedicated transportation agency would like to conduct some trench analysis, a series of followup trench investigations are important to ensure the reliability of the data observed. For these reasons, this study took an indirect approach. Basically, previous empirical studies were reviewed first to understand the statistics of the layer contributions. It was then followed by computational analyses using various software packages with different deformation theories, hoping additional insights could be gained that would help us to determine a reasonable combination of the layer contribution percentages. Results from these studies are reported below.

\subsubsection{Empirical Studies}

In past, several trench studies have been done to estimate layer contribution to rutting. Some of these studies are discussed below.

AASHO (1962) reported that a change in thickness of $32 \%$ for surface, $14 \%$ for base, $45 \%$ for subbase and $9 \%$ for subgrade could be caused by total rut in a pavement (Caliendo 2012). Calibration and developmental effort for a new M-E rutting model for 61 sections of GPS - 1 experiment in LTPP database was done. It concluded that surface layer has marginal contribution to total rutting. The base/subbase layer was the major contributor of rutting. The contribution of subgrade layer towards rutting was less than that of base layer, but greater than AC layer. (Ali et al. 1998)

Accelerated loading facility (ALF) results were used in calibration of VESYS5 rutting model for Texas State. Results from trench studies were used to determine the observed layer contributions of rutting. ALF-TxMLS study reported average contributions to rutting of $67.8 \%$ for AC layer, $25.9 \%$ for base layer and $6.3 \%$ for subgrade layer. These rutting's were extracted from MDD (Multi depth deflectometer). As observed in case of analysis with default models in MEPDG, percentage contributions to rutting in AL-TxMLS also varied along the service life of pavement. (Zhou and Scullion 2002) 


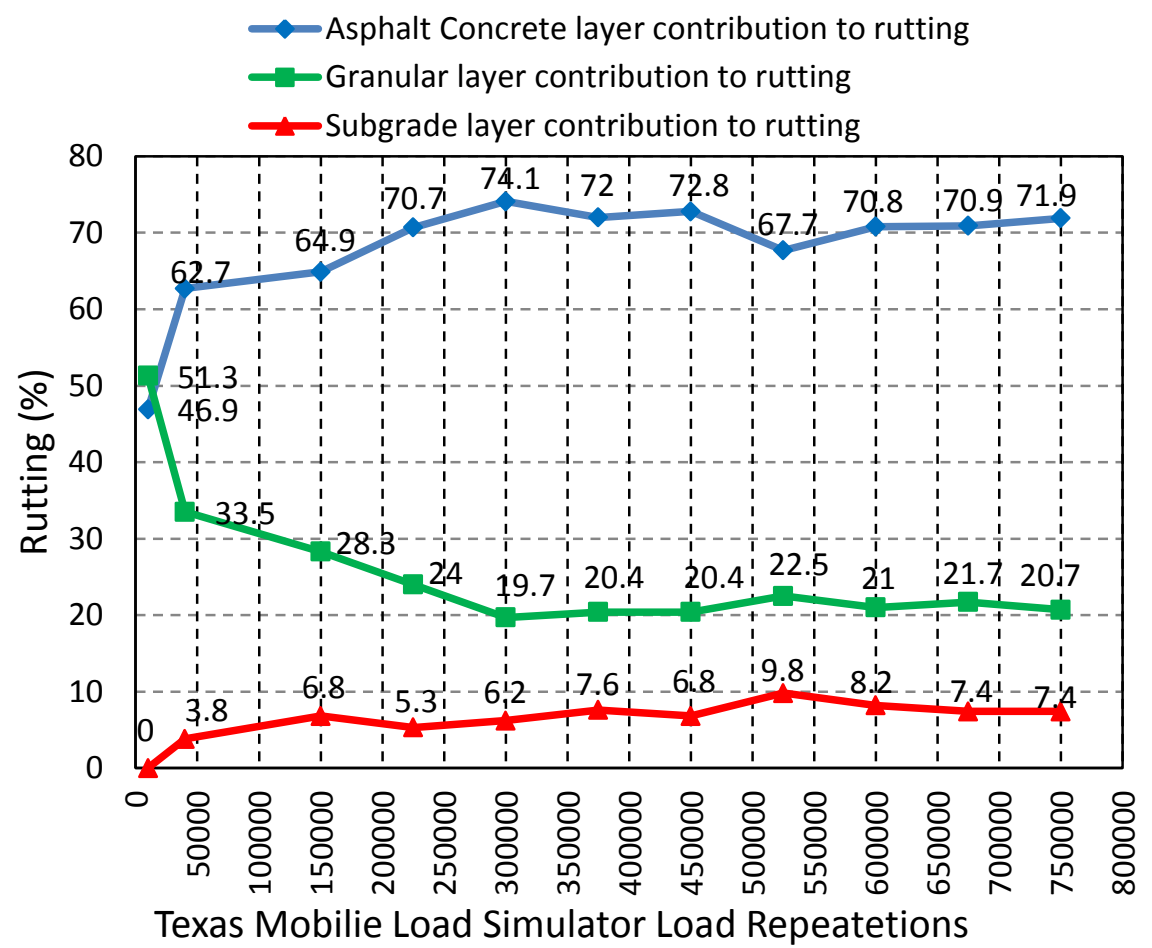

Figure 3.4: Variation of layers percentage contributions with TxMLS load repetitions.

Another study reported in (Salama et al. 2006) is layer contributions calculated from ALFFHWA field observations. Layer contribution to rutting was classified in thick and thin surface layer. Layers contribution to rutting from ALF-FHWA (Thick) and ALF-FHWA (Thin) are shown in Figure 3.5.

Salama et al. (2006) calibrated the VESYS mechanistic-empirical rut model for 109 in-service pavement sections from SPS-1, LTPP. It used the calibrated model to predict average layer contribution to rutting in 43 in SPS-1 pavement sections from LTPP database. On average $57 \%$ from AC layer, $27 \%$ from the base layer, and 16\% from the subgrade from the analysis of calibrated rutting models. This finding was found to match very well the observations made in (Zhou and Scullion 2002) for ALF-TxMLS (Accelerated Loading Facility-Texas Mobile Load Simulator) data. Layer contributions from these empirical studies are summarized in Figure 3.5. 


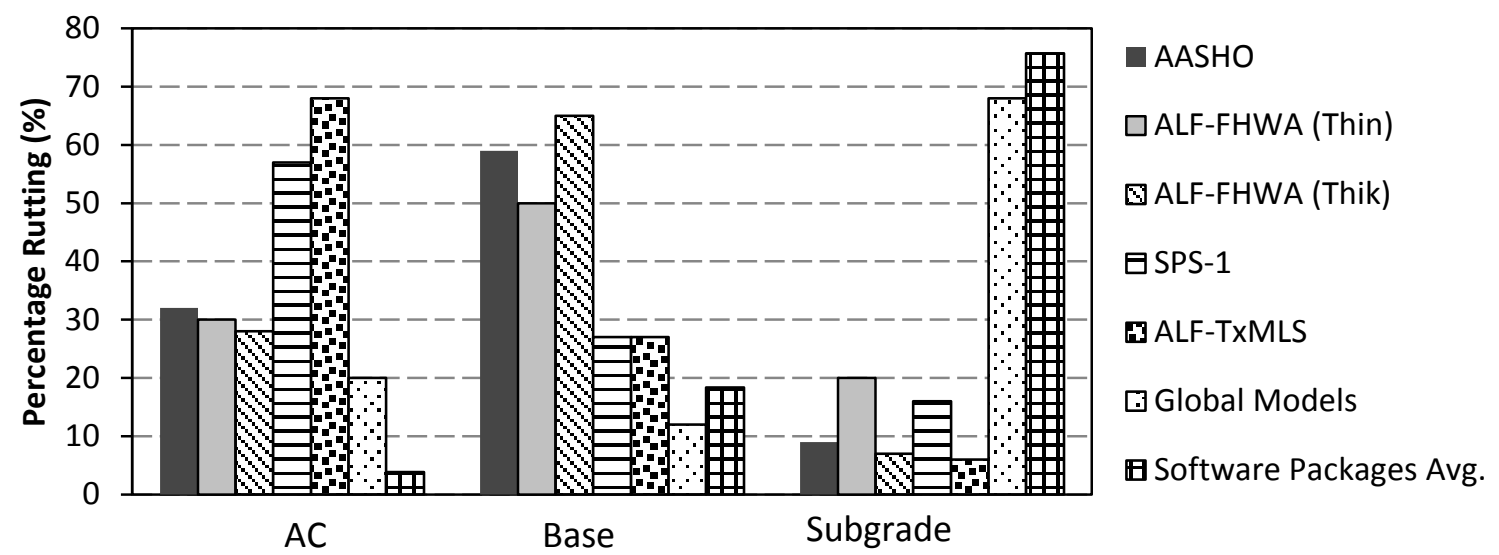

Figure 3.5: Summary of layers contribution to rutting (New Pavement Sections).

In a more MEPDG related research [(NCHRP 2004) Part 3, Chapter 6: AC Rehabilitation] a table presents percentage of surface rutting obtained from trench studies and experience. It recommends development of similar type of table for estimating initial rut depths for Level 2 and 3. However it can be observed these layer contributions to rutting are different from one reported in AASHO (1962).

Table 3-1: Average Percentage of Surface Rutting for different Pavement layers and Subgrade.

[Table 3.6.9 of NCHRP(2004)]

\begin{tabular}{|l|c|c|c|}
\hline \multirow{2}{*}{\multicolumn{1}{c|}{ Layer }} & \multicolumn{3}{|c|}{ HMA Surface Thickness } \\
\cline { 2 - 4 } & Less Than 4 in. & $\mathbf{4 - 8}$ in. & Greater Than 8 in. \\
\hline Asphalt Concrete & 70 & 80 & 100 \\
\hline Granular Base & 15 & 10 & 0 \\
\hline Granular Subbase & 10 & 5 & 0 \\
\hline Subgrade & 5 & 5 & 0 \\
\hline
\end{tabular}




\subsubsection{Layers Contribution to Rutting from Software Packages}

Another approach is to use the percentage contribution to elastic displacement as a surrogate to emulate the percentage contribution to the permanent deformation. Three linear elastic multilayer programs named WESLEA, KenPave and mePADS were used to estimate the surface displacement in a typical flexible pavement structure design in Ontario $(22 \mathrm{~cm}$ AC layer, $15 \mathrm{~cm}$ granular base, $45 \mathrm{~cm}$ granular subbase, and silty sand subgrade with $M_{r}=25 \mathrm{MPa}$ ).

Similar results as shown in Table 3-2 for displacement in the pavement were obtained from all three software packages. The software generated results predict much higher rutting in subgrade and negligible rutting in AC layer. Therefore, this approach turned out not to be trustable.

Table 3-2: Layers contribution to Rutting from Software Packages

\begin{tabular}{|c|c|c|c|}
\hline Software Package & $\begin{array}{c}\text { Asphalt } \\
\text { Concrete } \\
(\%)\end{array}$ & $\begin{array}{c}\text { Granular } \\
(\%)\end{array}$ & $\begin{array}{c}\text { Subgrade } \\
(\%)\end{array}$ \\
\hline WESLEA & 2.63 & 11.54 & 79.67 \\
\hline KenPave & 2.97 & 19.35 & 77.68 \\
\hline mePADS & 5.88 & 24.18 & 69.93 \\
\hline
\end{tabular}

Difference in software predicted and field observed empirical values is clearly visible from this table. Software generated results predicted higher rutting in subgrade layer and negligible rutting in AC layer.

\subsubsection{Findings from DARWin-ME ${ }^{\mathrm{TM}}$ Global Models}

The third approach to indirectly determining the layer contribution to rutting is to use the same layer contributions in DARWin-ME ${ }^{\mathrm{TM}}$ of the default global models. This approach was actually used in NCHRP 1-37A for global calibration. Reconstructed and rehabilitated flexible pavement sections for Ontario were analyzed using globally calibrated models to deduce a value for percentage rutting associated with each layer in these two different types of pavements. 
Pavements exhibit a concave trend of rutting with respect to pavement service life/load applications. Equal increment in service life of pavement, produces a larger increment in rut depth in the beginning as compared to that in the end years of pavement life. This general trend is due to hardening of material with pavement service life.

The default models were used to analyze 10 reconstructed pavement sections in the local calibration database. The average percentage contribution of rutting of each layer along service life is shown in Figure 3.6. It is observed that the percentage rutting associated to subgrade and granular base layer decreases with the service life while that of asphalt concrete layer increases. The life-long average observed contribution of rutting was 20\% in AC layer, $12 \%$ in granular base/subbase layer, and $68 \%$ rutting in subgrade layer.

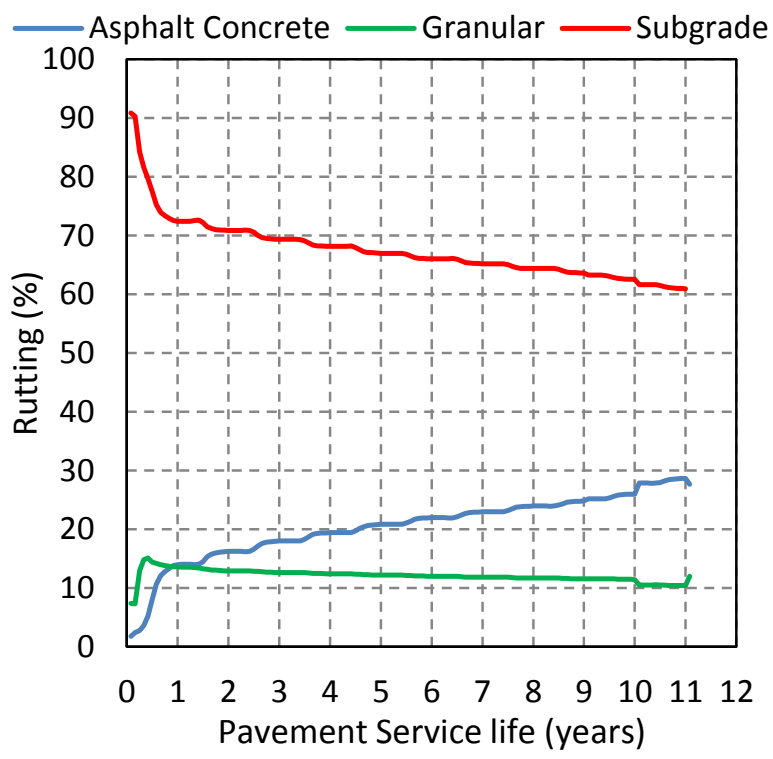

Figure 3.6: Percentage layer contribution of rutting for new or reconstructed sections along service life of the pavements

Similarly, 32 rehabilitated pavement sections from MTO PMS-2 data were analyzed. The average percentage layer contribution of rutting for rehabilitated pavement sections along service life of the pavements is shown in Figure 3.7. The life-long average observed contribution of rutting was 33\% in AC layer, 32\% in granular base/subbase layer, and $35 \%$ rutting in subgrade 
layer. It shows all layers have similar contribution of rutting in rehabilitated pavement sections. The average layer contributions of rutting are calculated for a service life of 11 years. However, pavement sections with service life longer than 11 years (after rehabilitation) will show even more contribution of rutting in AC layer.

General trend of variation of rutting was similar to that of new or reconstructed pavement sections. However very small decrease in contribution of subgrade layer was observed per year and the subgrade contribution towards rutting remained quite same throughout the service life of the pavement. This smaller variation can be explained by the fact that subgrade layer has already been compacted during first life cycle of rehabilitated pavement sections. However, as earlier mentioned these recorded observations are only for a limited duration of time (11 years), whereas a properly maintained pavement section life span can be as long as 20 to 30 years.

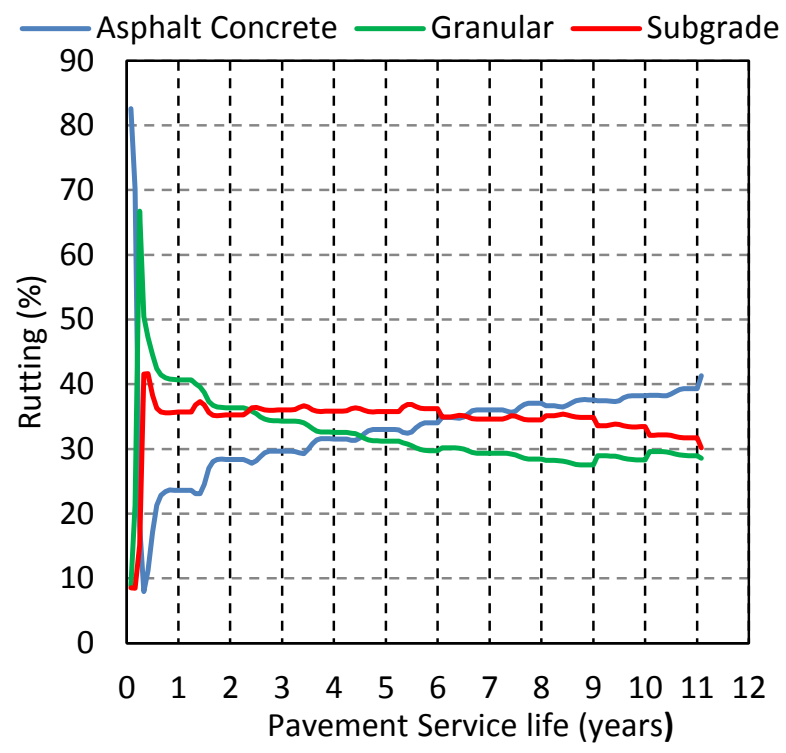

Figure 3.7: Percentage layer contribution of rutting for rehabilitated sections along service life of the pavements.

Research on layer contribution to rutting was done from several aspects. Contradicting results were found from global default models, elastic multilayer computer packages and empirical studies. These values were compared with the rutting contributions measured during former 
studies in USA. In Ontario, this topic has not been seen in the literature. In the following study, the layer contribution of rutting measured by AASHO in 1962 (i.e., 32\% for AC, 59\% for granular layers and 9\% for fine-grained soil) was selected as the main scenario for local calibration of new and reconstructed pavement sections. For rehabilitated pavement sections a practice similar to few other transportation agencies mentioned in Chapter 2 were adopted, rutting in subgrade layer was taken as zero while 50\% layer contribution of rutting was selected for AC layer and granular layer each.

\subsection{Local Calibration Methodology}

The study takes a layer-by-layer, section-by-section local calibration strategy. Each section was individually calibrated for the measured rut points throughout the service life of the pavement, hence a longitudinal calibration. Based on previous discussion, the selected layer rutting contribution percentages are used to calculate the observed rutting in all layers as a percentage of the observed total surface rutting. Meanwhile, the layer rut depths are predicted by using DARWin-ME $^{\mathrm{TM}}$. The RSS of each individual structural layer is calculated by comparing the observed layer rutting and the DARWin-ME ${ }^{\mathrm{TM}}$ predicted layer rutting. Minimization of the layer RSS leads to the optimal value of the corresponding local calibration parameters. The local calibration methodology can be described as a two stage methodology. In the first stage $\beta_{\mathrm{GB}}, \beta_{\mathrm{GB}}$ and $\beta_{\mathrm{AC} 1}$ are calibrated while in the second stage $\beta_{\mathrm{AC} 1}, \beta_{\mathrm{AC} 2}$ and $\beta_{\mathrm{AC} 3}$ are optimized.

Local calibration of granular and subgrade are relatively straightforward due to a single multiplier calibration factor $\beta_{\mathrm{GB}}$ for base and $\beta_{\mathrm{SG}}$ for subgrade. Initially calibration sections are analysed with default calibration models where all calibration parameters are equal to 1 . On the basis of this analysis near-optimal value for $\beta_{\mathrm{GB}}$ and $\beta_{\mathrm{SG}}$ are calculated from the following equation:

$$
\beta=\frac{\sum d_{i}}{\sum D_{i}}
$$

where $d_{i}$ is the measured layer rut, and $D_{\mathrm{i}}$ is the calculated layer rut based on the default global model. This does not always pin-point the optimal value therefore it is recommended to verify or 
fine-tune the resulted calibration parameter by fitting a quadratic function over five sample parameters around this point.

The optimization of the three parameters in the AC rutting model $\left(\beta_{\mathrm{AC} 1}, \beta_{\mathrm{AC} 2}, \beta_{\mathrm{AC} 3}\right)$ involves a large amount of computational effort as it requires iteration and the convergence. The optimization requires iterations and surrogate model. Iterations are needed because the RSS minimization is a nonlinear optimization problem. A surrogate model is necessary because DARWin-ME ${ }^{\mathrm{TM}}$ is a computationally intensive package. The use of surrogate model can reduce the computational time and accelerate convergence.

The calibration process of $\mathrm{AC}$ model starts with an initial point $\left(\beta_{\mathrm{AC} 1}^{(0)}, \beta_{\mathrm{AC} 2}^{(0)}, \beta_{\mathrm{AC} 3}^{(0)}\right)$ all being the default value of 1 . The multiplier calibration parameter in AC model, $\beta_{A C 1}$ is calculated in the same manner in which $\beta_{\mathrm{GB}}$ and $\beta_{\mathrm{SB}}$ of granular and subgrade models are calculated. During this process the exponential calibration parameters $\left(\beta_{\mathrm{AC} 2}, \beta_{\mathrm{AC} 3}\right)$ were kept constant at default value of 1 . The resultant combination of this process was treated as the initial iterate $\left(\beta_{\mathrm{AC} 1}^{(0)}, \beta_{\mathrm{AC} 2}^{(0)}=1, \beta_{\mathrm{AC} 3}^{(0)}=1\right)$ and error associated with this iterate is $\mathrm{RSS}^{(0)}$. Initial iterate of calibration parameters will be used to create design sample which is a set of calibration parameters used for constructing a surrogate models and hence used in iterative optimization of AC rutting model. This concludes the first stage of longitudinal calibration approach.

The second stage involves calibration of the AC model by optimization of three AC model calibration parameters. A response surface model (RSM) is used as a surrogate for the DARWin$\mathrm{ME}^{\mathrm{TM}}$ prediction for the optimization process. The RSM is a full quadratic polynomial function of the all three beta's of the AC rutting model. A linear regression based on least squared method is performed to construct the response surface. RSM used for optimization in this study is as follows:

$$
\begin{gathered}
f\left(\beta_{\mathrm{AC} 1}, \beta_{\mathrm{AC} 2}, \beta_{\mathrm{AC} 3}\right)= \\
\alpha_{1}+\alpha_{2} \beta_{\mathrm{AC} 1}+\alpha_{3} \beta_{A C 2}+\alpha_{4} \beta_{A C 3}+\alpha_{5} \beta_{A C 1}{ }^{2}+\alpha_{6} \beta_{A C 2}{ }^{2}+\alpha_{7} \beta_{A C 3}{ }^{2}+ \\
\alpha_{8} \beta_{A C 1} \beta_{A C 2}+\alpha_{9} \beta_{A C 2} \beta_{A C 3}+\alpha_{10} \beta_{A C 1} \beta_{A C 3}
\end{gathered}
$$

The problem was unconstrained as no conditions were imposed on the independent variables. The unconstrained multivariable minimization $\left[\min _{x} f\left(\beta_{\mathrm{AC} 1}, \beta_{\mathrm{AC} 2}, \beta_{\mathrm{AC} 3}\right)\right]$ was performed using an fminuncon general unconstrained minimization function from MATLAB ${ }^{\circledR}$ Optimization 
Toolbox. The objective of this minimization was to obtain a global minimizer $\left(\beta_{\mathrm{AC} 1}{ }^{*}, \beta_{\mathrm{AC} 2}{ }^{*}, \beta_{\mathrm{AC} 3}{ }^{*}\right)$ such that

$$
f\left(\beta_{\mathrm{AC} 1}{ }^{*}, \beta_{\mathrm{AC} 2}{ }^{*}, \beta_{\mathrm{AC} 3}{ }^{*}\right) \leq f\left(\beta_{\mathrm{AC} 1}, \beta_{\mathrm{AC} 2}, \beta_{\mathrm{AC} 3}\right) \text { for all } \beta_{\mathrm{AC} 1}, \beta_{\mathrm{AC} 2}, \beta_{\mathrm{AC} 3},
$$

These sampling is done considering some guidelines. Full factorial sampling was done with three levels within in each calibration parameter, which means three values of a calibration parameter in a sample. Due to full factorial nature sampling with 3 factors in 3 levels the sample contained $3 \times 3 \times 3=27$ sample points. One level is initial iterate itself while other two levels are the one above and another below the initial iterate. The DARWin-ME ${ }^{\mathrm{TM}}$ software is used to analyse 27 sample points in a single iteration. The constant intervals between three levels of iteration are selected on the basis of following criteria:

1. Change in exponential calibration parameters $\beta_{\mathrm{AC} 2}$ and $\beta_{\mathrm{AC} 3}$ have greater effect on permanent deformation than the change in $\beta_{\mathrm{AC} 1}$ calibration parameter. Therefore, sampling interval between two levels of calibration parameters $\beta_{\mathrm{AC} 2}$ and $\beta_{\mathrm{AC} 3}$ was taken half of interval in $\beta_{\mathrm{AC} 1}$.

2. The sampling interval should be within the following limit: $\beta_{\mathrm{AC} 1} \leq 0.05$ and $\beta_{\mathrm{AC} 2}, \beta_{\mathrm{AC} 3} \leq 0.025$

The first iteration should contain a wider interval between three levels within the earlier mention criteria. First iteration of 27 combinations is analyzed in the DARWin-ME ${ }^{\mathrm{TM}}$ to compute RSS, and then the RSM is built on this sample and optimized using MATLAB ${ }^{\circledR}$. The optimized iteration is then treated as sampling point in sampling for next iteration.

For convergence, an adaptive step sizing strategy and intelligent stopping rules are adopted. The intervals of levels in next iteration should be either same or reduced. If the RSS of new optimized iteration is same $\left[\mathrm{RSS}^{i}-\mathrm{RSS}^{i-1} \approx 0\right]$ where, $i$ is the ith iteration, and difference between all optimized $\beta_{\mathrm{AC} 1}^{i}, \beta_{\mathrm{AC} 2}^{i}, \beta_{\mathrm{AC} 3}^{i}$ and $\beta_{\mathrm{AC} 1}^{i-1}, \beta_{\mathrm{AC} 2}^{i-1}, \beta_{\mathrm{AC} 3}^{i-1}$ is small as 0.03 , than intervals between next levels of sampling should be cognitively reduced. The interval between levels of samples kept reducing in subsequent iterations till the values of calibration parameters started to converge. Following are the final conditions for stopping criteria of this local calibration effort.

1. The interval between the samples of $\beta_{\mathrm{AC} 1}$ reaches as low as 0.005 ; 
2. $\mathrm{RSS}_{i}-\mathrm{RSS}_{i-1} \approx 0$;

3. Limit the maximum number of iterations required to 6 for each pavement section;

Finally select the $\beta_{\mathrm{AC} 1}, \beta_{\mathrm{AC} 2}, \beta_{\mathrm{AC} 3}$ value corresponding to minimum RSS from the sample library as the calibrated coefficients for AC rutting model. Flowchart describing the calibration process is shown in Figure 3.8. The results for reconstructed and rehabilitated pavement sections calibrated using this methodology is provided in next chapters. 


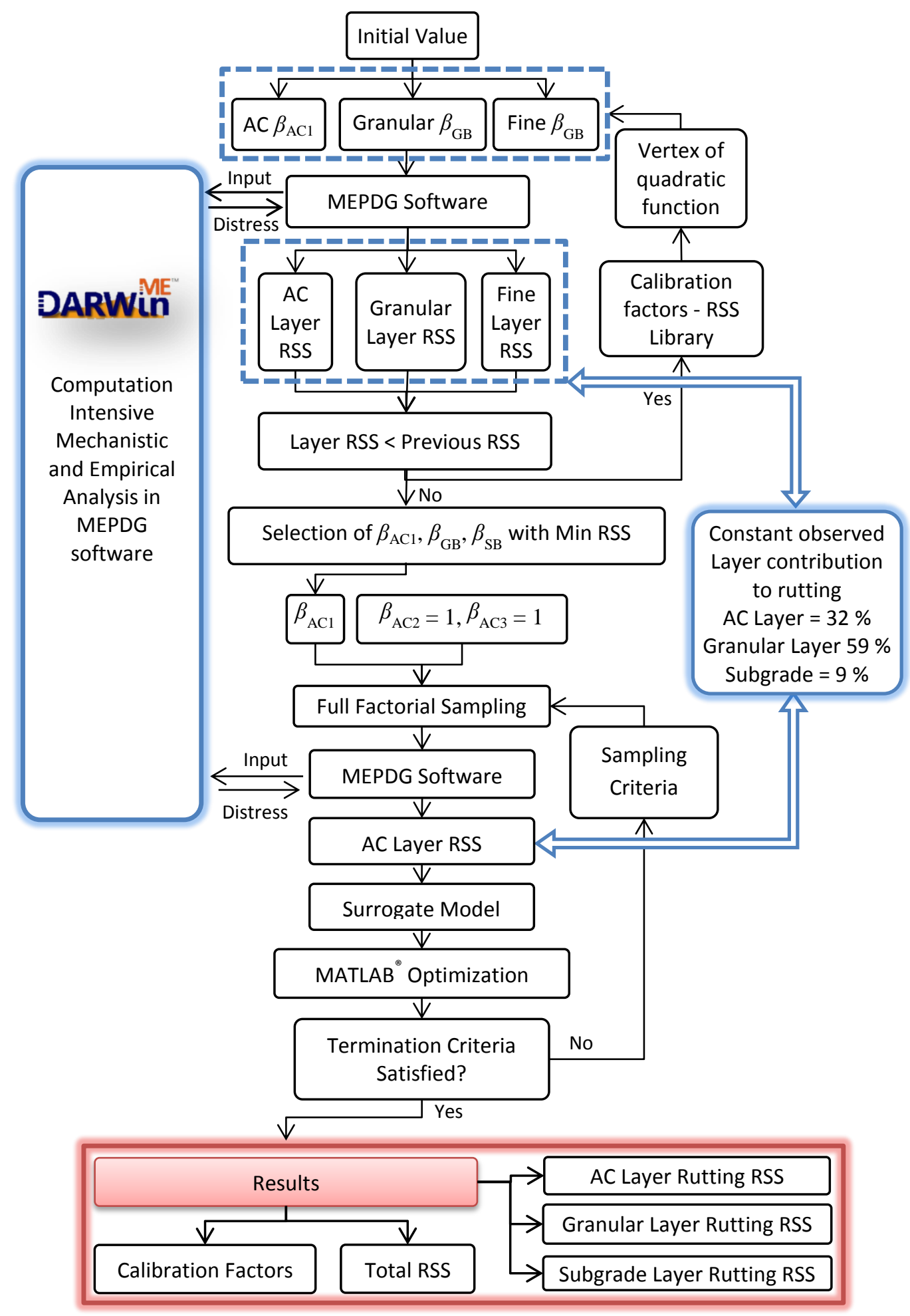

Figure 3.8: Flowchart for Section-by-section longitudinal local calibration based on layers rutting contribution. 


\section{CHAPTER 4 LOCAL CALIBRATION OF RECONSTRUCTED FLEXIBLE PAVEMENTS}

\subsection{Characterization of Data for MEPDG}

The first step of any local calibration procedure is the collection of input database and selection of their hierarchical input level for the MEPDG method. The hierarchical input level selected for inputs in this local calibration has to be similar to input levels expected during design of pavements segments. Selected input's hierarchical level is important because it will produce significant effect on final standard error of distress prediction models. Input error associated with each input parameter contributes towards total standard error. Selection of hierarchical level in local calibration is dictated by regional DOT's data collection policies. The MEPDG project inputs used in this research was collected from database developed by Jannat (2012) and Ontario default inputs guide under MTO (2012). The selection of hierarchical input completely relied on the already available database where, no additional tests were performed to further upgrade the input level. The locations of 51 flexible pavement sections are shown in Figure 4.1. These sections were taken from Highway 6, 7, 8, 11, 85, 400, 401, 403, 404, 410,417 and 427.

A typical design with the MEPDG required numerous inputs. A visual representation of basic material, traffic and climate inputs required to analyze the MEPDG project in the DARWin$\mathrm{ME}^{\mathrm{TM}}$ are shown in Figure 4.2. For designing a particular pavement these inputs can be grouped under six topics general project information, design criteria, traffic, climate, structure layering and material properties, but for the purpose of local calibration the inputs under topic of design criteria are not required. The MEPDG general project inputs and traffic data is characterised in Appendix A, climatic information in available in Appendix B and pavement material information is provided in Appendix $\mathrm{C}$ of this thesis. These input parameters were used during local calibration of reconstructed and rehabilitated flexible pavement sections. 


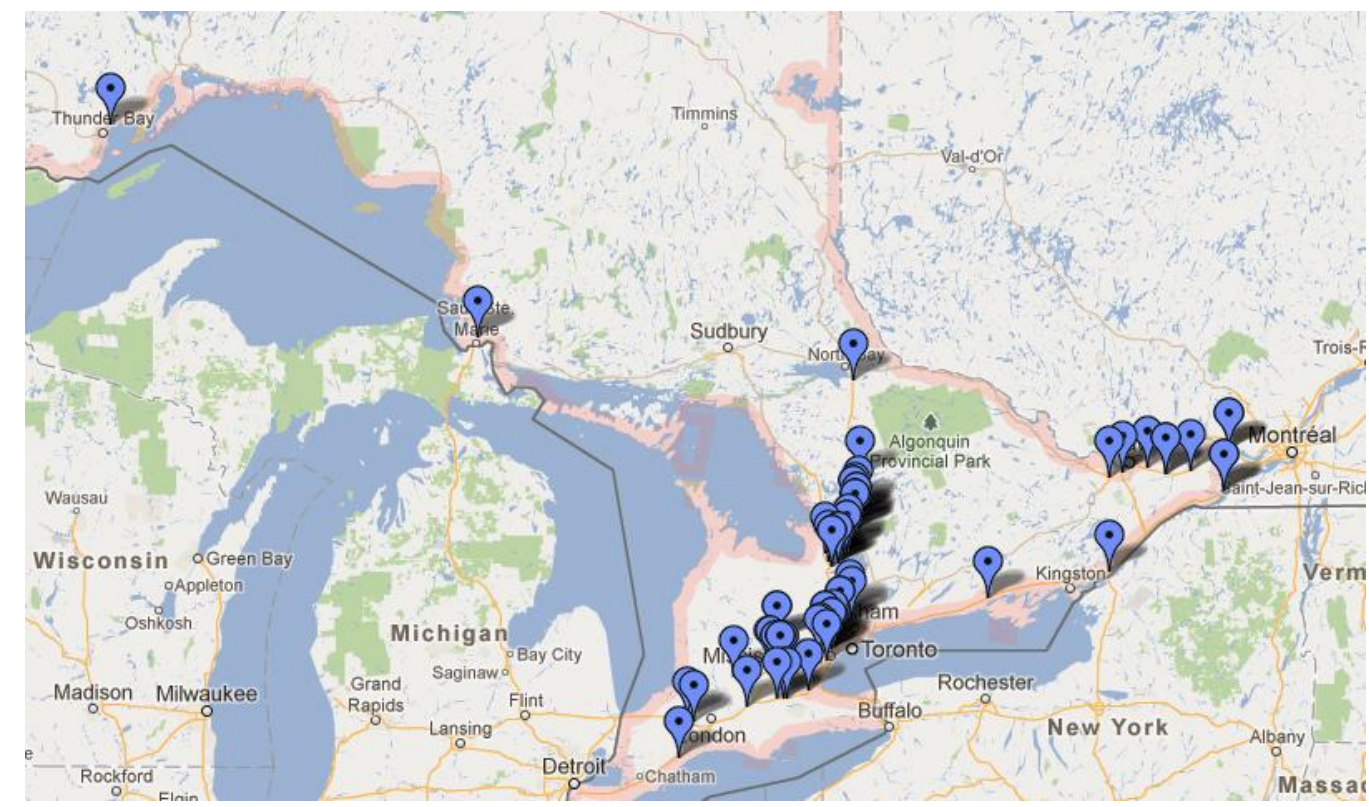

Figure 4.1: Locations of the 51 flexible pavement sections on Google Maps

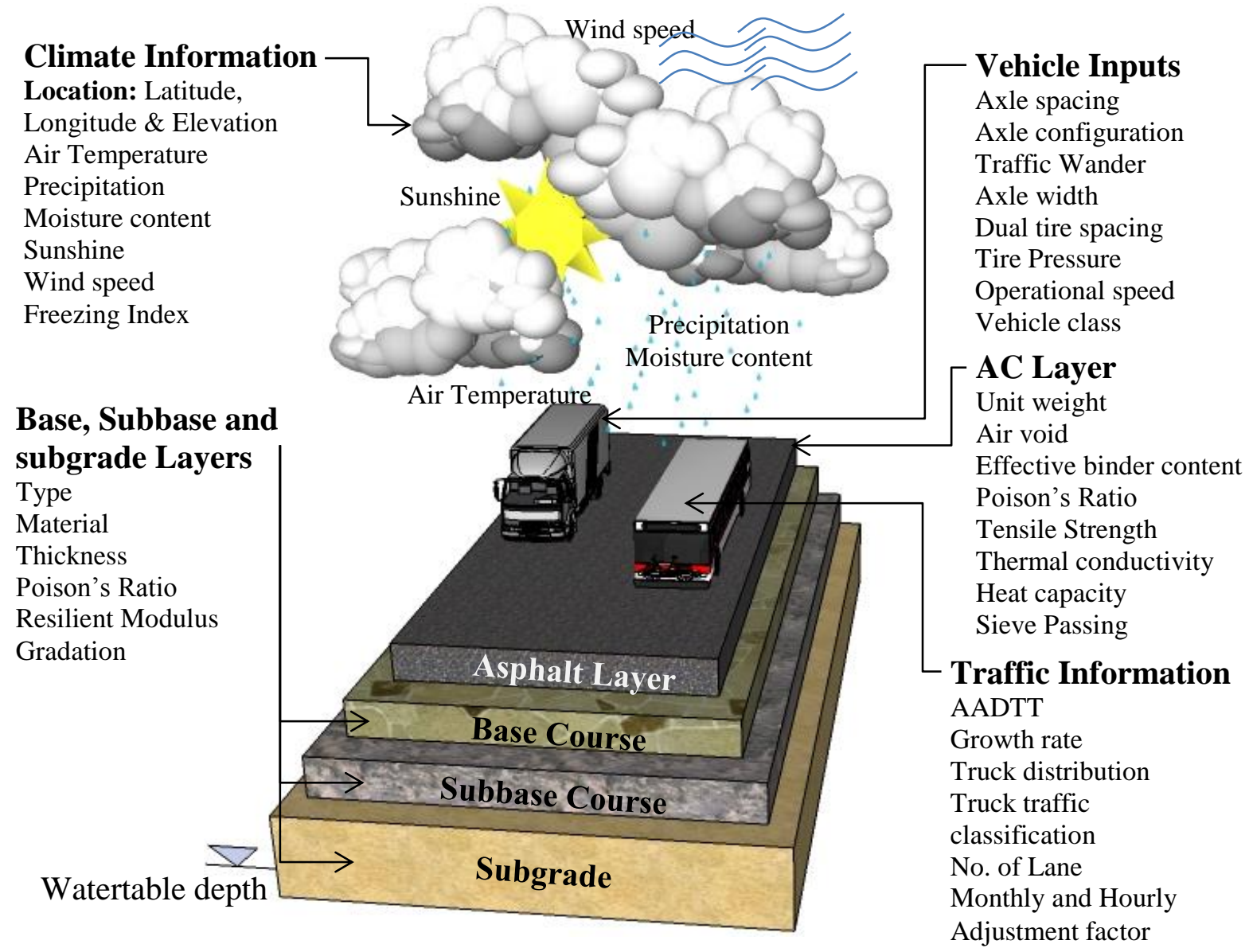

Figure 4.2: Visual representation of basic MEPDG inputs in typical DARWin-ME ${ }^{\mathrm{TM}}$ project. 


\subsection{Observed Rutting}

Rutting observed in field is considered as the most essential part of any local calibration process. The accuracy of collected rut depth affects the overall accuracy of design. These rutting were collected from PMS-2 system of MTO. After the examination of Ontario's pavement sections in the LTPP database, the author realized early in the research that the LTPP database cannot be used for longitudinal local calibration of the MEPDG rutting models for Ontario. This realization came after acknowledging the absence of more than two pavement rut depth in the LTPP database.

Ontario started recording rutting in 2002; hence no rutting measurement was available in Ontario before 2002. While reliable rut depths were only started to be recorded in PMS-2 database after 2004. Therefore pre-overlay ruts of none of the selected rehabilitated section were available, which lead to a brief study over selection of pre-overlay rut for local calibration of rehabilitated sections in Ontario, which will be discussed in chapter 5. MTO staff measured rutting with roughness using the Automatic Road Analyzer (ARAN) which greatly reduces the role of rater or equipment which causes variability in data.

The magnitude of the distress randomly fluctuated, which exhibited high variability in the measured data. Hence, observed rutting data was reviewed for each roadway section included in the study. Pavement section with a minimum of 4 rutting data points was allowed to be included in local calibration database. Visual inspections of rutting data were performed to identify the anomalies and outlier or blunders before using them in the study. Any zeros rut values found in between the pavement service life was removed as they represented non-entry values. Measurement that were on the same year of structural rehabilitation were carefully selected as either the first reading of the next cycle or the last reading of the ongoing cycle.

The magnitude of residual error can further be reduced by using smoothed observed rutting data instead of original observed rutting data. Unlike the modified rutting used by some researchers, observed values in its un-modified form (as observed) are used in this local calibration study. According to classic trend of rutting over time, initial deformation is due to densification of unbound and bound layers of pavement. The rate of deformation then slows down as the HMA layer stiffens. This stiffening of HMA layer with service life of pavement contributes to shear resistance with time. Hence, a power function could be used to represent the 
strain rate (White and Haddock 2002). Power law curve was used for smoothening irregularities in observed rutting data, which significantly reduced RSS value of previously found local minima's.

The comparison of original observed rutting, local minima predicted rutting and smoothed observed rutting for a typical new reconstructed flexible pavement section is shown in Figure 4.3. Comparison plot between the smoothened, original and predicted rutting shows that the scope of synchroneity between predicted and smoothed rutting curves is far better than that of observed rutting. Observed rutting points were only available from year 2002 to 2009, hence predicted rutting points corresponding to these years were used to generate power law or smoothed curve and to calculate RSS. Therefore rutting predictions starting from 2002 to 2009 tends to show even better affinity towards the smoothened rutting points.

Table 4-1 provides the reduction of RSS on using smoothed observed rutting as compared to that of RSS obtained from original observed rutting. This reduction of RSS from smoothened rutting results depends upon the extent of scatterings of original observed rutting around curve obtained from power law. The RSS value of smoothed curve is smaller than RSS of original observed rutting. However, this does not effect in terms of selection of final calibration parameters as same set of calibration parameters will be derived from local calibration with smoothed and original observed rutting.

Meanwhile, in this research original observed rutting data were used instead of smoothed observed rutting data as AASHTO (2010) does not recommends the use of smoothed data. If smoothed or modified data is to be used then variance associated with this smoothed data is also need to be considered with the calibration error (AASHTO 2010). Although, AASHTO (2010) does not recommends the use of smoothed data. 
PMS-2 I.D. 1200

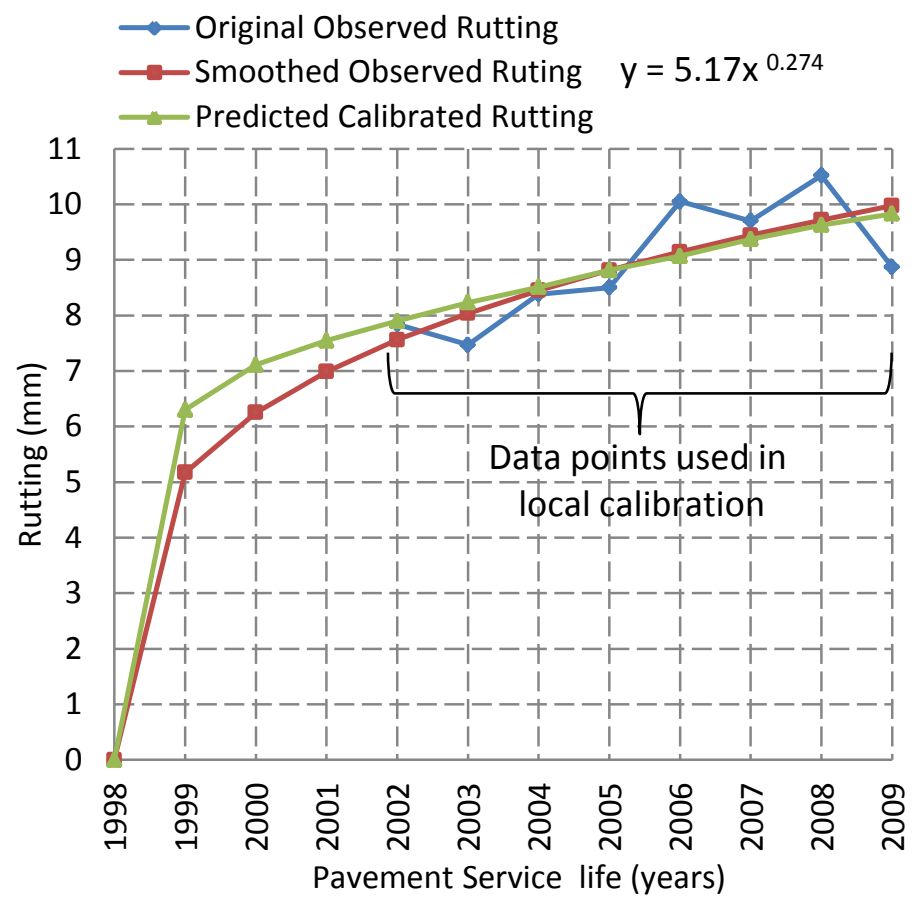

Figure 4.3: Observed rutting, Predicted rutting and smoothed rutting comparison graph.

Table 4-1: Comparison of RSS from Original Observed Rutting and Smoothed Observed Rutting

\begin{tabular}{|l|l|l|}
\hline Description & BIAS & RSS \\
\hline Original observed rutting \& Predicted rutting & 0.1893 & 0.1958 \\
\hline Smoothed observed rutting \& Predicted rutting & 0.0200 & 3.4866 \\
\hline
\end{tabular}

\subsection{Local Calibration Results of Reconstructed Flexible Pavement Sections}

\subsubsection{Locally Calibrated Parameters}

The permanent deformation models for new/reconstructed pavement sections are calibrated by using longitudinal local calibration methodology described in Chapter 3. Section-by-section longitudinal calibrations for ten reconstructed flexible pavement sections were performed for three permanent deformation models. The initial iterate $\beta_{\mathrm{AC} 1}^{(0)}$ for AC layer, $\beta_{\mathrm{GB}}$ for base and $\beta_{\mathrm{SG}}$ for subgrade calibrated during the first stage of calibration approach are listed together with the 
corresponding RSS, bias and percentage layer contributions in Table 4-2. Note again during the first stage local calibration the exponent parameters $\beta_{\mathrm{AC} 2}$ and $\beta_{\mathrm{AC} 3}$ both were fixed at the default value of 1 .

Table 4-2: First stage Section-by-section Local Calibration results for Reconstructed Pavements.

\begin{tabular}{|c|c|c|c|c|c|c|c|c|c|c|c|}
\hline $\begin{array}{l}\text { SC } \\
\text { ID. }\end{array}$ & \multicolumn{3}{|c|}{ Rutting Model } & \multicolumn{3}{|c|}{ Layers RSS } & \multirow{2}{*}{$\begin{array}{l}\text { Total } \\
\text { Bias }\end{array}$} & \multirow{2}{*}{$\begin{array}{l}\text { Total } \\
\text { RSS }\end{array}$} & \multicolumn{3}{|c|}{$\begin{array}{c}\text { Average Layer Contribution } \\
\text { [\%] After Calibration }\end{array}$} \\
\hline & $\beta_{\mathrm{AC} 1}^{(0)}$ & $\beta_{\mathrm{GB}}$ & $\beta_{\mathrm{SG}}$ & $\mathrm{AC}$ & Granular & Subgrade & & & AC & Granular & Subgrade \\
\hline 9 & 0.19 & 3.06 & 0.033 & 0.1816 & 0.2378 & 0.0074 & 0.011 & 0.8510 & 31.84 & 58.83 & 9.34 \\
\hline 43 & 0.16 & 3.17 & 0.033 & 0.1417 & 0.2281 & 0.0051 & -0.530 & 0.6047 & 31.76 & 59.20 & 8.74 \\
\hline 191 & 0.52 & 1.57 & 0.039 & 0.0241 & 0.2128 & 0.0047 & 0.031 & 0.4535 & 31.93 & 58.92 & 9.14 \\
\hline 376 & 0.44 & 0.41 & 0.025 & 0.3676 & 1.0798 & 0.0243 & 0.082 & 2.6442 & 31.65 & 59.26 & 9.09 \\
\hline 1049 & 0.16 & 0.96 & 0.037 & 0.2919 & 0.7121 & 0.0163 & -0.569 & 2.0159 & 30.72 & 60.15 & 9.13 \\
\hline 1053 & 0.20 & 0.63 & 0.016 & 0.1236 & 0.3104 & 0.0070 & 0.027 & 0.7799 & 32.16 & 59.09 & 8.75 \\
\hline 1188 & 0.40 & 1.11 & 0.040 & 1.1199 & 0.4038 & 0.0082 & -0.555 & 3.0429 & 30.80 & 60.14 & 9.06 \\
\hline 1189 & 0.48 & 1.27 & 0.041 & 0.5194 & 0.2239 & 0.0055 & -0.129 & 1.2219 & 31.52 & 59.43 & 9.06 \\
\hline 1200 & 0.64 & 1.61 & 0.050 & 1.5700 & 1.3401 & 0.0363 & -0.862 & 4.0960 & 32.35 & 58.95 & 8.71 \\
\hline 1311 & 0.56 & 0.66 & 0.022 & 1.1646 & 2.8296 & 0.0630 & -0.613 & 8.3139 & 31.62 & 59.28 & 9.10 \\
\hline
\end{tabular}

The calibration parameter $\beta_{\mathrm{AC} 1}^{(0)}$ obtained during first stage was taken as the initial values for further calibration of AC rutting performance model. The results of second stage section-bysection longitudinal calibration are presented in

Table 4-3.

The second stage result shows that the RSS of AC layer has been reduced for all pavement sections whereas total RSS has also been reduced for all except 2 sections (376 \& 1053) have slightly larger total RSS. This shows that although the optimization of AC rutting model resulted in reduction of RSS of AC layer but the total RSS did increased for few sections. 
Layer percentage contributions in each layer were similar to the selected percentage contributions for observed layer (e.g. $\approx 32$ for $\mathrm{AC}$ layer, $\approx 59$ for granular layer and $\approx 9$ for subgrade layer), hence not tabulated in the following table.

Table 4-3: Second stage Section-by-section Longitudinal Local Calibration results for Reconstructed Pavements.

\begin{tabular}{|c|c|c|c|c|c|c|}
\hline \multirow{3}{*}{ I.D. } & \multicolumn{3}{|c|}{ Rutting Model } & \multirow{3}{*}{ AC RSS } & \multirow{3}{*}{ Total Bias } & \multirow{3}{*}{ Total RSS } \\
\hline & \multicolumn{3}{|c|}{$\mathrm{AC}$} & & & \\
\hline & $\boldsymbol{\beta}_{\mathrm{AC} 1}$ & $\boldsymbol{\beta}_{\mathrm{AC} 2}$ & $\boldsymbol{\beta}_{\mathrm{AC} 3}$ & & & \\
\hline 9 & 0.144 & 1.738 & 0.229 & 0.063 & 0.120 & 0.6601 \\
\hline 43 & 0.162 & 1.091 & 0.920 & 0.098 & -0.075 & 0.5649 \\
\hline 191 & 0.290 & 0.975 & 1.105 & 0.022 & -0.002 & 0.4363 \\
\hline 376 & 0.310 & 1.200 & 0.835 & 0.309 & 0.038 & 2.6932 \\
\hline 1049 & 0.196 & 0.991 & 0.985 & 0.257 & -0.018 & 1.9728 \\
\hline 1053 & 0.256 & 1.262 & 0.719 & 0.097 & 0.055 & 0.8067 \\
\hline 1188 & 0.370 & 1.040 & 0.970 & 1.064 & -0.737 & 2.9352 \\
\hline 1189 & 0.470 & 1.130 & 0.870 & 0.383 & -0.303 & 1.0645 \\
\hline 1200 & 0.368 & 1.480 & 0.580 & 0.454 & -0.319 & 3.4449 \\
\hline 1311 & 0.336 & 1.182 & 0.892 & 1.105 & -0.158 & 8.2359 \\
\hline
\end{tabular}

\subsubsection{Discussion and Regression}

Large variation is observed in the final local calibration parameters. The AC scaling parameter $\beta_{\mathrm{AC} 1}$ varied from 0.14 to $0.47, \beta_{\mathrm{AC} 2}$ varied from 0.975 to 1.738 and $\beta_{\mathrm{AC} 3}$ varied from 0.229 to 1.105. Because of the large difference in the percentage contribution from the subgrade soil based on the AASHO study and that from the MEPDG default model (9\% vs. 68\% as discussed previously), the subgrade soil parameter $\beta_{\mathrm{SG}}$ is extremely small, ranging from 0.016 to 0.050 . The major characteristics of reconstructed flexible pavement sections are shown in Table 4-7. 
For AC model regression between the results of the first stage results of $\beta_{\mathrm{AC} 1}^{(0)}$ with total AADTT, thickness of AC layer and average observed rutting in a pavement section give 0.779 correlation (Table $4-4)$.

$$
\beta_{\mathrm{AC} 1}^{(0)}=0.140-6.735 \times 10^{-9} \mathrm{AADTT}+6.199 \times 10^{-5} T_{\mathrm{AC}}+0.0602 \mathrm{PD}_{\mathrm{Avg}}
$$

where

AADTT $=$ Total AADTT expected at the end of pavement life

$T_{\mathrm{AC}}=$ Thickness of AC layer $(\mathrm{mm})$

$\mathrm{PD}_{\text {Avg }}=$ Average permanent deformation observed in subgrade $(\mathrm{mm})$

Table 4-4: Statistics of $\beta_{\mathrm{AC} 1}{ }^{(0)}$ regressed equation for reconstructed section.

\begin{tabular}{lr}
\hline \multicolumn{2}{c}{ Regression Statistics } \\
\hline Multiple R & 0.882 \\
R Square & 0.779 \\
Adjusted R Square & 0.668 \\
Standard Error & 0.105 \\
Observations & 10 \\
\hline
\end{tabular}

Meanwhile, since the AASHO study showed a major contribution of the total surface rutting was from the base and subbase layers, the granular base/subbase calibration parameter $\beta_{\mathrm{GB}}$ varies across the default value of 1 . The lowest value is 0.41 for section 376 while the greatest value 3.17 for section 43 . The lowest value of $\beta_{\mathrm{GB}}$ for section 376 can be explained as granular layer of this section has the maximum thickness $(870 \mathrm{~mm})$. The higher end values for $\beta_{\mathrm{GB}}$ of 3.165 and 3.062 for section 9 and 43 can be clarified due to presence of $100 \mathrm{~mm}$ cement treated OGDL (Open graded drainage layer) with $M_{\mathrm{R}}=13790 \mathrm{MPa}$. This cement treated layer of granular material provides a long term protection to the underneath granular layer. An average value 3.114 can be used for granular OGDL cement treated layer. Similarly, the influence of thickness of AC layer is also evident from the locally calibrated parameter. The section 376 and 1311 (Table 4-2) has the lowest values for $\beta_{\mathrm{GB}}$ calibrated parameter due to presence of a thin AC layer protection. Regression for granular layer calibrated parameters with thickness of granular layer, 
equivalent resilient modulus, AADTT and thickness of AC layer showed a good correlation (0.93). However, this correlation becomes 0.617 (Table 4-5) when two OGDL pavement sections (outliners) are removed from data set, which shows that more data is needed to come to any solid conclusion for granular layer.

$$
\beta_{\mathrm{GB}}=2.74-0.00285 T_{\text {gran }}-0.00304 M_{\text {eqv }}-4.2 \times 10^{-10} \mathrm{AADTT}+0.00267 T_{\mathrm{AC}}
$$

where

$$
\begin{aligned}
& T_{\text {gran }}=\text { Total thickness of granular layer }(\mathrm{mm}) \\
& M_{\text {eqv }}=\text { Equivalent resilient modulus of granular layer (MPa) }
\end{aligned}
$$

Table 4-5: Statistics of $\beta_{\mathrm{GB}}$ regressed equation for reconstructed section.

\begin{tabular}{lr}
\hline \multicolumn{2}{c}{ Regression Statistics } \\
\hline Multiple R & 0.786 \\
R Square & 0.617 \\
Adjusted R Square & 0.107 \\
Standard Error & 0.419 \\
Observations & 8 \\
\hline
\end{tabular}

Regression of subgrade layer calibrated parameters was done on the basis of subgrade modulus and the average observed permanent deformation in a pavement section. Subgrade layer calibrated parameter showed very good correlation (0.967) with subgrade modulus and average observed rutting in a pavement section. Regressed equation obtained is as follows

$$
\beta_{\mathrm{SG}}=-0.02171+0.000917 M_{\mathrm{r}}+0.005412 \mathrm{PD}_{\mathrm{Avg}}
$$

where

$M_{r}=$ Resilient Modulus of Subgrade layer (MPa)

Table 4-6: Statistics of $\beta_{\mathrm{SB}}$ regressed equation for reconstructed section.

\begin{tabular}{lr}
\hline \multicolumn{2}{c}{ Regression Statistics } \\
\hline Multiple R & 0.983 \\
R Square & 0.967 \\
Adjusted R Square & 0.958 \\
Standard Error & 0.002 \\
Observations & 10 \\
\hline
\end{tabular}


It shows that the prediction of rutting in $\beta_{\mathrm{SB}}$ is mainly depended on these two factors. The average observed rutting in subgrade is the same rutting used for calibration of these models. Average permanent deformation is not available while designing a new pavement section, however in case of a reconstructed pavement section average rutting in subgrade of last 4-6 years rutting information can be used.

The averages of optimal values for the five calibration parameters of the ten sections are $\beta_{\mathrm{AC} 1}=0.290, \beta_{\mathrm{AC} 2}=1.209, \beta_{\mathrm{AC} 3}=0.810, \beta_{\mathrm{GB}}=1.455$ and $\beta_{\mathrm{SG}}=0.034$. The reason for the large variation in the local calibration parameters is not clear and it needs further study in future. It is observed that except for sections 1200 and 1311, the local calibration results in very small bias and RSS. For all sections, the percentage layer contributions averaged along the observational life has maintained to be consistent with the pre-defined percentage contributions of the AASHO study.

Table 4-7: Major Input Characteristics of Reconstructed pavement sections.

\begin{tabular}{|c|c|c|c|c|c|c|c|c|c|}
\hline $\begin{array}{c}\text { PMS-2 } \\
\text { Section } \\
\text { I.D. }\end{array}$ & Zone & Highway & $\begin{array}{c}\text { Design } \\
\text { life } \\
\text { (years) }\end{array}$ & $\begin{array}{c}\text { Total } \\
\text { AADTT }\end{array}$ & $\begin{array}{c}\text { No. of } \\
\text { Total } \\
\text { Layers }\end{array}$ & $\begin{array}{c}\text { Total } \\
\text { AC } \\
\text { thickness } \\
\text { (mm) }\end{array}$ & $\begin{array}{c}\text { Top } \\
\text { AC } \\
\text { layer }\end{array}$ & $\begin{array}{c}\text { Total } \\
\text { Granular } \\
\text { thickness } \\
(\mathbf{m m})\end{array}$ & $\begin{array}{c}\text { Subgrade } \\
\text { Modulus } \\
\text { (MPa) }\end{array}$ \\
\hline 9 & SO & 1 & 11 & $17,025,000$ & 6 & 260 & DFC & 400 & 35 \\
\hline 43 & SO & 1 & 11 & $22,700,000$ & 6 & 260 & DFC & 400 & 35 \\
\hline 191 & SO & 7 & 18 & $7,208,550$ & 6 & 330 & HL-1 & 450 & 40 \\
\hline 376 & NO & 11 & 11 & $2,634,600$ & 5 & 130 & HL-1 & 870 & 27.6 \\
\hline 1049 & SO & 401 & 14 & $52,901,200$ & 4 & 250 & DFC & 640 & 38 \\
\hline 1053 & SO & 401 & 9 & $18,650,400$ & 5 & 240 & DFC & 650 & 15 \\
\hline 1188 & SO & 402 & 10 & $7,809,230$ & 6 & 220 & HL-1 & 600 & 31 \\
\hline 1189 & SO & 402 & 11 & $8,522,460$ & 6 & 220 & HL-1 & 600 & 25 \\
\hline 1200 & SO & 402 & 11 & $8,190,480$ & 6 & 220 & HL-1 & 600 & 25 \\
\hline 1311 & SO & 417 & 10 & $3,921,290$ & 6 & 140 & HL-1 & 600 & 17.2 \\
\hline
\end{tabular}




\subsubsection{Comparison with Pooled and Global Calibration}

For comparison purpose, a pooled longitudinal calibration was also performed. The pooled calibration was the common approach that was seen reported in previous local calibration studies. Basically the rutting data from different sections are all pooled together to calculate the total RSS which is then minimized a single set of optimal calibration parameters. In this study, the two exponent parameters $\beta_{\mathrm{AC} 2}$ and $\beta_{\mathrm{AC} 3}$ were kept constant at 1 . The total RSS was minimized at $\beta_{\mathrm{AC} 1}=0.3, \beta_{\mathrm{GB}}=0.8$ and $\beta_{\mathrm{SG}}=0.03$, which are different from the averaged value in the section-by-section calibration, particularly for $\beta_{\mathrm{GB}}$. This gap between the pooled and average $\beta_{\mathrm{SG}}$ can significantly reduce by not including two sections ( 9 and 43) with OGDL.

The section-by-section RSS based on the pooled calibration are also shown in Table 4-8. In terms of layer RSS and total RSS, the residuals from the pooled calibration are much greater than those from the section-by-section calibration.

Table 4-8: RSS of Reconstructed sections based on the Pooled local calibration results.

\begin{tabular}{|c|c|c|c|c|}
\hline SC I.D. & $\begin{array}{c}\text { AC } \\
\text { Rutting }\end{array}$ & $\begin{array}{c}\text { Granular } \\
\text { Rutting }\end{array}$ & $\begin{array}{c}\text { Subgrade } \\
\text { Rutting }\end{array}$ & Total Rutting \\
\hline $\mathbf{9}$ & 4.06 & 21.88 & 0.01 & 8.67 \\
\hline $\mathbf{4 3}$ & 7.61 & 23.45 & 0.01 & 5.49 \\
\hline $\mathbf{1 9 1}$ & 1.68 & 7.80 & 0.04 & 18.38 \\
\hline $\mathbf{3 7 6}$ & 1.83 & 47.89 & 0.07 & 36.51 \\
\hline $\mathbf{1 0 4 9}$ & 10.95 & 2.14 & 0.06 & 5.45 \\
\hline $\mathbf{1 0 5 3}$ & 2.14 & 2.93 & 0.54 & 14.78 \\
\hline $\mathbf{1 1 8 8}$ & 2.63 & 6.86 & 0.13 & 20.69 \\
\hline $\mathbf{1 1 8 9}$ & 4.72 & 14.97 & 0.19 & 41.59 \\
\hline $\mathbf{1 2 0 0}$ & 19.84 & 58.13 & 0.94 & 169.59 \\
\hline $\mathbf{1 3 1 1}$ & 6.74 & 6.25 & 0.30 & 8.08 \\
\hline Subtotal & $\mathbf{6 2 . 2 0}$ & $\mathbf{1 9 2 . 3 0}$ & $\mathbf{2 . 2 9}$ & $\mathbf{3 2 9 . 2 4}$ \\
\hline
\end{tabular}


Comparison plot for residual errors (Figure 4.4) of predicted total rut depth showed that for section by section calibration residuals errors were equally scattered on both sides of zero line, whereas for pooled calibration for total rut less than $5 \mathrm{~mm}$ observed rutting were larger than predicted rutting and vice versa. Another way of comparing the two calibration approaches are through the prediction versus observation plots (Figure 4.5). The section-by-section calibration gave exceptionally efficient results with a $\mathrm{R}^{2}$ value of 0.88 which shows extreme correlation between the predicted and observed values. As expected, the pooled calibration shows extremely poor correlation (0.016) with relatively high standard error of 2.217. Similarly, for comparison purpose prediction versus observed plots for asphalt concrete, granular and subgrade layer were plotted in Figure 4.6. All layers plots gave similar correlation value, however the standard error in each layer was distributed according to the percentage contribution of rutting used to obtain observed rutting in each layer. The highest standard error was in granular layer of 0.336, while standard error in asphalt and subgrade layer was 0.240 and 0.0515 .

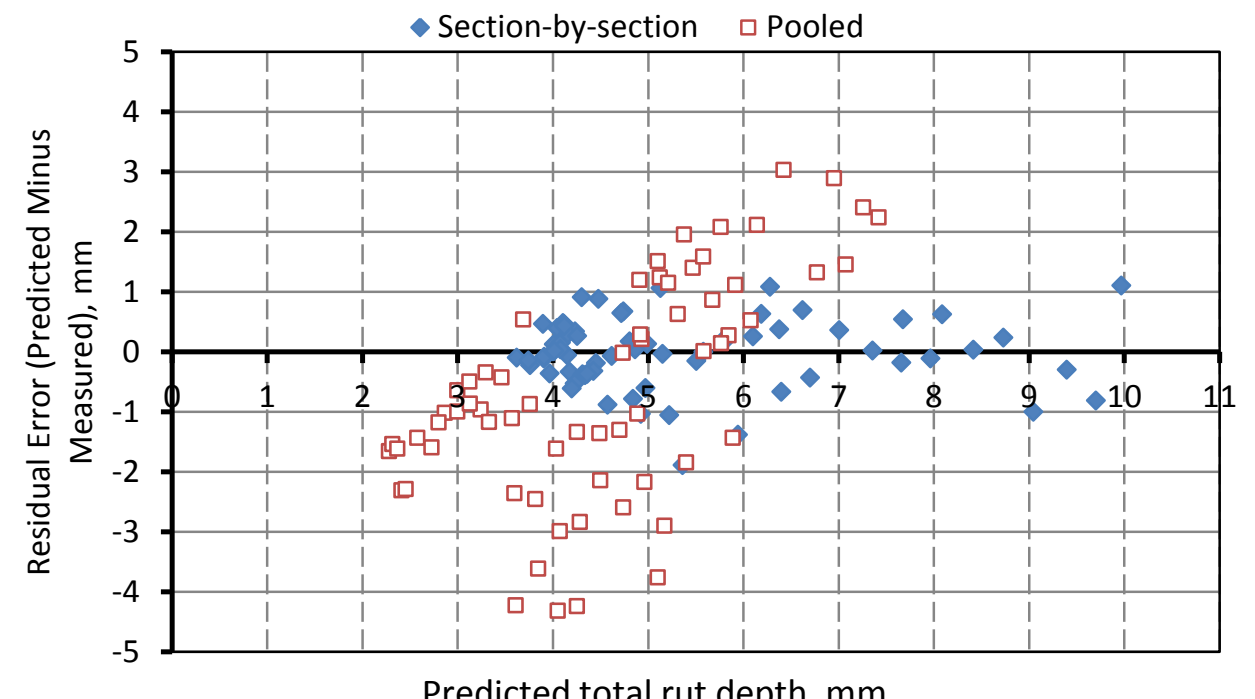

Figure 4.4: Residual Errors for total predicted rut depth after calibration for reconstructed sections. 

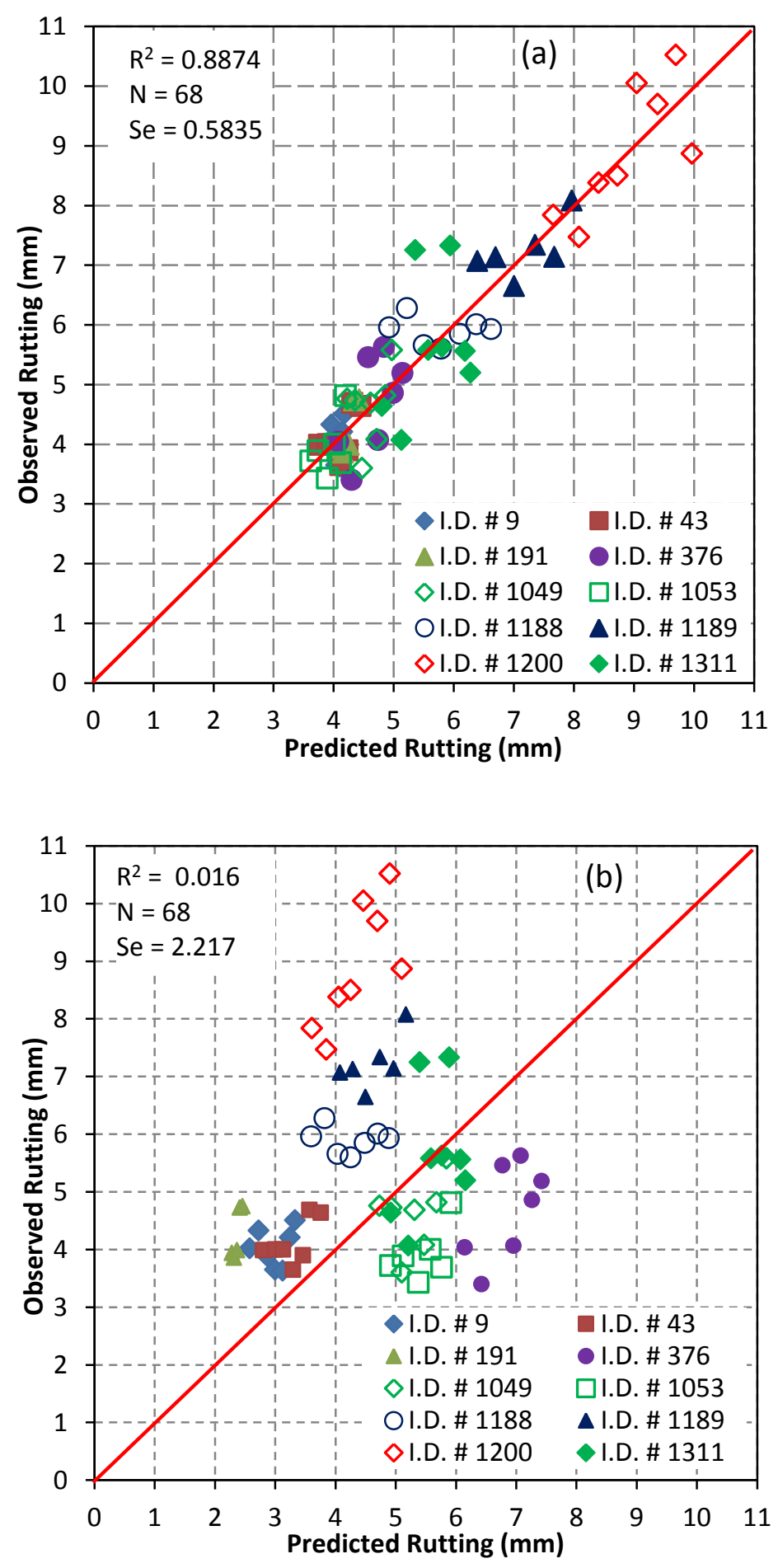

Figure 4.5: After-calibration prediction versus observation plots. (a) section-by-section calibration; (b) pooled calibration. 

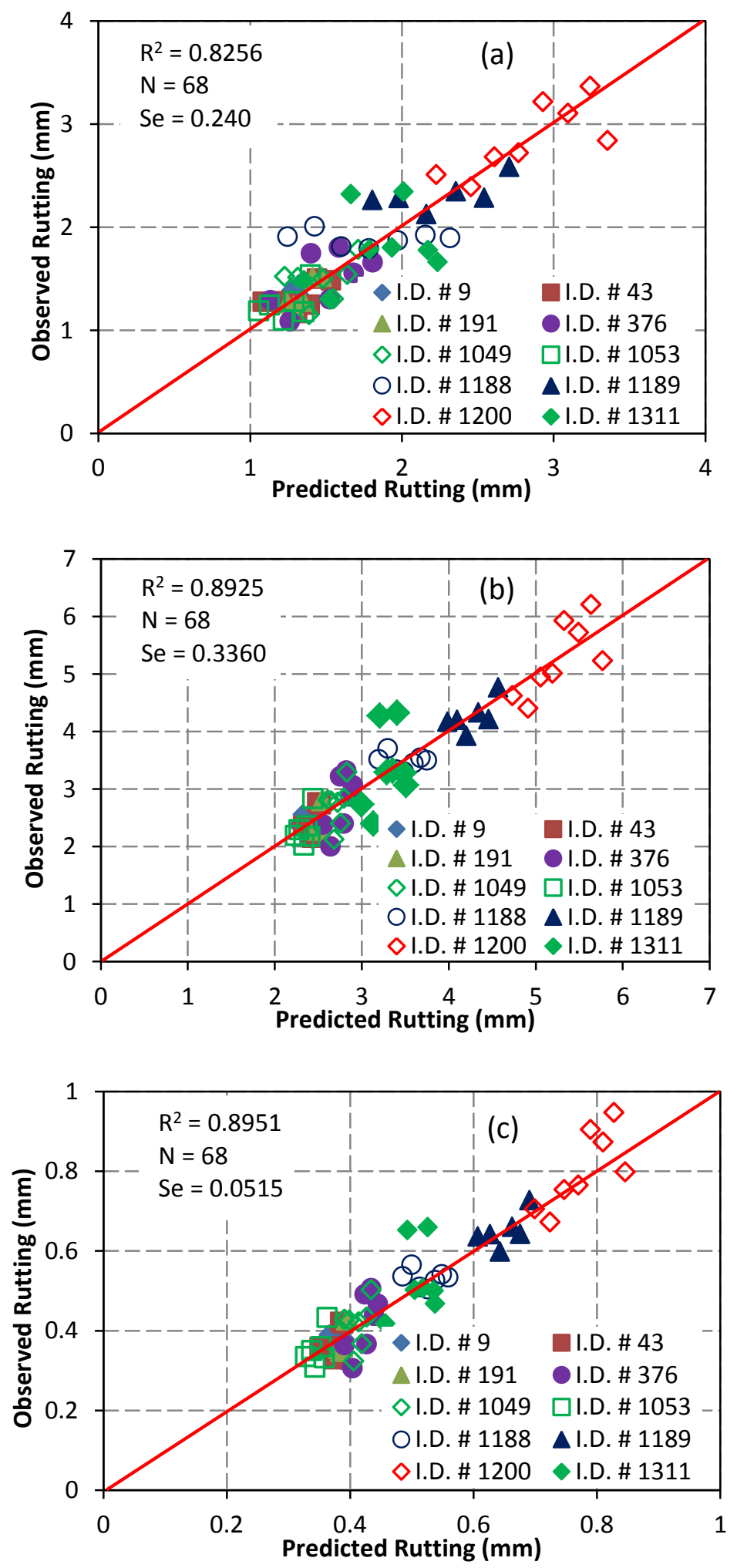

Figure 4.6: After- section-by-section calibration prediction versus observation plots. (a) Asphalt concrete layer; (b) Granular layer (c) Subgrade layer. 
Longitudinal comparison of predicted layer rutting for section 376 is shown in Figure 4.7. While the section-by-section calibration provides accurate prediction, the predicted rutting based on the pooled calibration is far off from the observed rutting as compared to AC or Subgrade rutting predictions. Predictions from global models are not included in this comparison as they extremely over predict the rutting for all layers.
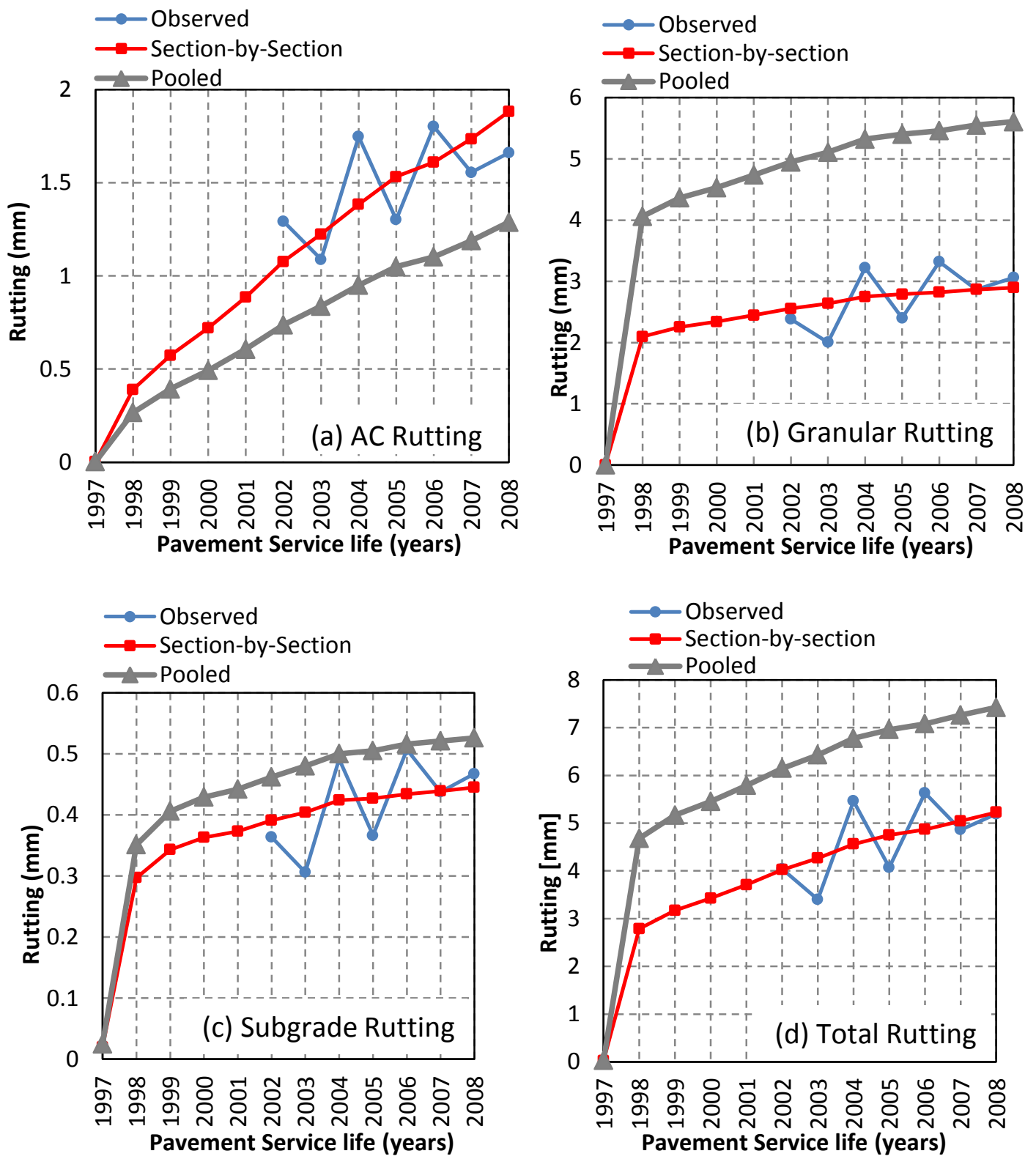

Figure 4.7: Longitudinal comparison of section-by-section and pooled calibration of section 376. 
The two local calibration results are also compared with the global calibration results in terms of the standard deviation. As shown in Table 4-9, it is argued that although the pooled calibration revealed very poor correlation between the predicted and observed rutting, the resulting overall standard deviation $(2.22 \mathrm{~mm})$ is actually comparable to the result from the global calibration, which was based on a much larger data set. It is also argued that the small standard deviation in section-by-section longitudinal calibration $(0.58 \mathrm{~mm})$ may be an underestimate of the uncertainty involved in local calibration, because the errors involved in point-by-point rut depth measurements and post processing of the point data can be much greater than this value. This brings up an issue of over-calibration in local calibration exercise. However, the current local calibration Guide (AASHTO 2010) did not provide much guidance in addressing this issue. Further study is obviously needed.

Table 4-9: Comparison of Statistics of Global calibration and Local calibration.

\begin{tabular}{|c|c|c|c|c|}
\hline Parameters & $\begin{array}{c}\text { Global calibration } \\
\text { (NCHRP 2004) }\end{array}$ & $\begin{array}{c}\text { Global calibration } \\
\text { (AASHTO 2008) }\end{array}$ & $\begin{array}{c}\text { Section-by-section } \\
\text { local calibration }\end{array}$ & $\begin{array}{c}\text { Pooled local } \\
\text { calibration }\end{array}$ \\
\hline Number of data points & 387 & 334 & 68 & 68 \\
\hline Standard deviation (mm) & 3.07 & 2.72 & 0.584 & 2.22 \\
\hline$R^{2}$ & 0.399 & 0.577 & 0.887 & 0.016 \\
\hline
\end{tabular}




\section{CHAPTER 5 LOCAL CALIBRATION OF REHABILITATED FLEXIBLE PAVEMENTS}

\subsection{Introduction}

This chapter presents the results of local calibration of 19 rehabilitated flexible pavements using the local calibration methodology in Chapter 3. It further presents results of comparison with a pooled calibration of same rehabilitated pavement section. But before local calibration, evaluation of the pre-overlay or pre-rehabilitation rut is performed, which is an important input parameter for rehabilitated pavement sections.

\subsection{Evaluation of Pre-overlay Rut}

In Ontario, a vast majority of roads have flexible pavements, and a main portion of them are rehabilitated sections. Various sensitivity analyses have indicated that pre-overlay rut was a very important parameter that has significant influence on the calculation of total surface permanent deformation of rehabilitated sections. Here, the pre-overlay rut refers to the terminal rut depth at the end of previous life cycle of a rehabilitated flexible pavement section. Previous local calibration studies have overlooked this input parameter because most of the studies used LTPP data, in which for rehabilitated sections the pre-overlay rut depths were often available, thanks to the good quality assurance program in LTPP.

Unfortunately, the actual rutting values were not measured in Ontario until 2002, while the majority of PMS-2 flexible pavement sections started their life cycles (either new or rehabilitated) before 2002. On the other hand, conflicting evidences were found during literature review in the hope of finding some 'Level-3' value for this particular input parameter. Clearly, an uncertain pre-overlay rut would result in an inefficient local calibration. Therefore, an investigation is needed to develop some guidelines and criteria for determining the pre-overlay rut value for rehabilitated flexible pavements for local calibration in Ontario. The ultimate goal of the investigation is to minimize the impact of an uncertain pre-overlay rut value on the accuracy of level-1 local calibration. This investigation is done based on the MTO's PMS-2 data. 


\subsubsection{Previous Work}

Among the large body of literature of local calibration of the MEPDG, a few important studies are mentioned here t to better understand the pre-overlay rut and the uncertainty associated with it.

For Washington, Li et al. (2009) divided the region in two parts Western and Eastern Washington. Different design parameters and distress data for calibration sections were used for these two regions. The pavement distress conditions on the design lane right before the first overlay were also different, pre-overlay rut value of 0.18 in $(4.572 \mathrm{~mm})$ and $0.32 \mathrm{in}(8.128 \mathrm{~mm})$ was used for Western and Eastern regions of Washington.

Hall et al. (2011) performed an initial local calibration for flexible pavements for the state of Arkansas using LTPP and PMS database. In his study on average 0.18 in $(4.83 \mathrm{~mm})$ total rut was observed in the calibrated pavement sections. $80 \%$ rutting was from 0.1 in $(2.54 \mathrm{~mm})$ to 0.3 in (7.62 mm) suggesting that "rutting measurement (typically by straightedge) were recorded as a maximum of 0.3in regardless of actual measurements. "(Hall et al. 2011). This statement shows the possibility of uncertainty in measurement of rutting values due to limitations of the straightedge instrument.

He et al. (2011) evaluated globally calibrated rutting models based on Alberta's PMS data. They used input level 3 for pre-rehabilitation condition. Pre-rehabilitation rut of $5.8 \mathrm{~mm}$ with rehabilitation condition 2 (Good) was used for pavement sections with milling before overlay, while $5.6 \mathrm{~mm}$ with rehabilitation condition of 3 (Fair) was used for straight overlays sections. They concluded that globally calibrated models had close predictions for straight overlays and under predicted rutting for sections with milling before overlays.

The AASHTO Manual of Practice of the MEPDG (AASHTO 2008) reviews a detailed stepby-step plan for assessment of existing pavement condition, or pre-rehabilitation condition assessment. It also provides hierarchical input levels for pavement evaluation for rehabilitation design. The pavement is evaluated on the basis of multiple categories e.g. structural and material durability, functional adequacy subsurface drainage conditions, sectional variations and other miscellaneous constraints. 
As previously mentioned Jannat (2012) did a study on Database Development for Ontario`s local calibration of MEPDG distress models. In her study, Pre-overlay rut of $4 \mathrm{~mm}$ was used for section cycles when pre-rehabilitation rut was unknown. Further a pre-rehabilitation condition rating of "Fair" or 3 was used in her research for Ontario sections. She concluded that globally calibrated models over predicts rut depth for flexible pavement sections in Ontario.

\subsubsection{Effects of Pre-Overlay Rut}

In the MEPDG rutting is estimated for each sub-season at the mid-depth of each sub-layer within the pavement structure to account for the different incremental permanent deformation under different traffic loading and material aging effects of various environmental factors (e.g., moisture and temperature) (AASHTO 2008). A strain-hardening principle defines the calculation of the cumulative permanent deformation. Figure 5.1 illustrates schematically the strainhardening rule for rehabilitated section. The broken line shows the conceived rut growth for existing layers. The actual rut depth of the pavement after rehabilitation should include the permanent deformation developed in the new overlays and any new deformation in the existing layers. However, due to the cumulative nature of the permanent deformation of pavement materials, to determine the added plastic deformation needs the knowledge of the historical information, which is often unavailable at the time of overlay design.

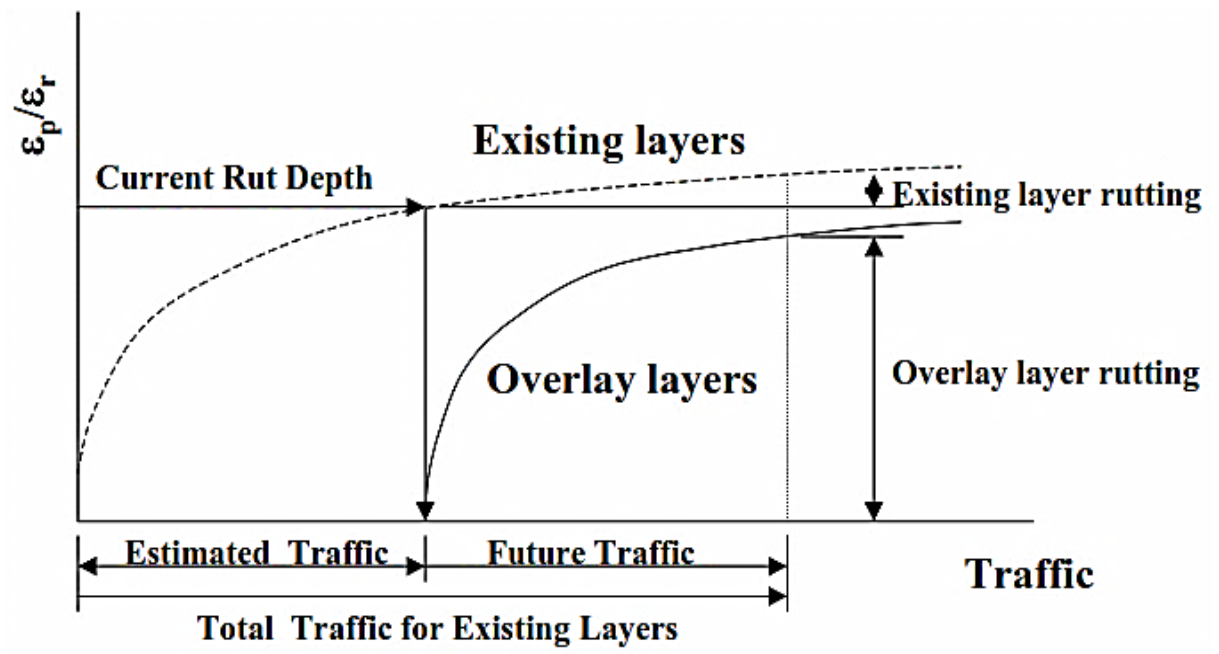

Figure 5.1: Effect of pre-overlay traffic on accumulation of rutting (after NCHRP (2004)) 
The approach that the MEPDG takes to estimating the missed rutting history in Figure 5.1 is to evaluate the pre-overlay rut depth from condition assessment of existing pavements. Ideally, a trench investigation should be done to determine the terminal rutting at different pavement structure layers. This information is then used to estimate the traffic, based on which the position at the broken line can be determined. Finally, the new rutting on the existing layers can be estimated by deducting the pre-overlay rut depth.

Of course, rarely have trench investigations been done. Realizing this hard-to-be-justified requirement, the MEPDG further provides an alternative but much easier solution: to obtain only the terminal total rut depth before rehabilitation. Using this total rut value, the DARWin-ME ${ }^{\mathrm{TM}}$ applies some default proportional values to estimate the rut at each layer. The subsequent steps are then the same as described in the preceding paragraph. Those default proportional values are tabulated and made available in (NCHRP 2004). The MEPDG also recommends that all agencies develop a similar kind of table. Note that this table is different from percentages specified by AASHO Road Test. Results of the AASSHO Road Test showed that generally $9 \%$ of total flexible pavement rutting is occurred in subgrade (Huang 2004). As another side remark, the preoverlay rut from a trench investigation corresponds to a Level 1 input, whereas the total surface rut plus default proportioning table is considered as a Level 3 input.

As the pre-overlay rutting values increases, the base and subgrade becomes stiff due to strain hardening. This results in lower rut values in base and subgrade during life of the subsequent overlay life cycle. Figure 5.1 shows that, due to the hardening effect of traffic prior to the overlay, the greater is the pre-overlay rutting, the slower the rutting in existing layers accumulates during the overlay period (NCHRP 2004).

Sensitivity analysis was done in order to evaluate the effect of this input parameter for a typical rehabilitated flexible pavement (section 951). Results of this sensitivity study are shown in Figure 5.2. Clearly, for this particular section of 11 years life, the terminal rut depth at the year of 2009 varies from about $5 \mathrm{~mm}$ to more than $8 \mathrm{~mm}$ when the pre-overlay rut depth is taken in the range of $4 \mathrm{~mm}$ and $12 \mathrm{~mm}$. This figure also shows that by increasing the pre-overlay rut, the rate of increase in the terminal rut is decreasing. 


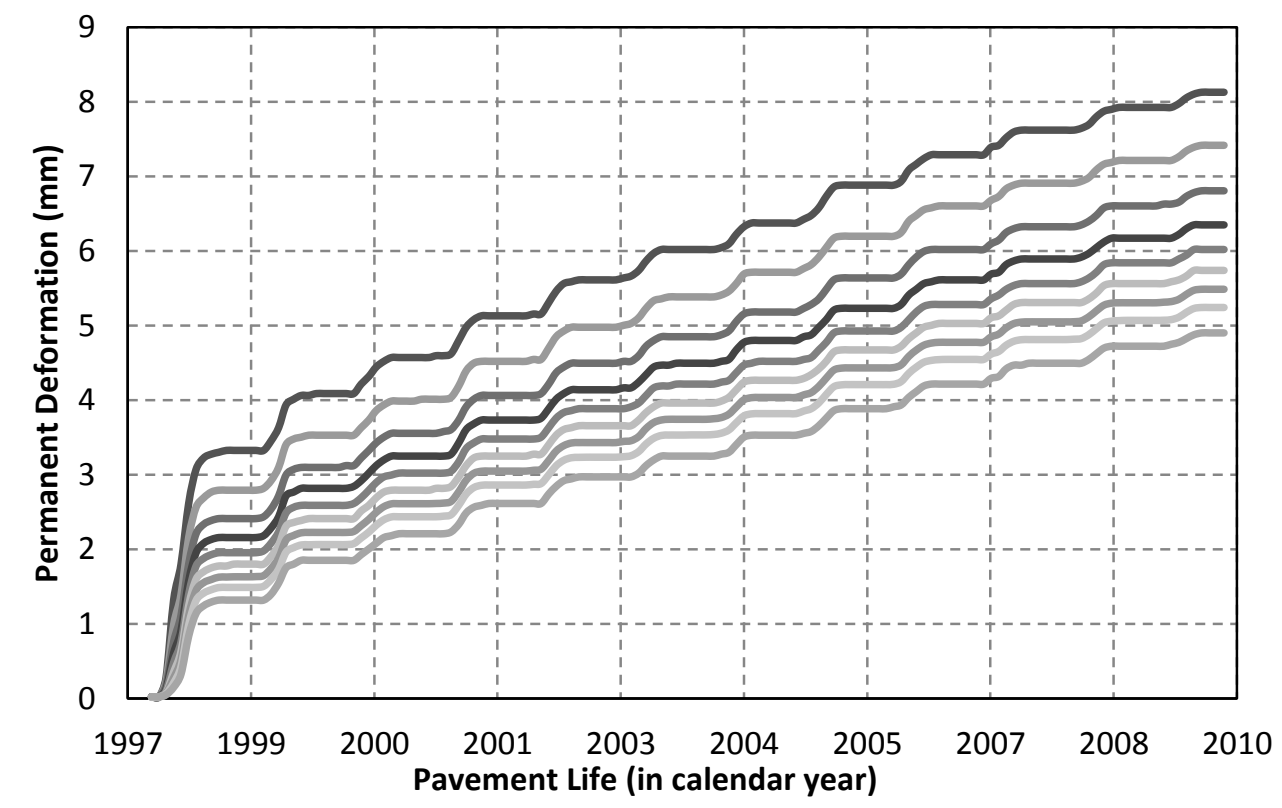

Figure 5.2: Sensitivity of permanent deformation to pre-overlay rut value (ranging from $4 \mathrm{~mm}$ at the top to $12 \mathrm{~mm}$ at the bottom) for a typical rehabilitated flexible pavement

\subsubsection{Approaches}

Since reliable rut depth readings were only available in PMS-2 after 2004 and included. Therefore, any rehabilitated pavement sections selected for local calibration of which the life cycle starts before 2004 have no pre-overlay rutting information. To estimate this important parameter, three approaches are taken in this study:

1) Frequency analysis, from which the summary statistics and variability of the preoverlay rut depth is also calculated;

2) Regression analysis, in which the empirical relationships between the rut depth and DMI and RCI are developed, with the hope that the pre-overlay rut depth, if needed and yet unavailable, can be predicted from the so established regression equations; and-

3) Scenario analysis. For this purpose, 51 rehabilitated pavement sections from both Southern and Northern Ontario were selected to investigate whether a general trend between the observed and predicted rutting values at different pre-overlay rut depths can be observed. The geographical locations of the selected sections are shown in Figure 4.1. 


\subsubsection{Statistical Estimation of Pre-overlay Rut Depth}

\subsubsection{Criteria for Identification of Pre-overlay rut}

Pre-overlay rut or terminal rut data was collected from PMS-2 database of Ontario. Identification of pre-overlay rut was not clearly evident in data due to inconsistencies; therefore identification of pre-overlay rut was done by two approaches.

In first approach, maximum rutting values from each section cycle of all pavements was selected and treated as the pre-overlay. Then it was make sure that not to include incomplete section cycles as the rut values corresponding to these section cycles would not be the end of cycle or pre-overlay value. Drawback of this approach due to discrepancies in the data, occasionally a maximum rut value does not means the end of pavement life. End of pavement life cycle dictated by DMI and RCI.

Therefore, in the second approach the identification was done on the basis of DMI and RCI. Rationally, DMI value of pavement should decrease supposing no major maintenances have been done during pavement life. Therefore, abrupt increase of DMI is an indication of an overlay and rutting value corresponding to the previous year was identified as the pre-overly rut of this section. All pre-overlay rut of sections was identified on the basis of same concept. In this identification process it was also confirmed not to include incomplete section cycle because rut values corresponding to these section cycles would not be the end of cycle or pre-overlay rut value.

\subsubsection{Frequency Distribution}

Frequency distribution is one of the most basic types of statistical analysis for any type of data. The rut data from the flexible pavement sections in the PMS-2 were analyzed. A total of 1175 flexible pavement sections identified from the first approach of identification of pre-overlay rut (based on maximum rut values). For each section, maximum rut depth of the life-cycle treated as the terminal rut depth because maximum rut is generally the pre-overlay rut when no intermediate rehabilitation has been performed. Finally, these pre-overlay rut values were used to construct a histogram, shown in Figure 5.3. Table 5-1 presents some other statistical parameters of the frequency distribution. On the basis of frequency distribution, a mean value of $7 \mathrm{~mm}$ can be used as a Level 3 input for the pre-overlay rut value for pavement sections in Ontario that 
does not have any reliable surface rut information available. Similar results were obtained from the frequency distribution of second identification approach (based on DMI and RCI), therefore results are not included here.

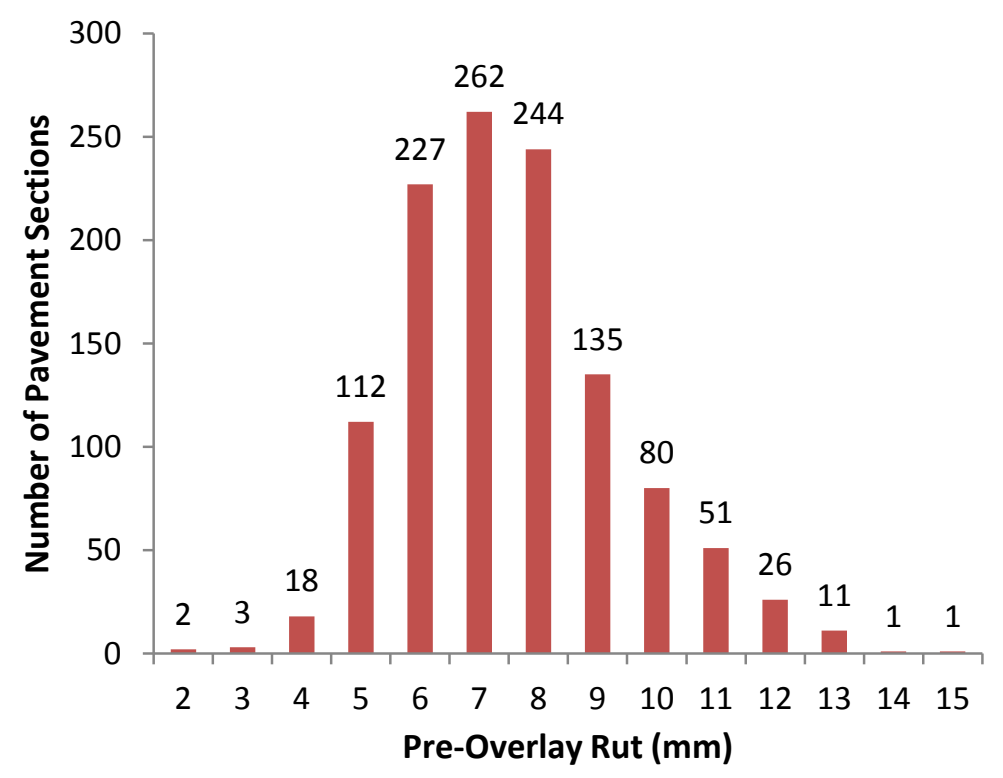

Figure 5.3: Histogram of the life-cycle maximum rut depth from PMS-2 database

\subsubsection{Regression Analysis}

The pre-overlay rut values may be better predicted if some empirical relationship can be established with other more readily available data such as DMI and RCI. Note that PCI is not used because PCI is essentially a mathematical function of DMI and RCI. The IRI is not used either, because the RCI in recent years was also a function of IRI. Based on a set of data from 864 pavement sections from the PMS-2 database, the regression analysis of the rut depth expressed by the DMI and RCI were conducted. Unfortunately, regression did not result in a very good fit with a R2 value of only 0.22 . The regression analysis of pre-overlay rutting as well as total rutting with DMI and RCI showed poor correlation. This poor correlation could be explained due to the element that; a) the DMI and RCI is subjective in nature and b) in field DMI is not only dependent on rut depth but a collective factor for many distresses like transverse cracking, longitudinal cracking etc. 
Regression statistics are shown in Table 5-2. Comparing the standard deviation $(1.835 \mathrm{~mm})$ in Table 5-1 and the standard error $(1.600 \mathrm{~mm})$ in Table 5-2, reduction of variation of the rut depth is very limited. This poor fitness of this data can be explained by many factors as the both DMI and RCI (before 1997) are subjective values. These analyses were done by using constant preoverlay rut for one group. Because of this, the use of the regression result does not seem to be promising. Thus, a further analysis is carried out to investigate the effects of the pre-overlay rut on local calibration.

Table 5-1: Parameters of Frequency distribution for Pre-overlay rut

\begin{tabular}{l|l}
\hline Functions & Total Rut \\
\hline Minimum & 2.360 \\
Maximum & 15.333 \\
Mean & 7.053 \\
Mode & 6.261 \\
Standard Deviation & 1.835 \\
\hline
\end{tabular}

Table 5-2: Regression Statistics of Rut depth with RCI and DMI

\begin{tabular}{l|l}
\hline \multicolumn{2}{c}{ Regression Statistics } \\
\hline Multiple R & 0.476 \\
R Square & 0.227 \\
Adjusted R Square & 0.225 \\
Standard Error & 1.60 \\
Observations & 864 \\
\hline
\end{tabular}

\subsubsection{Scenario Analyses}

DARWin-ME ${ }^{\mathrm{TM}}$ analyses with the default global models were performed for different preoverlay rut depths ranging from 4 to $12 \mathrm{~mm}$ at an incremental step of $1 \mathrm{~mm}$. According to MTO pavement condition rating manual, wheel-path rut severity at these range of rutting values are from very slight to slight class (Chong et al. 1989). The number of AC layers in those pavement sections varies from 2 to 7 , showing that some sections have undergone through multiple rehabilitation activities in their service history. The starting value of $4 \mathrm{~mm}$ was selected because it was recommended by the MTO staff (Jannat 2012). A total of 51 x $9=459$ pavement simulations were run for this study. The end of life observed rutting was then compared with the 
DARWin-ME ${ }^{\mathrm{TM}}$ predicted rutting. The results are summarized in Figure 5.4. More statistics are shown in Table 5-3.

Over prediction of total rutting when pre-overlay rut of $4 \mathrm{~mm}$ is used is evident from the results show in Figure 5.4 (a). Similar results were also predicted by (Jannat 2012), where only 9 rehabilitated pavement sections were under predicting rutting values. Although the trend of over prediction of rutting was visible throughout Ontario but it was more clearly observed in Northern Ontario, where 14 out of 16 new and rehabilitated pavement sections were over predicting the rutting values. While only 2 of the 9 under predicted pavement sections were from Northern Ontario showing even a severe over prediction trend particularly for Northern Ontario.

As the frequency distributions showed the mean max rut value is $7 \mathrm{~mm}$, therefore all 51 rehabilitated pavement sections were reanalyzed with a pre-overlay rut value of $7 \mathrm{~mm}$. Comparison of observed with predicted rut values is shown in Figure 5.4 (d). In this case, the bias was reduced to $0.477 \mathrm{~mm}$, in contrast of the $3.206 \mathrm{~mm}$ bias for pre-overlay of $4 \mathrm{~mm}$. This significant improvement in bias was the reason that triggers this study to analyze more variations of rut depth.

Comparison of the graphs in Figure 5.4 shows that the simple regression relationship between the observed rutting and predicted rutting is converged after the pre-overlay rut is greater than 8 mm. This is a very interesting observation, which, to the author's best knowledge, was not reported in earlier literature. Comparison of Table 5-3 further shows that pre-overlay rut of $8 \mathrm{~mm}$ leads to a minimum bias among the 51 pavement sections, whereas a selection of $9 \mathrm{~mm}$ leads to the least root mean square error (RMSE). These all suggest that for future local calibration, a preoverlay rut of 7 to $9 \mathrm{~mm}$ can be taken, which will improve accuracy and precision of rut prediction of globally calibrated model. 


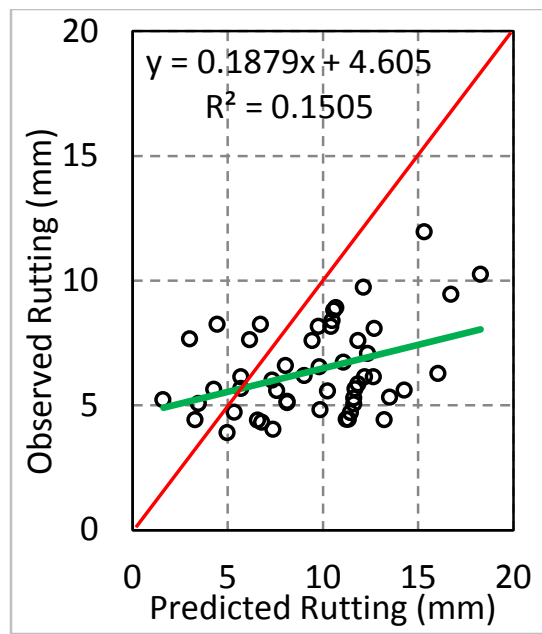

(a) Pre-overlay rut $=4 \mathrm{~mm}$

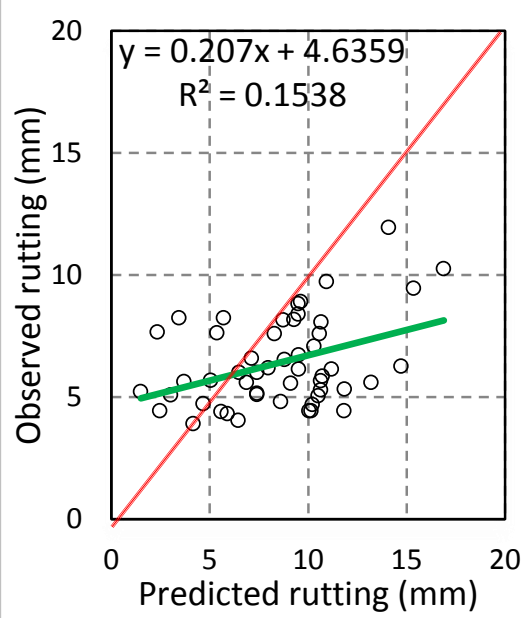

(b) Pre-overlay rut $=5 \mathrm{~mm}$

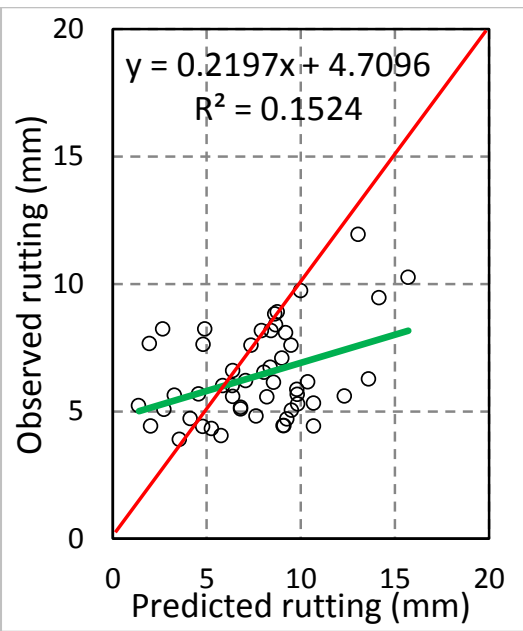

(c) Pre-overlay rut $=6 \mathrm{~mm}$
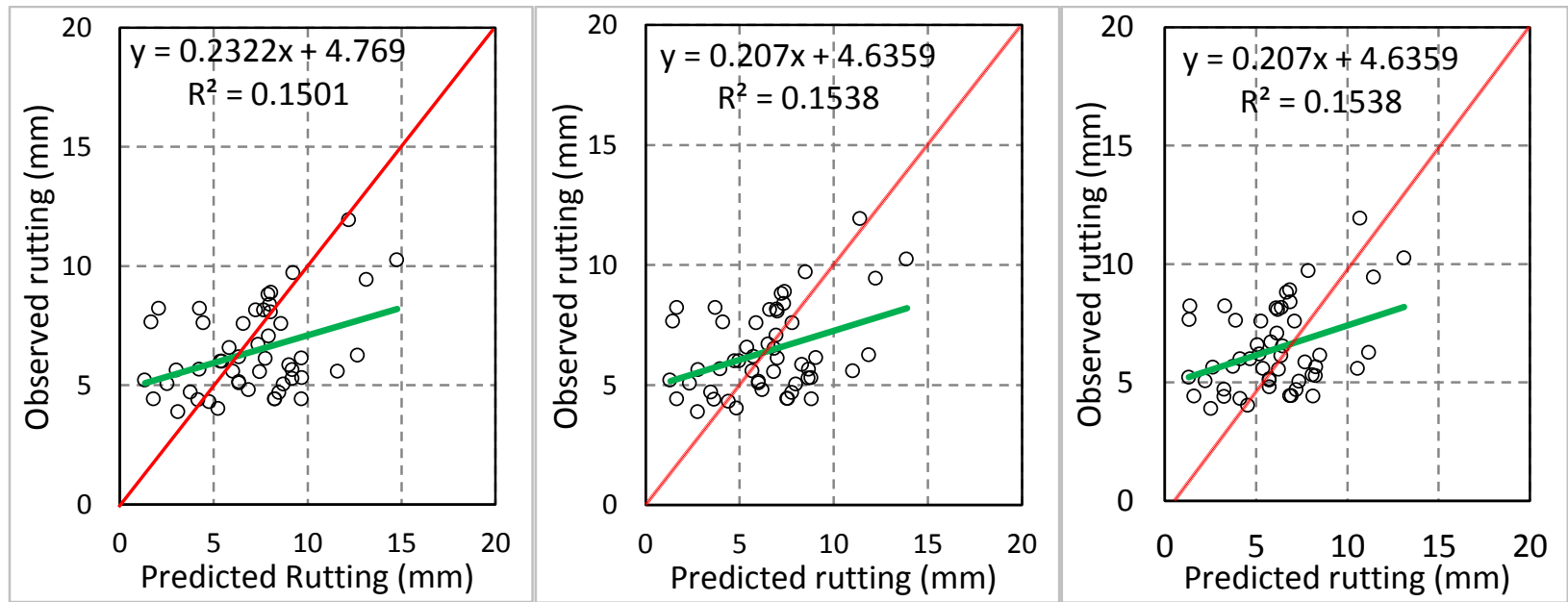

(d) Pre-overlay rut $=7 \mathrm{~mm}$

(e) Pre-overlay rut $=8 \mathrm{~mm}$

(f) Pre-overlay rut $=9 \mathrm{~mm}$

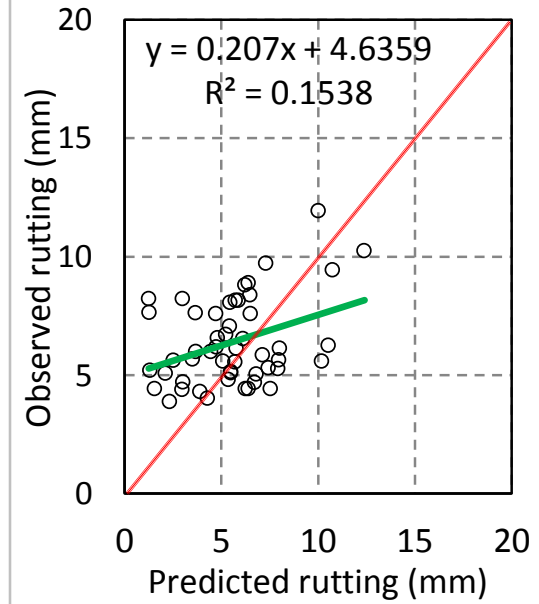

(g) Pre-overlay rut $=10 \mathrm{~mm}$

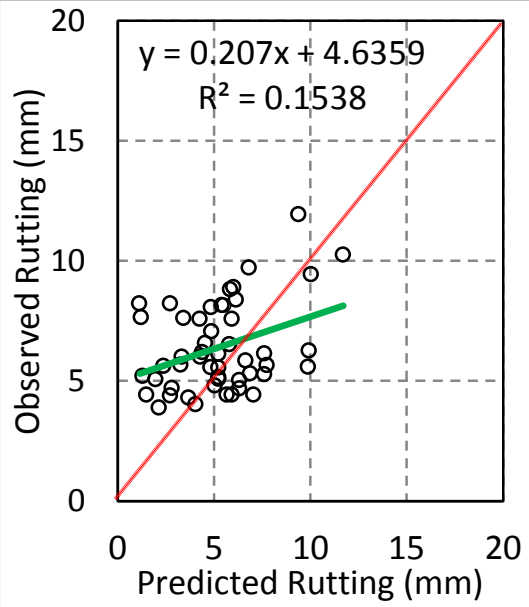

(h) Pre-overlay rut $=11 \mathrm{~mm}$

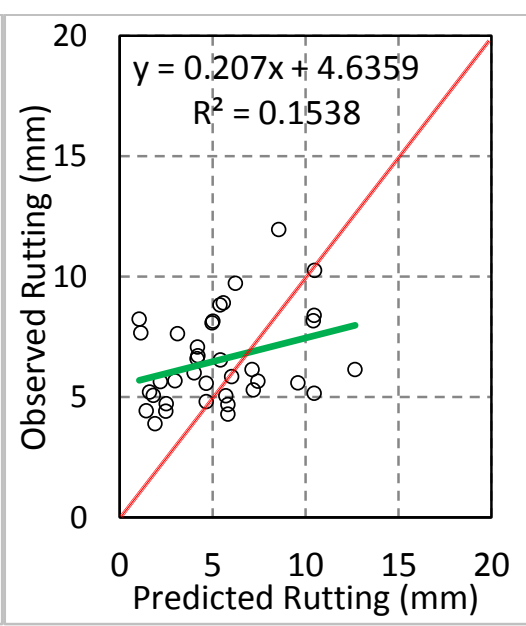

(i) Pre-overlay rut $=12 \mathrm{~mm}$

Figure 5.4: Comparison of predicted with observed rut depth 
Table 5-3: Regression analysis results for multiple Pre-overlay Rut values.

\begin{tabular}{l|lllllllll}
\hline \multirow{2}{*}{ Parameter } & \multicolumn{8}{|c}{ Pre-overlay Rut $(\mathrm{mm})$} \\
\cline { 2 - 11 } & 4 & 5 & 6 & 7 & 8 & 9 & 10 & 11 & 12 \\
\hline R Square & 0.151 & 0.153 & 0.152 & 0.150 & 0.153 & 0.153 & 0.153 & 0.153 & 0.153 \\
Mean BIAS & 3.206 & 2.095 & 1.281 & 0.477 & 0.067 & -0.403 & -0.801 & -1.235 & -0.605 \\
Root Mean Square & 4.709 & 3.772 & 3.222 & 3.004 & 2.672 & 2.594 & 2.598 & 2.638 & 3.701 \\
Error (RMSE) & 3.323 & 2.914 & 2.663 & 2.494 & 2.355 & 2.269 & 2.213 & 2.198 & 2.912 \\
Std. Deviation (SD) & 3.3212 \\
\hline
\end{tabular}

\subsubsection{Summary}

This study primarily focused on pre-overlay rut depth. Although this is only one input of MEPDG software it is a highly sensitive parameter for prediction of rutting in rehabilitated sections. Both statistical analysis and DARWin-ME ${ }^{\mathrm{TM}}$ simulation confirmed that $4 \mathrm{~mm}$, the value suggested by the MTO staff, should not be used as a default value for local calibration when site-specific value is unavailable. Rather, Ontario's roads possess a widely varying terminal rut depth before rehabilitation. Without introducing any local calibration coefficients in DARWin-ME ${ }^{\mathrm{TM}}$, the study has shown that both the bias and RMSE reduced drastically when the average terminal rut depth of $7 \mathrm{~mm}$ was used for the pre-overlay value. Further analysis also suggested that a value more than $8 \mathrm{~mm}$ does not seem to change a lot of the local calibration results. Hence, pre-overlay rut value of $7 \mathrm{~mm}$ was used for rehabilitated pavement sections whose pre-overlay rut value was unavailable.

\subsection{Local Calibration Results of Rehabilitated Flexible Pavement Sections}

\subsubsection{Locally Calibrated Parameters}

The permanent deformation models for rehabilitated flexible pavement sections are calibrated by using longitudinal local calibration methodology described in Chapter 3. Section-by-section longitudinal calibrations for nineteen rehabilitated flexible pavement sections were performed for three permanent deformation models. These sections were calibrated against the layer rutting obtained from $50 \%$ contribution of rutting by AC layer and $50 \%$ by granular layer. It was assumed that subgrade layer has no rutting therefore $\beta_{\mathrm{SG}}$ was fixed at zero. The values for initial iterate $\beta_{\mathrm{AC} 1}^{(0)}$ and $\beta_{\mathrm{GB}}$ obtained during the first stage of calibration approach are listed together 
with the corresponding RSS, bias in Table 5-4. The percentage contributions in each layer were similar to the selected percentage contributions for observed layer (e.g. $\approx 50$ for AC layer, $\approx 50$ for granular layer), hence not tabulated in the following table. Note again during the first stage of local calibration the exponent parameters $\beta_{\mathrm{AC} 2}$ and $\beta_{\mathrm{AC} 3}$ both were fixed at the default value of 1.

Table 5-4: First stage Section-by-section Local calibration results for Rehabilitated pavements

\begin{tabular}{|c|c|c|c|c|c|c|c|}
\hline \multirow{2}{*}{ S. No. } & \multirow{2}{*}{ I.D. } & \multicolumn{2}{|c|}{ Rutting Model } & \multicolumn{2}{|c|}{ Layers RSS } & \multirow{2}{*}{$\begin{array}{c}\text { Total } \\
\text { Bias }\end{array}$} & $\begin{array}{c}\text { Total } \\
\text { RSS }\end{array}$ \\
\cline { 3 - 6 } & & $\boldsymbol{A C}_{\text {AC1 }}^{(\mathbf{0})}$ & $\boldsymbol{\beta}_{\text {GB }}$ & AC & Granular & & \\
\hline 1 & 139 & 1.100 & 1.090 & 1.489 & 0.520 & 0.751 & 3.429 \\
\hline 2 & 217 & 0.885 & 1.274 & 0.458 & 0.215 & -0.122 & 0.938 \\
\hline 3 & 347 & 1.000 & 1.860 & 0.820 & 0.241 & 0.326 & 1.023 \\
\hline 4 & 348 & 1.180 & 1.124 & 1.697 & 0.362 & -0.605 & 1.043 \\
\hline 5 & 349 & 1.100 & 1.297 & 0.859 & 0.419 & 0.294 & 0.526 \\
\hline 6 & 350 & 1.200 & 1.308 & 1.010 & 0.962 & 1.631 & 1.738 \\
\hline 7 & 353 & 1.000 & 1.303 & 0.533 & 1.463 & 0.671 & 1.075 \\
\hline 8 & 356 & 0.630 & 0.713 & 0.389 & 0.757 & 0.324 & 2.139 \\
\hline 9 & 357 & 0.988 & 1.337 & 0.126 & 0.525 & -0.165 & 0.793 \\
\hline 10 & 358 & 1.000 & 0.726 & 1.194 & 0.538 & -2.915 & 1.645 \\
\hline 11 & 361 & 0.970 & 0.614 & 0.335 & 0.277 & 0.017 & 0.664 \\
\hline 12 & 377 & 0.900 & 0.853 & 2.013 & 2.064 & 2.777 & 6.458 \\
\hline 13 & 378 & 1.300 & 0.985 & 1.118 & 6.596 & 0.594 & 10.973 \\
\hline 14 & 379 & 1.100 & 1.336 & 1.230 & 1.078 & 1.583 & 2.337 \\
\hline 15 & 386 & 0.900 & 0.804 & 0.698 & 0.762 & 1.923 & 2.208 \\
\hline 16 & 803 & 0.480 & 1.140 & 0.300 & 0.112 & -0.446 & 0.472 \\
\hline 17 & 811 & 0.400 & 2.245 & 0.085 & 0.112 & -0.059 & 0.325 \\
\hline 18 & 951 & 0.740 & 1.237 & 0.610 & 0.391 & -0.617 & 0.991 \\
\hline 19 & 981 & 1.190 & 0.641 & 2.260 & 2.731 & 0.040 & 6.038 \\
\hline
\end{tabular}

The calibration parameter $\beta_{\mathrm{AC} 1}^{(0)}$ obtained during first stage was taken as the initial values for further calibration of AC rutting performance model. The results of second stage section-bysection longitudinal calibration are presented Table 5-5. 
Table 5-5: Second stage Section-by-section Longitudinal Local calibration results for Rehabilitated pavements.

\begin{tabular}{|c|c|c|c|c|c|c|c|}
\hline \multirow{3}{*}{ S. No. } & \multirow{3}{*}{ I.D. } & \multicolumn{3}{|c|}{ Rutting Model } & \multirow{2}{*}{$\begin{array}{c}\text { Layers } \\
\text { RSS }\end{array}$} & \multirow{3}{*}{$\begin{array}{l}\text { Total } \\
\text { Bias }\end{array}$} & \multirow{3}{*}{$\begin{array}{l}\text { Total } \\
\text { RSS }\end{array}$} \\
\hline & & \multicolumn{3}{|c|}{$\mathbf{A C}$} & & & \\
\hline & & $\beta_{\text {AC1 }}$ & $\beta_{\mathrm{AC} 2}$ & $\boldsymbol{\beta}_{\mathrm{AC} 3}$ & $\mathbf{A C}$ & & \\
\hline 1 & 139 & 1.010 & 1.230 & 0.770 & 0.982 & -0.280 & 2.804 \\
\hline 2 & 217 & 0.900 & 1.230 & 0.770 & 0.299 & -0.152 & 0.830 \\
\hline 3 & 347 & 1.010 & 1.230 & 0.770 & 0.444 & -0.318 & 0.794 \\
\hline 4 & 348 & 0.276 & 1.601 & 0.581 & 0.220 & 0.029 & 0.383 \\
\hline 5 & 349 & 1.050 & 1.255 & 0.745 & 0.238 & -0.143 & 0.437 \\
\hline 6 & 350 & 1.100 & 1.155 & 0.850 & 0.467 & 0.044 & 1.624 \\
\hline 7 & 353 & 0.490 & 1.235 & 0.865 & 0.242 & -0.133 & 1.515 \\
\hline 8 & 356 & 0.270 & 0.935 & 1.185 & 0.324 & -0.015 & 1.914 \\
\hline 9 & 357 & 0.980 & 1.055 & 0.945 & 0.109 & 0.145 & 0.860 \\
\hline 10 & 358 & 0.225 & 1.447 & 0.774 & 0.257 & -0.053 & 0.762 \\
\hline 11 & 361 & 0.366 & 1.408 & 0.721 & 0.181 & 0.073 & 0.644 \\
\hline 12 & 377 & 0.440 & 1.175 & 0.925 & 1.067 & 0.296 & 5.735 \\
\hline 13 & 378 & 0.300 & 1.080 & 1.130 & 1.071 & 0.429 & 9.764 \\
\hline 14 & 379 & 1.010 & 1.230 & 0.770 & 0.571 & -0.186 & 2.386 \\
\hline 15 & 386 & 0.295 & 1.166 & 0.989 & 0.296 & 0.114 & 1.863 \\
\hline 16 & 803 & 0.356 & 1.115 & 0.935 & 0.245 & -0.072 & 0.426 \\
\hline 17 & 811 & 0.400 & 1.000 & 1.000 & 0.085 & -0.059 & 0.325 \\
\hline 18 & 951 & 0.287 & 1.157 & 0.983 & 0.567 & -0.272 & 0.951 \\
\hline 19 & 981 & 1.250 & 1.170 & 0.820 & 1.878 & 0.012 & 6.331 \\
\hline
\end{tabular}

The AC layer RSS corresponding to the optimized coefficients, obtained from five consecutive iterations are plotted in Figure 5.5 for fourteen calibration sections. It can be observed that the 2nd iteration in several calibration sections have the highest RSS and afterwards RSS tends to decrease as the interval between levels of sampling reduces. 


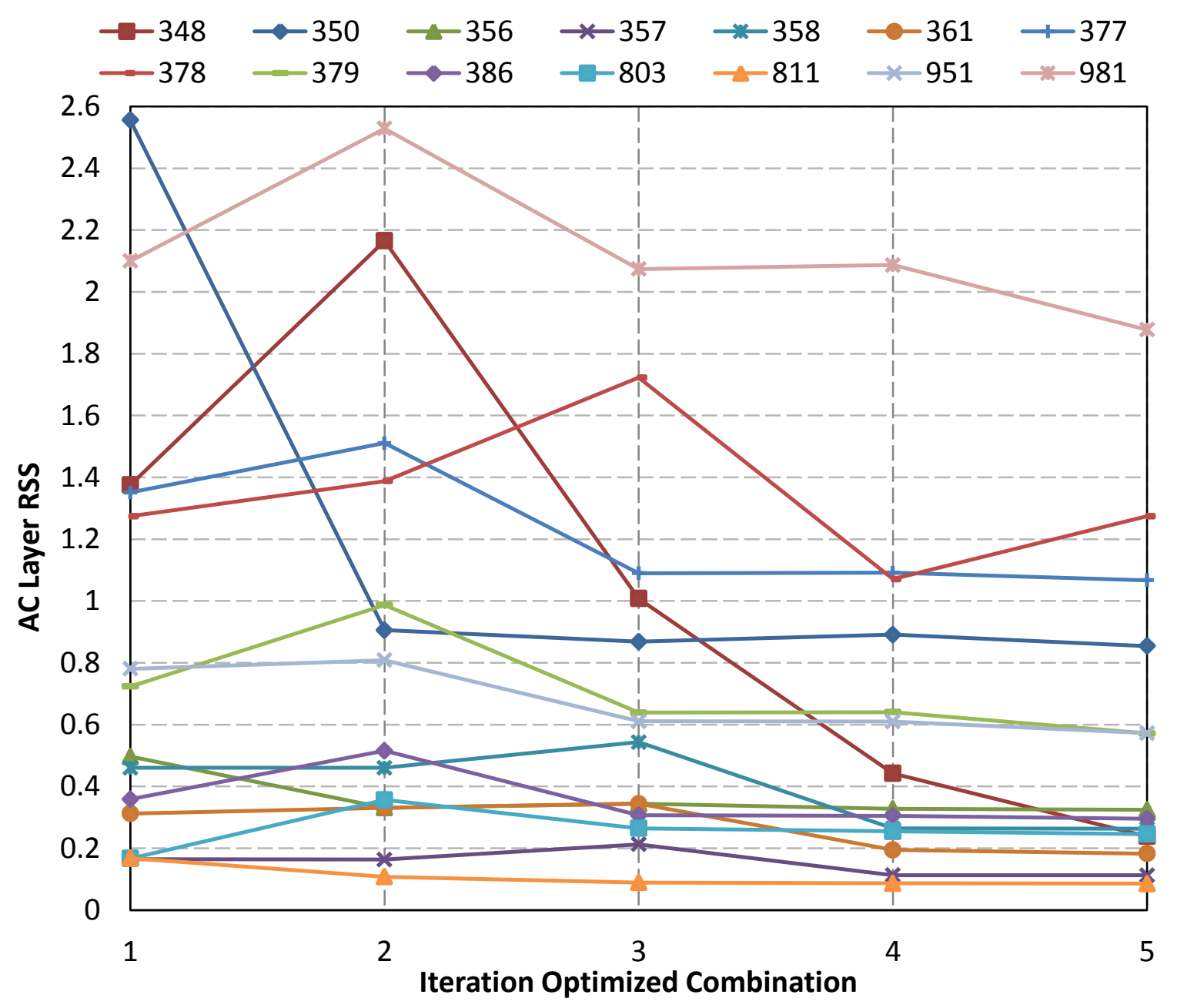

Figure 5.5: AC Layer RSS of Optimized Combinations obtained during Second stage of calibration (Fourteen Calibration sections).

\subsubsection{Discussion and Regression}

The rehabilitated pavement sections also showed variation in local calibration parameters of permanent deformation models. The AC scaling parameter $\beta_{\mathrm{AC} 1}$ varied from 0.276 to 1.250 , $\beta_{\mathrm{AC} 2}$ varied from 0.935 to 1.601 and $\beta_{\mathrm{AC} 3}$ varied from 0.581 to 1.185 . The granular layer calibration parameter $\beta_{\mathrm{GB}}$ varied from 0.614 to 2.245 . The major characteristics of rehabilitated flexible pavement sections are shown in Table 5-6. 
Table 5-6: Major Input Characteristics of Rehabilitated pavement sections.

\begin{tabular}{|c|c|c|c|c|c|c|c|c|c|}
\hline \multirow[b]{2}{*}{ I.D. } & \multirow[b]{2}{*}{ Zone } & \multirow[b]{2}{*}{ Highway } & \multirow[b]{2}{*}{$\begin{array}{l}\text { Total } \\
\text { AADTT }\end{array}$} & \multirow[b]{2}{*}{$\begin{array}{c}\text { No. of } \\
\text { Total } \\
\text { Layers }\end{array}$} & \multirow[b]{2}{*}{$\begin{array}{c}\text { Top } \\
\text { AC } \\
\text { layer }\end{array}$} & \multicolumn{2}{|c|}{ Thickness } & \multicolumn{2}{|c|}{ Resilient Modulus } \\
\hline & & & & & & $\begin{array}{c}\text { Total } \\
\text { AC } \\
(\mathrm{mm})\end{array}$ & $\begin{array}{l}\text { Total } \\
\text { Granular } \\
\text { (mm) }\end{array}$ & $\begin{array}{l}\text { Granular } \\
\text { Equivalent } \\
\text { (MPa) }\end{array}$ & $\begin{array}{c}\text { Subgrade } \\
\text { (MPa) }\end{array}$ \\
\hline 139 & so & 6 & $5,046,760$ & 7 & HL1 & 230 & 575 & 176.1 & 35 \\
\hline 217 & SO & 8 & $6,667,120$ & 6 & DFC & 275 & 600 & 175.0 & 40 \\
\hline 347 & so & 11 & $8,557,830$ & 7 & HL1 & 210 & 650 & 188.5 & 40 \\
\hline 348 & so & 11 & $5,419,770$ & 7 & HL1 & 170 & 650 & 188.5 & 35 \\
\hline 349 & so & 11 & $6,445,420$ & 7 & HL1 & 210 & 650 & 188.5 & 35 \\
\hline 350 & so & 11 & $4,643,060$ & 7 & HL1 & 210 & 650 & 188.5 & 35 \\
\hline 353 & so & 11 & $7,236,770$ & 7 & HL1 & 220 & 650 & 188.5 & 40 \\
\hline 356 & NO & 11 & $4,527,240$ & 5 & HL3M & 159 & 600 & 175.0 & 35 \\
\hline 357 & NO & 11 & $3,044,380$ & 7 & HL3 & 260 & 600 & 175.0 & 35 \\
\hline 358 & NO & 11 & $3,404,890$ & 5 & HL1 & 141 & 600 & 175.0 & 50 \\
\hline 361 & NO & 11 & $2,975,970$ & 5 & HL1 & 141 & 600 & 175.0 & 50 \\
\hline 377 & so & 11 & $9,368,470$ & 6 & HL1 & 120 & 650 & 188.5 & 40 \\
\hline 378 & so & 11 & $5,419,770$ & 6 & HL1 & 120 & 650 & 188.5 & 40 \\
\hline 379 & so & 11 & $6,500,740$ & 7 & HL1 & 240 & 650 & 188.5 & 35 \\
\hline 386 & NO & 11 & $4,527,240$ & 6 & HL3M & 165 & 600 & 175.0 & 35 \\
\hline 803 & so & 85 & $12,986,600$ & 7 & DFC & 210 & 620 & 201.6 & 25 \\
\hline 811 & so & 85 & $12,856,900$ & 5 & DFC & 185 & 170 & 338.2 & 40 \\
\hline 951 & so & 400 & $10,892,600$ & 5 & DFC & 270.5 & 762 & 210.0 & 41 \\
\hline 981 & so & 400 & $4,006,410$ & 5 & HL1 & 100 & 550 & 177.3 & 40 \\
\hline
\end{tabular}

The calibrated parameters of $\beta_{\mathrm{AC} 1}^{(0)}$ obtained during first stage of the local calibration methodology were used to develop a regressed equation. The regression of $\beta_{\mathrm{AC} 1}^{(0)}$ calibration parameter was done with total AADTT and thickness of AC layer which are among the major input characteristics (Table 5-6) of the MEPDG. The regression gives a correlation of 0.45 with the results of all nineteen calibrated parameters. However regressing again after removing five outliers from the scattered plot drastically increased the correlation to 0.898. This regressed equation is as follows:

$$
\beta_{\mathrm{AC} 1}^{(0)}=1.700-8.4 \times 10^{-8} \mathrm{AADTT}-0.00047 \mathrm{~T}_{\mathrm{AC}}
$$


where

$T_{\mathrm{AC}}=$ Thickness of AC layer $(\mathrm{mm})$

$\mathrm{AADTT}=$ Total AADTT expected at the end of pavement life

Table 5-7: Statistics of $\beta_{\mathrm{AC1}}{ }^{(0)}$ regressed equation for rehabilitated section.

\begin{tabular}{lr}
\hline \multicolumn{2}{c}{ Regression Statistics } \\
\hline Multiple R & 0.948 \\
R Square & 0.898 \\
Adjusted R Square & 0.879 \\
Standard Error & 0.093 \\
Observations & 14 \\
\hline
\end{tabular}

The largest value of calibration parameter for granular layer $\beta_{\mathrm{GB}}$ Was 2.245 for section 811 . The AADTT of this section is in in higher range. The presence of a $25 \mathrm{~mm}$ BTB layer with the resilient modulus of $1000 \mathrm{MPa}$ makes it a relatively stronger granular layer. The section 911 has the lowest value for granular layer calibration parameter 0.641. This value can be explained by the fact that this section traffic is in the lowest range and absence of thick AC layer to protect the granular surface. Hence on the basis of above observation granular layer calibrated parameters were regressed with total AADTT, equivalent resilient modulus of granular layer, thickness of AC layer and thickness of granular layer. The resulted regressed equation showed good correlation of 0.746 (Table 5-8).

$$
\begin{gathered}
\beta_{\mathrm{GB}}=-1.1533-6.168 \times 10^{-10} \mathrm{AADTT}+8.435 \times 10^{-5} T_{\text {gran }}+0.00793 M_{\mathrm{eqv}}+ \\
0.00382 T_{\mathrm{AC}}
\end{gathered}
$$

where

$$
\begin{aligned}
& \mathrm{T}_{\text {gran }}=\text { Total thickness of granular layer }(\mathrm{mm}) \\
& \mathrm{M}_{\text {eqv }}=\text { Equivalent resilient modulus of granular layer }(\mathrm{MPa}) \\
& \mathrm{T}_{\mathrm{AC}}=\text { Thickness of } \mathrm{AC} \text { layer }(\mathrm{mm})
\end{aligned}
$$


Table 5-8: Statistics of $\beta_{\mathrm{GB}}$ regressed equation for rehabilitated section.

\begin{tabular}{ll}
\hline \multicolumn{2}{c}{ Regression Statistics } \\
\hline Multiple R & 0.864 \\
R Square & 0.746 \\
Adjusted R Square & 0.674 \\
Standard Error & 0.233 \\
Observations & 19 \\
\hline
\end{tabular}

The averages of optimal values for the five calibration parameters of the ten sections are $\beta_{\mathrm{AC} 1}=0.632, \beta_{\mathrm{AC} 2}=1.203, \beta_{\mathrm{AC} 3}=0.869, \beta_{\mathrm{GB}}=1.152$ and $\beta_{\mathrm{SG}}=0$. In case of rehabilitated sections also it is observed that except for sections 377, 378 and 981, the local calibration resulted in very small bias and RSS. It was discovered that minimization of AC RSS in few section (section 357, 379 and 981) lead to increase in total RSS of section, which was the result of variation in $\beta_{\mathrm{AC} 1}$ the multiplier calibration parameter. For all sections, the percentage layer contributions averaged along the observational life has maintained to be consistent with the pre-defined percentage contributions of 50 for $\mathrm{AC}$ layer and $50 \%$ for granular layer

\subsubsection{Comparison with Pooled and Global Calibration}

The results section-by-section local calibration was compared with the results of pooled calibration for rehabilitated pavement sections. This pooled calibration is performed in a different approach from reconstructed sections, by analysing all rehabilitated calibration sections with the same nineteen sets of locally calibrated parameters obtained by section-by-section calibration and one set that is average of nineteen calibrated parameters. Hence, total twenty combinations were analysed for all calibration sections. Finally, layer calibration parameters producing minimum RSS were selected as the pooled or level-3 calibrated parameters. The total RSS was minimized at $\beta_{\mathrm{AC} 1}=0.9, \beta_{\mathrm{AC} 2}=1.23, \beta_{\mathrm{AC} 3}=0.77, \beta_{\mathrm{GB}}=0.985$ and $\beta_{\mathrm{SG}}=0$, which are also different from the averaged value in the section-by-section calibration.

The RSS of each section after pooled calibration are also shown in Table 5-9. In terms of layer RSS and total RSS, the residuals from the pooled calibration are much greater than those from the section-by-section calibration. 
Table 5-9: RSS of Rehabilitated sections based on the Pooled local calibration results.

\begin{tabular}{|l|l|l|l|}
\hline Sc. I.D & Total RSS & AC RSS & Granular RSS \\
\hline $\mathbf{1 3 9}$ & 5.26 & 1.56 & 1.14 \\
\hline $\mathbf{2 1 7}$ & 4.58 & 0.30 & 3.76 \\
\hline $\mathbf{3 4 7}$ & 70.21 & 3.09 & 44.82 \\
\hline $\mathbf{3 4 8}$ & 23.52 & 9.83 & 3.34 \\
\hline $\mathbf{3 4 9}$ & 29.56 & 4.95 & 10.67 \\
\hline $\mathbf{3 5 0}$ & 42.83 & 7.84 & 14.27 \\
\hline $\mathbf{3 5 3}$ & 19.62 & 0.99 & 12.25 \\
\hline $\mathbf{3 5 6}$ & 100.23 & 33.84 & 17.74 \\
\hline $\mathbf{3 5 7}$ & 8.29 & 0.18 & 8.38 \\
\hline $\mathbf{3 5 8}$ & 7.11 & 2.04 & 15.41 \\
\hline $\mathbf{3 6 1}$ & 22.69 & 0.22 & 23.73 \\
\hline $\mathbf{3 7 7}$ & 12.06 & 1.19 & 7.45 \\
\hline $\mathbf{3 7 8}$ & 43.48 & 28.63 & 6.60 \\
\hline $\mathbf{3 7 9}$ & 24.06 & 2.40 & 11.77 \\
\hline $\mathbf{3 8 6}$ & 11.27 & 0.88 & 6.09 \\
\hline $\mathbf{8 0 3}$ & 14.68 & 25.98 & 1.80 \\
\hline $\mathbf{8 1 1}$ & 2.41 & 30.91 & 16.95 \\
\hline $\mathbf{9 5 1}$ & 1.36 & 2.43 & 4.68 \\
\hline $\mathbf{9 8 1}$ & 21.65 & 11.17 & 50.41 \\
\hline $\begin{array}{l}\text { Total } \\
\text { RSS }\end{array}$ & 459.63 & 166.87 & 260.11 \\
\hline & & & \\
\hline
\end{tabular}

Comparison plot for residual errors (Figure 5.6) of predicted total rut depth showed that for both section by section and pooled calibration residuals errors were equally scattered on both sides of zero line. This shows results of pooled calibration for rehabilitated sections are better than that of reconstructed sections. Further comparison through the prediction versus observation plots (Figure 5.8) showed pooled calibration has better $\mathrm{R}^{2}(0.339)$ than reconstructed sections. This $\mathrm{R}^{2}$ is comparable to the $0.399 \mathrm{R}^{2}$ of global default models (Table 4-9). The standard error of pooled calibration $1.756 \mathrm{~mm}$ is also far better than the standard error of globally calibrated models which is $3.07 \mathrm{~mm}$ (Table 4-9). This $\mathrm{R}^{2}$ can further be improved to 0.464 and standard error to $1.608 \mathrm{~mm}$ by removing outliner section 356 from the data set. This section shows largest permanent deformation in the database, where large permanent deformations are not frequently observed in rehabilitated pavement sections. 


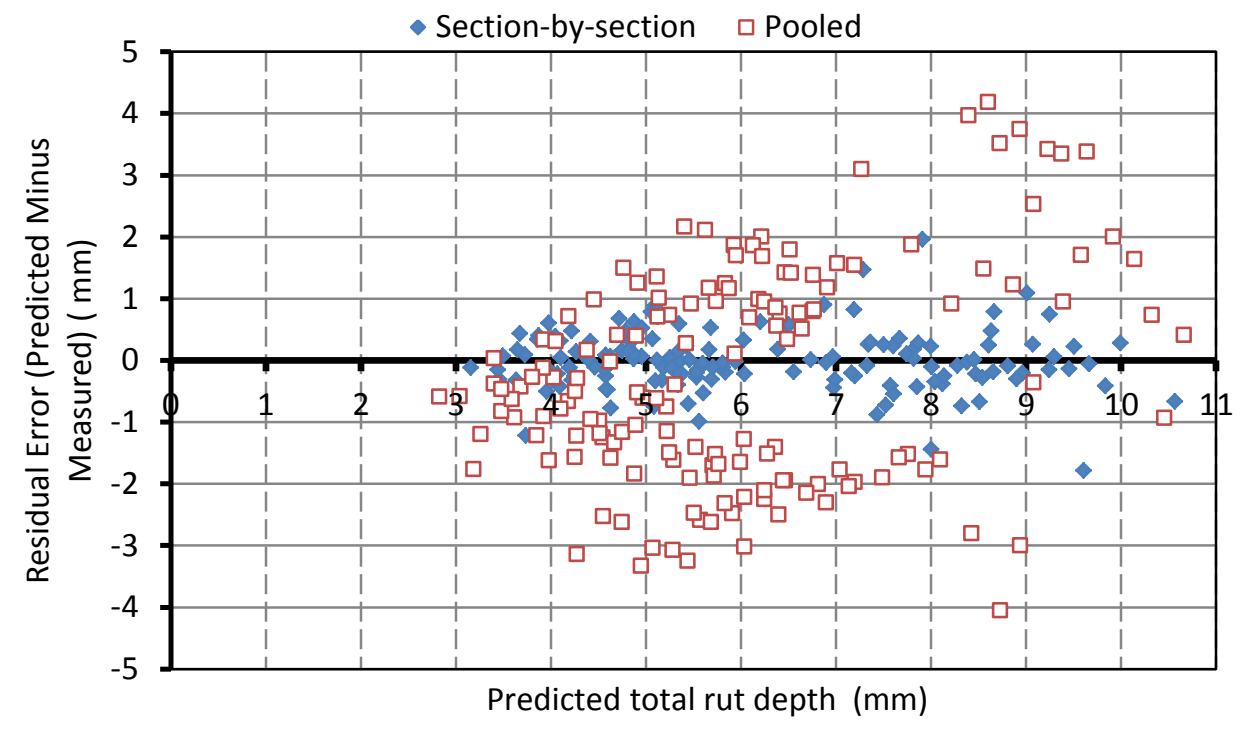

Figure 5.6: Residual Errors for total predicted rut depth after calibration for rehabilitated sections.

The predicted versus observed plots of section-by-section calibration for asphalt concrete and granular layer is plotted in Figure 5.8. As expected, both layer showed a good $\mathrm{R}^{2}$ and small standard error value. Longitudinal comparison of predicted layer rutting for section 358 is shown in Figure 5.9. While the section-by-section calibration provides accurate prediction, the predicted rutting based on the pooled calibration is far off from the observed rutting as compared to AC rutting predictions. Predictions from global models are not included in this comparison as they extremely over predict the rutting for all layers. 

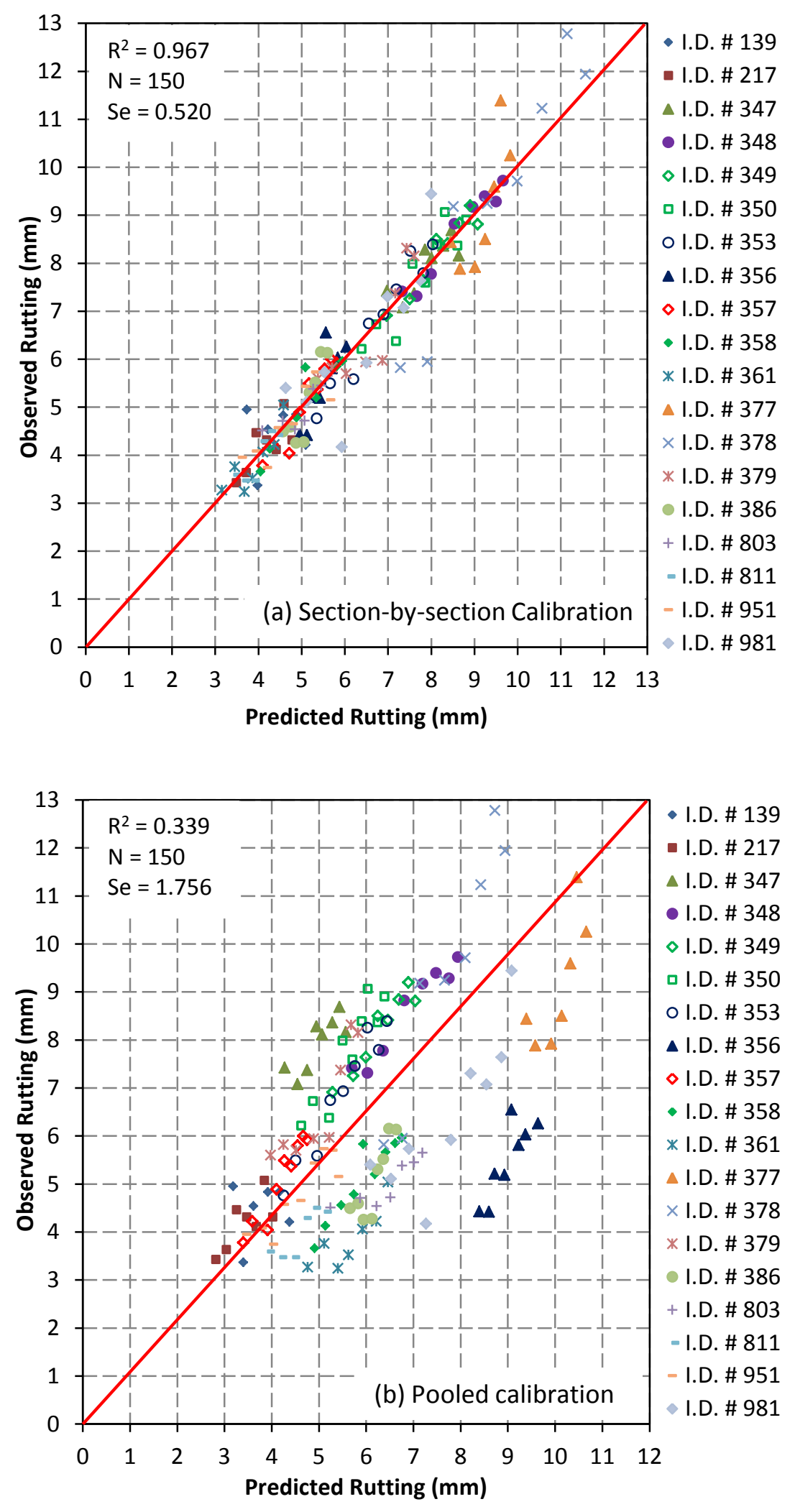

Figure 5.7: Prediction versus observation comparison plots after calibration of rehabilitated sections. 

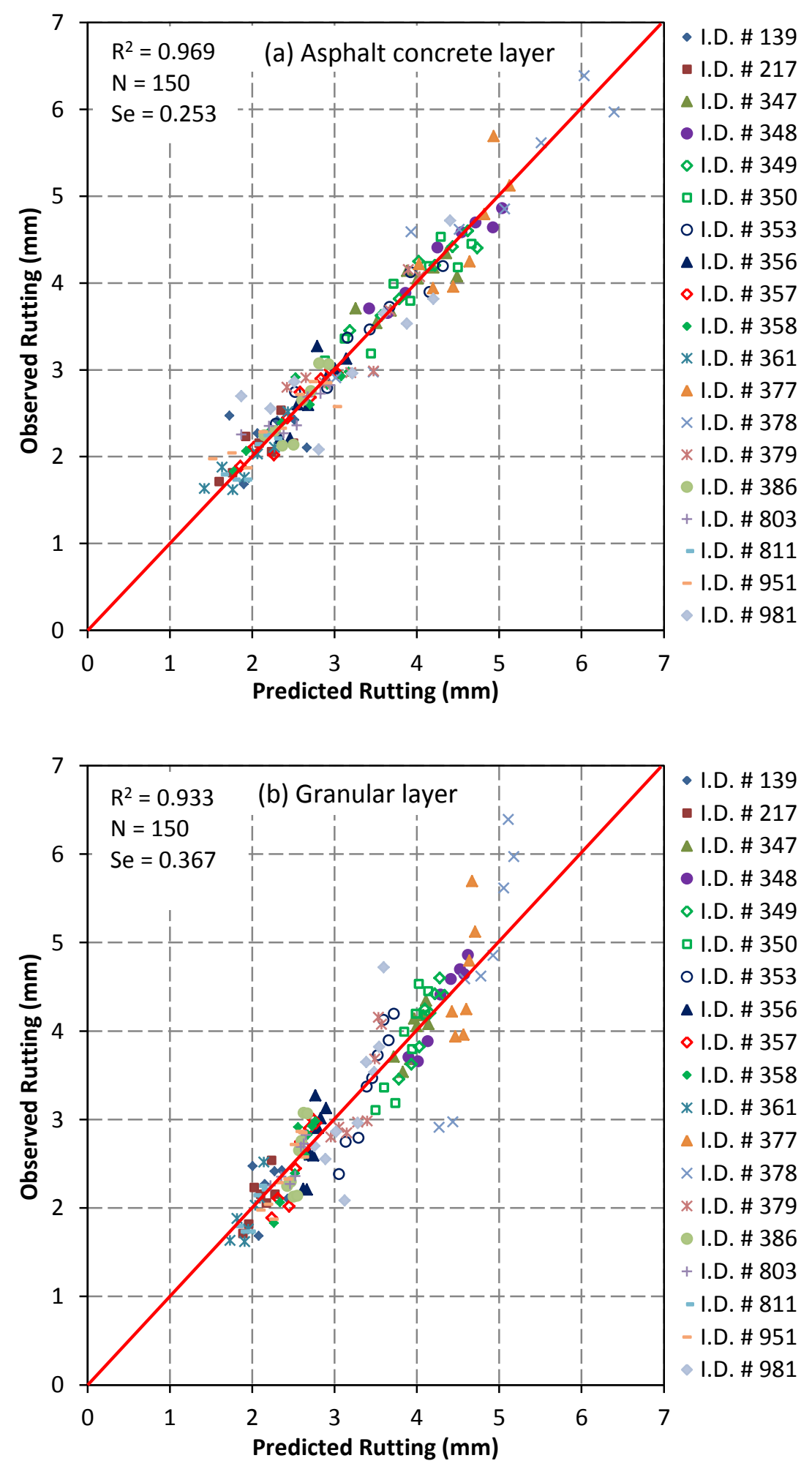

Figure 5.8: After-section-by-section calibration prediction versus observation plots for rehabilitated sections. 

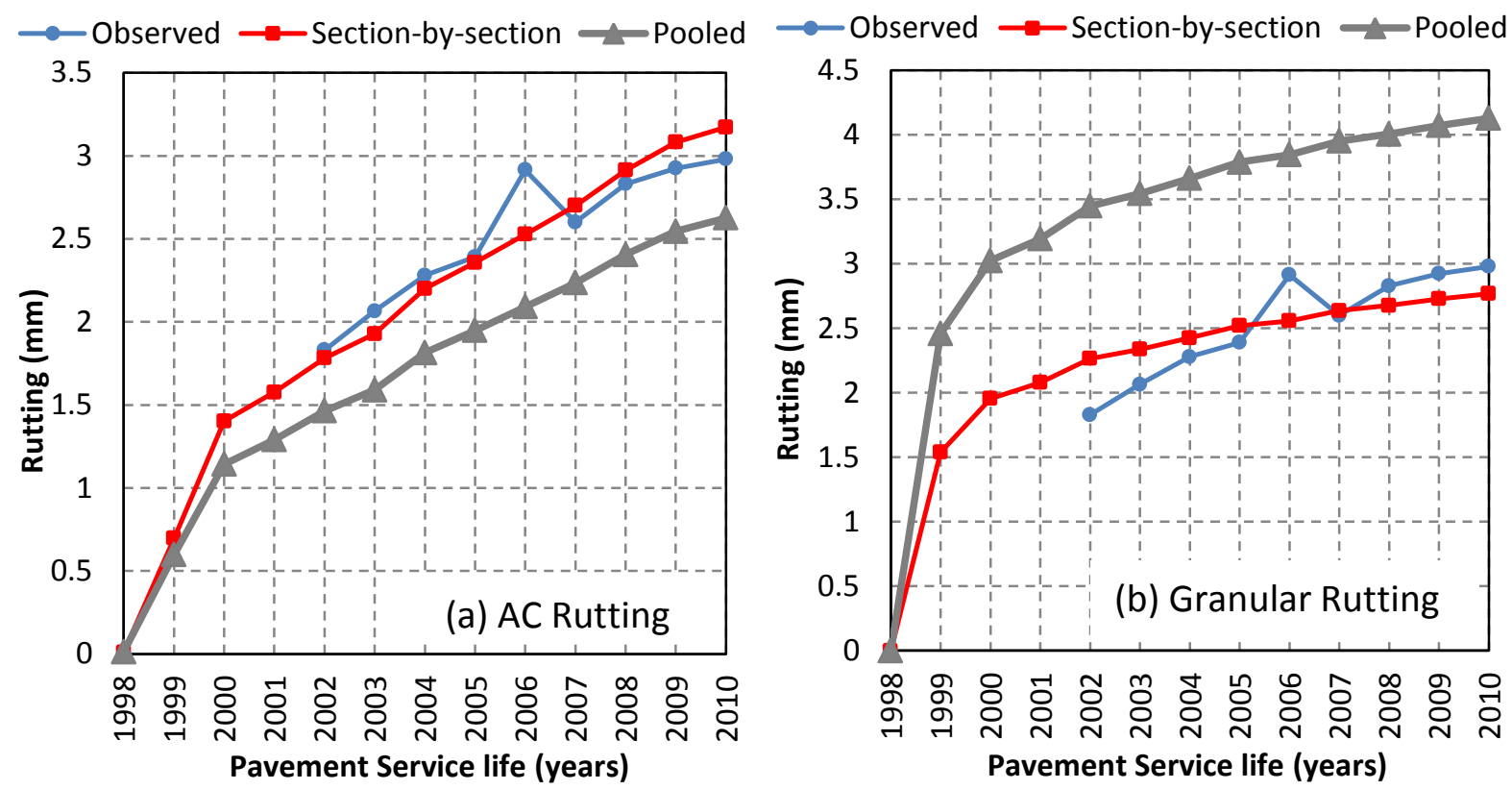

Figure 5.9: Longitudinal comparison of section-by-section and pooled calibration of section 358. 


\section{CHAPTER 6 SUMMARY, CONCLUSIONS AND RECOMENDATIONS}

This chapter summarizes the conclusions of this thesis research and presents recommendations for future MEPDG local calibration studies for permanent deformation models.

\subsection{Summary}

The challenges and findings of local calibration methodology and results are summarized in this section. It was found that the process of calibration of MEPDG rutting models involved multiple local optima, when calibrated for total observed rutting. To deal with this under-determinacy, a set of percentage contributions to the total rutting from different structural layers were proposed based on previous empirical studies and computation observations. These layer contributions were used to predict field rutting in individual layers. In the calibration of reconstructed section the layer contribution of rutting measured by AASHO in 1962 (i.e., 32\% for AC, 59\% for granular layers and 9\% for fine-grained soil) was selected. In the calibration of rehabilitated pavement sections 50\% layer contribution of rutting was selected for AC layer and granular layer each. The reconstructed pavement sections were calibrated section-by-section using the developed methodology, which were compared with pooled calibration. Similarly, then the rehabilitated calibration sections were also calibrated and results were compared with pooled calibration.

\subsection{Conclusions}

The following conclusions are drawn from this study:

- The two stage layer-by-layer, section-by-section local calibration process was developed and semi-automated using DARWin-ME ${ }^{\mathrm{TM}}$ coupled with Excel Macros. The iterative local calibration is achieved by optimization of RSM, cognitive reduction of intervals and finally achieving convergence of RSS. 
- The pooled calibration parameters $\left(\beta_{\mathrm{AC} 1}=0.9, \beta_{\mathrm{AC} 2}=1.23, \beta_{\mathrm{AC} 3}=0.77, \beta_{\mathrm{GB}}=\right.$ 0.985 and $\beta_{\mathrm{SG}}=0$ ) of rehabilitated pavement sections has improved $\mathrm{R}^{2}(0.464)$ and reduced standard error $(1.608 \mathrm{~mm})$ than that obtained during calibration of global rutting models. Hence, this shows that these calibration parameters can be adopted as level-3 calibration parameters for rehabilitated pavement sections.

- The locally calibrated parameters obtained for reconstructed pavement sections from section-by-section local calibration were spread over a wide range. The AC scaling parameter $\beta_{\mathrm{AC} 1}$ varied from 0.14 to $0.47, \beta_{\mathrm{AC} 2}$ varied from 0.975 to 1.738 and $\beta_{\mathrm{AC} 3}$ varied from 0.229 to 1.105 . Hence, using an average of these calibration parameters will not be suitable for use for Ontario.

- The granular calibrated parameters of reconstructed sections showed good correlation (0.54) with thickness of granular layer, equivalent resilient modulus of granular layer, AADTT and thickness of AC layer. For OGDL cement treated layer, an average value 3.114 can be used as granular layer calibration parameter.

- The pre-overlay rut, which is an important parameter in the rehabilitation information of rehabilitated pavement sections, was unavailable for pavement section in Ontario. The level-3 pre-overlay rut input value of $7 \mathrm{~mm}$ was proposed by the author after frequency distribution of pavement pre-overlay rut values in Ontario's PMS-2 database and DARWin-ME ${ }^{\mathrm{TM}}$ analysis of selected rehabilitated pavement sections with default rutting models.

- The local calibration results for rehabilitated pavement sections also showed large variations in calibration parameters. The calibration parameters for rutting model $\beta_{\mathrm{AC} 1}$ varied from 0.276 to $1.250, \beta_{\mathrm{AC} 2}$ varied from 0.935 to 1.601 and $\beta_{\mathrm{AC} 3}$ varied from 0.581 to 1.185 . The granular layer rutting calibration parameter $\beta_{\mathrm{GB}}$ varied from 0.614 to 2.245 .

- The regression correlation of rehabilitated calibration parameters with major input characteristics is good. These major input characteristics include thickness of AC layer, AADTT, thickness of granular layer and equivalent resilient modulus of granular layer. 
- The total rut depth in the performance database varied irrationally along the service life of a section. The use of power law can needlessly reduce the magnitude of RSS and standard error of the calibrated section but the locally calibrated parameters will be same from both types: original observed and smoothed observed rut depths.

- Regressed equations for reconstructed sections can also be used to predict calibration parameters on the basis of major input characteristics of pavements and most importantly the observed rutting used for calibrating those pavement sections.

\subsection{Recommendations}

This section provides the important recommendations that the author believes that would be useful for a future effective local calibration of permanent deformation models in Ontario.

- It should be remembered that the individual layer rutting used in this research was predicted from the layer contributions findings of a 50-year-old research done in the U.S. Hence, the layer contribution study for flexible pavement sections in Ontario and its sensitivity to major input parameters is desperately needed. As a long term goal, Ontario should also establish an average rut depth values for different zones, layer materials, AADTT and thickness.

- It is important to understand that the database used in this research was only limited to reconstructed pavement sections and no new flexible pavement section was a part of this research. Hence new pavement sections should be included in this database before recalibration of MEPDG rutting model for Ontario. Similarly information for more reconstructed sections should be collected to enhance the local calibration study.

- It is recommended to collect more rehabilitated pavement sections whose performance history and pre-overlay rut information is available. Hence, more rehabilitated pavement sections which are rehabilitated after 2002 should be included in the database. 
APPENDICES 


\section{APPENDIX A General Project \& Traffic Data for DARWin-ME ${ }^{\mathrm{TM}}$}

\section{A.1 General Project Inputs}

General inputs required for a typical project in DARWin-Me ${ }^{\mathrm{TM}}$ are given in Table A-1. Limit values of distress were the default values as well as recommended in DOT manual for MEPDG inputs (MTO 2012).

Table A-1: General Project Input's Requirement for DARWin-ME ${ }^{\mathrm{TM}}$

\begin{tabular}{|c|c|c|c|c|c|}
\hline S.I & Item Name & \multicolumn{4}{|c|}{ Input Requirement } \\
\hline \multirow{6}{*}{1.} & \multirow{6}{*}{$\begin{array}{c}\text { General } \\
\text { Information }\end{array}$} & \multicolumn{4}{|l|}{ i. Design Type } \\
\hline & & \multicolumn{4}{|l|}{ ii. Pavement Type } \\
\hline & & \multicolumn{4}{|l|}{ iii. Design Life } \\
\hline & & \multicolumn{4}{|l|}{ iv. Base construction (month, year) } \\
\hline & & \multicolumn{4}{|l|}{ v. Pavement Construction (month, year) } \\
\hline & & \multicolumn{4}{|l|}{ vi. Traffic Opening (month, year) } \\
\hline \multirow{9}{*}{2} & \multirow{9}{*}{$\begin{array}{c}\text { Performance } \\
\text { Criteria }\end{array}$} & \multirow{2}{*}{ Input Requirement } & \multicolumn{2}{|c|}{ Value } & \multirow{2}{*}{ Source } \\
\hline & & & Limit & Reliability & \\
\hline & & i. Initial IRI (m/km) & & & \\
\hline & & ii. Terminal IRI & 2.7 & $50 \%$ & Default \\
\hline & & iii. AC top-down fatigue cracking $(\mathrm{m} / \mathrm{km})$ & 378.8 & $50 \%$ & Default \\
\hline & & iv. AC bottom-up fatigue cracking $(\mathrm{m} / \mathrm{km})$ & 25 & $50 \%$ & Default \\
\hline & & v. AC thermal fracture $(\mathrm{m} / \mathrm{km})$ & 189.4 & $50 \%$ & Default \\
\hline & & vi. Permanent deformation - total $(\mathrm{mm})$ & 19 & $50 \%$ & Default \\
\hline & & vii. Permanent deformation $-\mathrm{AC}(\mathrm{mm})$ & 6 & $50 \%$ & Default \\
\hline \multirow{6}{*}{3} & \multirow{6}{*}{$\begin{array}{c}\text { Project } \\
\text { identifiers }\end{array}$} & i. Display Name & \multicolumn{3}{|c|}{ ii. Country } \\
\hline & & iii. Description of object & \multicolumn{3}{|c|}{ iv. Province/State } \\
\hline & & v. Approver & \multicolumn{3}{|c|}{ vi. District } \\
\hline & & vii. Date Approved & \multicolumn{3}{|c|}{ viii. Direction of travel } \\
\hline & & ix. Author & \multicolumn{3}{|c|}{ x. Station } \\
\hline & & xi. Date created & \multicolumn{3}{|c|}{ xii. Highway } \\
\hline
\end{tabular}

Here, predicted distresses at $50 \%$ reliability were considered upon the recommendations of local calibration guide. Project identifiers are not compulsory but are recommended to identify 
the pavement section under consideration. Other inputs in Table A-1 does not affect the predicted distresses, hence they have no influence on local calibration.

DARWin-ME ${ }^{\mathrm{TM}}$ provides 41 places for traffic inputs, these inputs are generally classified in 7 main categories AADTT (annual average daily truck traffic), traffic volume adjustment, axle distribution, traffic capacity, axle configuration, lateral traffic wander and wheel base. Traffic inputs in these main categories are described below.

\section{A.2 Annual Average Daily Truck Traffic}

Two-way AADTT: It is the annual average number of truck traffic passing daily over the pavement in both directions. This value was estimated for the base year from the product of annual average daily traffic (AADT) and fraction form of percentage of heavy trucks, available in PMS-2 database.

Number of lanes: It is the number of lanes in design direction.

Percent of Truck in design direction: It is the percentage of total trucks passing from over the pavement of design direction. Its value was taken as 50\%, which is a level-3 value.

Percent trucks in design lane: Percentage of total trucks in design lane were calculated from the Table A-2, which was obtained from MTO (2012).

Table A-2: Ontario Recommended Percentage of Trucks in Design Lane (MTO 2012)

\begin{tabular}{|c|c|c|}
\hline $\begin{array}{c}\text { Number of Lanes } \\
\text { in One Direction }\end{array}$ & AADT (both directions) & $\begin{array}{c}\text { Percentage of Trucks } \\
\text { in Design Lane (\%) }\end{array}$ \\
\hline 1 & All & 100 \\
\hline 2 & $<15,000$ & 90 \\
& $>15,000$ & 80 \\
\hline \multirow{2}{*}{3} & $<25,000$ & 80 \\
& 25,000 to 40,000 & 70 \\
& $>40,000$ & 60 \\
\hline \multirow{2}{*}{4} & $<40,000$ & 70 \\
& $>40,000$ & 60 \\
\hline \multirow{2}{*}{5} & $<50,000$ & 60 \\
& $>50,000$ & 60 \\
\hline
\end{tabular}


Operational speed: "Operational is the speed at which drivers are observed operating their vehicles during free-flow conditions" (AASHTO 2001). Operational speed of pavement sections was selected on the basis of Table A-3, which provides general operational speed on the basis of highway class.

Table A-3: Classification of operational speed on highway type.

\begin{tabular}{|c|c|}
\hline Highway Type & Speed $(\mathbf{K m} / \mathbf{h r})$ \\
\hline Freeway & 100 \\
\hline Arterial & 80 \\
\hline Collector & 60 \\
\hline Local & 50 \\
\hline
\end{tabular}




\section{A.3 Traffic Volume Adjustment}

Truck Traffic Classification (TTC): Groups of TTC are shown in Table A-4; each TTC groups consist of different vehicle class distribution for different classes.

Table A-4: Truck Traffic classification (AASHTOWare Pavement ME Design)

\begin{tabular}{|c|c|c|l|}
\hline TTC & Bus (\%) & Multi-trailer $(\%)$ & Single- trailer and single trailer unit (SU) trucks \\
\hline 1 & $(>2 \%)$ & $(<2 \%)$ & Predominantly single-trailer trucks. \\
\hline 2 & $(>2 \%)$ & $(<2 \%)$ & $\begin{array}{l}\text { Predominantly single-trailer trucks with a low percentage of single-unit } \\
\text { trucks. }\end{array}$ \\
\hline 3 & $(<2 \%)$ & $(2-10 \%)$ & Predominantly single-trailer trucks. \\
\hline 4 & $(>2 \%)$ & $(<2 \%)$ & $\begin{array}{l}\text { Predominantly single-trailer trucks with a low to moderate amount of } \\
\text { single-unit trucks. }\end{array}$ \\
\hline 5 & $(<2 \%)$ & $(>10 \%)$ & Predominately single-trailer trucks. \\
\hline 6 & $(>2 \%)$ & $(<2 \%)$ & Mixed truck traffic with a higher percentage of single-unit trucks. \\
\hline 7 & $(<2 \%)$ & $(2-10 \%)$ & Mixed truck traffic with a higher percentage of single-trailer trucks. \\
\hline 8 & $(<2 \%)$ & $(>10 \%)$ & High percentage of single-trailer truck with some single-unit trucks. \\
\hline 9 & $(>2 \%)$ & $(<2 \%)$ & $\begin{array}{l}\text { Mixed truck traffic with about equal percentages of single-unit and } \\
\text { single-trailer trucks. }\end{array}$ \\
\hline 10 & $(<2 \%)$ & $(2-10 \%)$ & $\begin{array}{l}\text { Mixed truck traffic with about equal percentages of single-unit and } \\
\text { single-trailer trucks. }\end{array}$ \\
\hline 11 & $(<2 \%)$ & $(>10 \%)$ & Mixed truck traffic with a higher percentage of single-trailer trucks. \\
\hline 12 & $(>2 \%)$ & $(<2 \%)$ & Mixed truck traffic with a higher percentage of single-unit trucks. \\
\hline 13 & $(<2 \%)$ & $(>10 \%)$ & $\begin{array}{l}\text { Mixed truck traffic with about equal percentages of single-unit and } \\
\text { single-trailer trucks. }\end{array}$ \\
\hline 14 & $(>2 \%)$ & $(<2 \%)$ & Predominantly single-unit trucks. \\
\hline 15 & $(<2 \%)$ & $(2-10 \%)$ & Predominantly single-unit trucks. \\
\hline 16 & $(<2 \%)$ & $(>10 \%)$ & Predominantly single-unit trucks. \\
\hline 17 & $(>25 \%)$ & $(<2 \%)$ & $\begin{array}{l}\text { Mixed truck traffic with about equal single-unit and single-trailer } \\
\text { trucks. }\end{array}$ \\
\hline
\end{tabular}

Vehicle class distribution: FHWA classified vehicles into 13 (Class 1 to 13) distinct classes, whereas in DARWin-ME ${ }^{\mathrm{TM}}$ traffic is distributed in 10 classes (Class 4 to 13), since light weight vehicle classifications are excluded. Vehicle class distributions for these 10 classes for each TTC group are given in Table A-5. 
Table A-5: TTC group description and corresponding vehicle (truck) class distribution (percentages) available in DARWin-ME ${ }^{\mathrm{TM}}$ (AASHTOWare Pavement ME Design)

\begin{tabular}{|c|c|c|c|c|c|c|c|c|c|c|c|}
\hline \multirow{2}{*}{$\begin{array}{c}\text { TTC } \\
\text { Groups }\end{array}$} & \multirow{2}{*}{ TTC Description } & \multicolumn{10}{|c|}{ FHWA Class } \\
\hline & & 4 & 5 & 6 & 7 & 8 & 9 & 10 & 11 & 12 & 13 \\
\hline 1 & Predominantly single-trailer trucks. & 1.3 & 8.5 & 2.8 & 0.3 & 7.6 & 74 & 1.2 & 3.4 & 0.6 & 0.3 \\
\hline 2 & $\begin{array}{l}\text { Predominantly single-trailer trucks with } \\
\text { a low percentage of single-unit trucks. }\end{array}$ & 2.4 & 14 & 4.5 & 0.7 & 7.9 & 66 & 1.4 & 2.2 & 0.3 & 0.2 \\
\hline 3 & Predominantly single-trailer trucks. & 0.9 & 12 & 3.6 & 0.2 & 6.7 & 62 & 4.8 & 2.6 & 1.4 & 6.2 \\
\hline 4 & $\begin{array}{l}\text { Predominantly single-trailer trucks with } \\
\text { a low to moderate amount of single-unit } \\
\text { trucks. }\end{array}$ & 2.4 & 23 & 5.7 & 1.4 & 8.1 & 55 & 1.7 & 2.2 & 0.2 & 0.4 \\
\hline 5 & Predominately single-trailer trucks. & 0.9 & 14 & 3.5 & 0.6 & 6.9 & 54 & 5 & 2.7 & 1.2 & 11 \\
\hline 6 & $\begin{array}{l}\text { Mixed truck traffic with a higher } \\
\text { percentage of single-unit trucks. }\end{array}$ & 2.8 & 31 & 7.3 & 0.8 & 9.3 & 45 & 2.3 & 1 & 0.4 & 0.3 \\
\hline 7 & $\begin{array}{l}\text { Mixed truck traffic with a higher } \\
\text { percentage of single-trailer trucks. }\end{array}$ & 1 & 24 & 4.2 & 0.5 & 10 & 42 & 5.8 & 2.6 & 1.3 & 8.4 \\
\hline 8 & $\begin{array}{l}\text { High percentage of single-trailer truck } \\
\text { with some single-unit trucks. }\end{array}$ & 1.7 & 19 & 4.6 & 0.9 & 6.7 & 45 & 6 & 2.6 & 1.6 & 12 \\
\hline 9 & $\begin{array}{l}\text { Mixed truck traffic with about equal } \\
\text { percentages of single-unit and single- } \\
\text { trailer trucks. }\end{array}$ & 3.3 & 34 & 12 & 1.6 & 9.9 & 36 & 1 & 1.8 & 0.2 & 0.3 \\
\hline 10 & $\begin{array}{l}\text { Mixed truck traffic with about equal } \\
\text { percentages of single-unit and single- } \\
\text { trailer trucks. }\end{array}$ & 0.8 & 31 & 6.9 & 0.1 & 7.8 & 38 & 3.7 & 1.2 & 4.5 & 6.7 \\
\hline 11 & $\begin{array}{l}\text { Mixed truck traffic with a higher } \\
\text { percentage of single-trailer trucks. }\end{array}$ & 1.8 & 25 & 7.6 & 0.5 & 5 & 31 & 9.8 & 0.8 & 3.3 & 15 \\
\hline 12 & $\begin{array}{l}\text { Mixed truck traffic with a higher } \\
\text { percentage of single-unit trucks. }\end{array}$ & 3.9 & 41 & 12 & 1.5 & 12 & 25 & 2.7 & 0.6 & 0.3 & 1.3 \\
\hline 13 & $\begin{array}{l}\text { Mixed truck traffic with about equal } \\
\text { percentages of single-unit and single- } \\
\text { trailer trucks. }\end{array}$ & 0.8 & 34 & 6.2 & 0.1 & 7.9 & 26 & 11 & 1.4 & 3.2 & 10 \\
\hline 14 & Predominantly single-unit trucks. & 2.9 & 57 & 10 & 3.7 & 9.2 & 15 & 0.6 & 0.3 & 0.4 & 0.3 \\
\hline 15 & Predominantly single-unit trucks. & 1.8 & 57 & 8.5 & 1.8 & 6.2 & 14 & 5.4 & 0 & 0 & 5.7 \\
\hline 16 & Predominantly single-unit trucks. & 1.3 & 48 & 11 & 1.9 & 6.7 & 13 & 4.3 & 0.5 & 0.1 & 13 \\
\hline 17 & $\begin{array}{l}\text { Mixed truck traffic with about equal } \\
\text { single-unit and single-trailer trucks. }\end{array}$ & 36 & 15 & 13 & 0.5 & 15 & 18 & 0.5 & 0.8 & 0.1 & 1.5 \\
\hline
\end{tabular}

Growth rate (\%): It is the rate of increase of AADTT per year. Since each segment's reliable traffic data were available from continuous traffic counts, therefore it was calculated separately for each segment on the basis of yearly AADTT. Some sections had negative growth rate which is not allowed as a growth rate input, therefore such section`s growth rate was take as zero. 
Growth function: Growth functions dictate the AADTT growth curve over pavement life. Among No, linear and compound, compound growth rate function was used in all projects as it was best fitted to annual increments in AADTT. The three growth functions available in DARWin-ME ${ }^{\mathrm{TM}}$ are given in Table A-6.

Table A-6: Functions used in forecasting AADTT over pavement age.

\begin{tabular}{|l|l|}
\hline Function & Model \\
\hline No growth & AADTT $=1.0$ AADTT $_{\text {BaseYear }}$ \\
\hline Linear growth & AADTT $=($ Growth Rate $)$ AGE + AADTT BaseYear \\
\hline Compound growth & AADTT $=$ AADTT $_{\text {BaseYear }}(\text { Growth Rate })^{\text {AGE }}$ \\
\hline
\end{tabular}

Monthly adjustment factor: This factor is used to distribute annual traffic over each month. Cumulative of monthly adjustment factor over all months should always be equal to 12 . Default values of 1.0 were used to equally distribute yearly traffic over 12 months.

Axle per Truck: It is required to calculate the load associated with trucks for each class. Singles, tandems, Tridems, quads Axle per truck are required for all 10 FHWA classes. It's values were taken from MTO (2012), which provides two different table sets of axle per truck for Southern (Table A-7) and Northern (Table A-8) Ontario region.

Table A-7: Southern Ontario Typical Axle Per Trucks Table (MTO 2012)

\begin{tabular}{|c|c|c|c|c|c|}
\hline FHWA Class & Singles & Tandems & Tridems & Quads & Total \\
\hline 4 & 1.620 & 0.390 & 0.000 & 0.000 & 2.400 \\
\hline 5 & 2.000 & 0.000 & 0.000 & 0.000 & 2.000 \\
\hline 6 & 1.010 & 0.993 & 0.000 & 0.000 & 2.996 \\
\hline 7 & 1.314 & 0.989 & 0.030 & 0.000 & 3.382 \\
\hline 8 & 2.162 & 0.845 & 0.000 & 0.000 & 3.852 \\
\hline 9 & 1.055 & 1.968 & 0.003 & 0.000 & 5.000 \\
\hline 10 & 1.446 & 1.234 & 0.700 & 0.088 & 6.366 \\
\hline 11 & 4.546 & 0.168 & 0.000 & 0.000 & 4.882 \\
\hline 12 & 2.859 & 1.526 & 0.000 & 0.000 & 5.911 \\
\hline 13 & 1.201 & 2.058 & 0.848 & 0.024 & 7.957 \\
\hline
\end{tabular}


Table A-8: Northern Ontario Typical Axle Per Trucks Table (MTO 2012)

\begin{tabular}{|c|c|c|c|c|c|}
\hline FHWA Class & Singles & Tandems & Tridems & Quads & Total \\
\hline 4 & 1.620 & 0.390 & 0.000 & 0.000 & 2.400 \\
\hline 5 & 2.000 & 0.000 & 0.000 & 0.000 & 2.000 \\
\hline 6 & 1.014 & 0.993 & 0.000 & 0.000 & 3.000 \\
\hline 7 & 1.244 & 0.962 & 0.043 & 0.000 & 3.297 \\
\hline 8 & 2.415 & 0.674 & 0.000 & 0.000 & 3.763 \\
\hline 9 & 1.048 & 1.955 & 0.014 & 0.000 & 5.000 \\
\hline 10 & 1.358 & 1.165 & 0.840 & 0.044 & 6.384 \\
\hline 11 & 3.845 & 0.535 & 0.000 & 0.000 & 4.915 \\
\hline 12 & 2.912 & 1.514 & 0.020 & 0.000 & 6.000 \\
\hline 13 & 1.100 & 2.012 & 0.945 & 0.011 & 8.003 \\
\hline
\end{tabular}

Hourly Adjustment factor: It is used to adjust daily traffic on hourly basis. Traffic is distributed throughout day with an interval of 1 hour. Default traffic hourly adjustment factors were used in the analysis.

\section{A.4 Axle Load Distribution}

It is "the percentage of the total axle applications within each load interval for a specific axle type and class". Axle load distribution is of four type's single, tandem, tridem and quad axle load distributions. These factors are used to distribute percentage of total axles to given load ranges for each class, which produces stress and strain in a pavement. These axle load distributions are provided for each month and class. The load ranges and intervals for each axle type are provided below.

Single axles $-1361 \mathrm{~kg}$ to $18597 \mathrm{~kg}$ at $454 \mathrm{~kg}$ intervals.

Tandem axles $-2722 \mathrm{~kg}$ to $37195 \mathrm{~kg}$ at $907 \mathrm{~kg}$ intervals.

Tridem and quad axles $-5443 \mathrm{~kg}$ to $46266 \mathrm{~kg}$ at $1360 \mathrm{~kg}$ intervals.

\section{A.5 Traffic Capacity}

Traffic capacity option enforces traffic cap on estimated traffic volumes used in the design so that highway capacity is not exceeded. 
AADT excluding trucks: It is obtained from the difference of AADT and AADTT, the resultant traffic belongs to classes 1 through 3 (motorcycles, cars, pickup-trucks, vans and SUV).

Other options include non-truck linear traffic growth rate, highway facility type, Highway terrain type and Rural or urban highway environment information. DARWin-ME ${ }^{\mathrm{TM}}$ uses this information to internally estimate capacity limit on the basis of 2000 Highway Capacity Manual (HCM). Inputting user-specified capacity limit is also possible to manually define a specific value for capacity limit.

\section{A.6 Axle Configuration}

Average axle width (m): It is the distance in feet between two outside edges of an axle. DARWin-ME $^{\mathrm{TM}}$ default values of 2.59 meter were used as average axle width.

Dual tire spacing (mm): It is the transverse distance in inches between the centers of a dual tire. DARWin-ME ${ }^{\mathrm{TM}}$ default values of $305 \mathrm{~mm}$ were used in pavement sections.

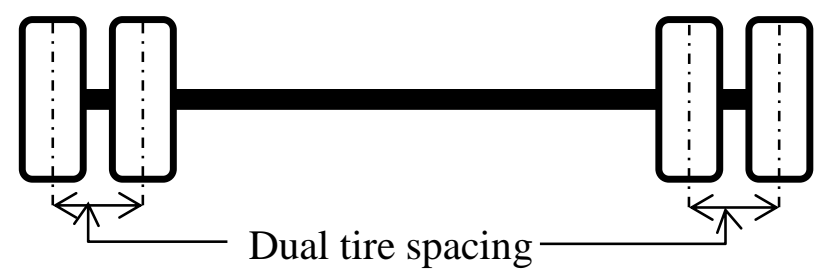

Figure A-1: Dual tire spacing in single axle with dual tire.

Tire pressure (kPa): It is the hot inflation pressure of tires in pounds per square inch. DARWin$\mathrm{ME}^{\mathrm{TM}}$ default value of $827.4 \mathrm{kPa}$ is used in sections.

Tandem axle spacing ( $\mathbf{m m})$ : It is the center-to-center longitudinal spacing between two consecutive axles in a Tandem configuration. Regional default value of $1.45 \mathrm{~m}$ was used in DARWin-ME ${ }^{\mathrm{TM}}$, shown in Figure A-2.

Tridem axle spacing (mm): It is the center-to-center longitudinal spacing between two consecutive axles in a Tridem configuration. Regional default value of $1.68 \mathrm{~m}$ was used in DARWin-ME $^{\mathrm{TM}}$, shown in Figure A-2.

Quad axle spacing (mm): It is the center-to-center longitudinal spacing between two consecutive axles in a Quad configuration. Regional default value of $1.32 \mathrm{~m}$ was used in DARWin-ME $^{\mathrm{TM}}$, shown in Figure A-2. 


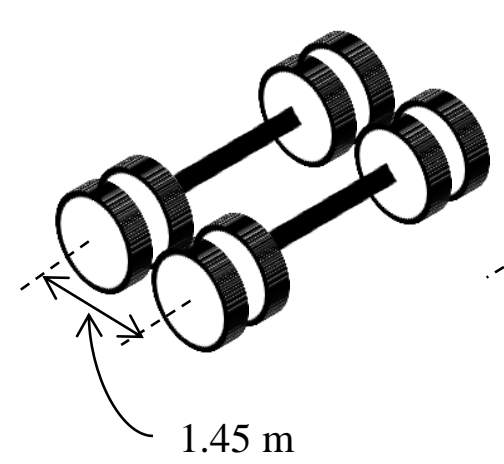

Tandem axle spacing

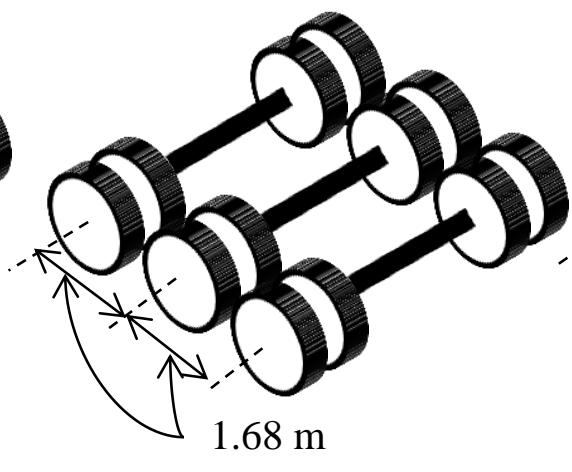

Tridem axle spacing

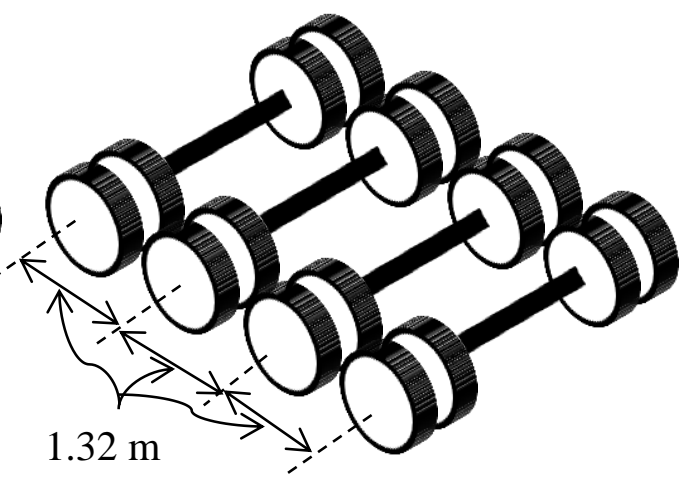

Quad axle spacing

Figure A-2: Tandem, Tridem, Quad axle spacing.

\section{A.7 Lateral Traffic Wander}

Mean wheel location (mm): It is the distance from the outer edge of the wheel to the pavement marking. DARWin-ME ${ }^{\mathrm{TM}}$ default value of $460 \mathrm{~mm}$ was used in analysis of sections.

Traffic wander standard deviation (mm): It is the divergence from the average lateral traffic wander. "This standard deviation is used to estimate the number of axle load repetitions over a single point in a probabilistic manner for the predicting distress and performance" (MTO 2012). DARWin-ME ${ }^{\mathrm{TM}}$ default value of $254 \mathrm{~mm}$ was used.

Design lane width (m): It is the width of the design lane. Level-1 value of design lane was obtained for each road section.

\section{A.8 Wheel Base}

Average spacing of short axles (m): It is the average longitudinal spacing of short axles. Regional default value of $5.1 \mathrm{~m}$ was used.

Average spacing of medium axles (m): It is the average longitudinal spacing of short axles. Regional default value of $4.6 \mathrm{~m}$ was used.

Average spacing of long axles (m): It is the average longitudinal spacing of short axles. Regional default value of $4.7 \mathrm{~m}$ was used.

Percent trucks with short, medium and long axles (\%): Percentage of trucks in design with short, medium and long axles. DARWin-ME ${ }^{\mathrm{TM}}$ default values were used.

Summary of these traffic inputs with its levels and source are given in Table A-9 
Table A-9: Traffic Inputs with level and source used for DARWin-ME ${ }^{\mathrm{TM}}$ projects of Ontario.

\begin{tabular}{|c|c|c|c|c|c|}
\hline & Parameter & Input Requirement & $\begin{array}{l}\text { Input } \\
\text { Level }\end{array}$ & Value & Source \\
\hline \multirow{5}{*}{1.} & \multirow{5}{*}{ AADTT } & i. $\quad$ Two-way AADTT & 1 & \multicolumn{2}{|r|}{ MTO Database } \\
\hline & & ii. Number of lanes & 1 & & MTO Database \\
\hline & & iii. Percent of Truck in design Direction & 3 & $50 \%$ & Local Calibration Guide \\
\hline & & iv. $\quad$ Percent trucks in design lane & 2 & Table A-2 & (MTO 2012) \\
\hline & & v. $\quad$ Operational speed (kph) & 3 & Table A-3 & General \\
\hline \multirow{11}{*}{2.} & \multirow{11}{*}{$\begin{array}{c}\text { Traffic } \\
\text { Volume } \\
\text { Adjustment }\end{array}$} & i. Truck Traffic Classification (TTC) & & & \\
\hline & & a. Vehicle class distribution & 2 & \multicolumn{2}{|r|}{ MTO Database } \\
\hline & & b. Growth rate & 1 & \multicolumn{2}{|r|}{ MTO Database } \\
\hline & & Growth function & 1 & Compound & MTO Database \\
\hline & & Monthly adjustment factor & 3 & 1 & DARWin-ME ${ }^{\mathrm{TM}}$ Default \\
\hline & & Hourly adjustment factor & 3 & \multicolumn{2}{|c|}{ DARWin-ME ${ }^{\mathrm{TM}}$ Default } \\
\hline & & \multicolumn{4}{|l|}{ Axle Per Truck } \\
\hline & & a. $\quad$ Single axle per truck & 2 & \multirow{4}{*}{$\begin{array}{l}\text { Table A-7 } \\
\text { Table A-8 }\end{array}$} & (MTO 2012) \\
\hline & & b. Tandem axle per truck & 2 & & (MTO 2012) \\
\hline & & c. Tridem axle per truck & 2 & & (MTO 2012) \\
\hline & & d. Quad axle per truck & 2 & & (MTO 2012) \\
\hline \multirow{4}{*}{3.} & \multirow{4}{*}{$\begin{array}{c}\text { Axle } \\
\text { Distribution }\end{array}$} & i. Single Axle Distribution & 2 & \multicolumn{2}{|r|}{ (MTO 2012) } \\
\hline & & ii. Tandem Axle Distribution & 2 & \multicolumn{2}{|r|}{ (MTO 2012) } \\
\hline & & iii. Tridem Axle Distribution & 2 & \multicolumn{2}{|r|}{ (MTO 2012) } \\
\hline & & iv. Quad axles Axle Distribution & 2 & \multicolumn{2}{|r|}{ (MTO 2012) } \\
\hline \multirow{7}{*}{4.} & \multirow{7}{*}{$\begin{array}{c}\text { Traffic } \\
\text { Capacity }\end{array}$} & Traffic Capacity & \multicolumn{2}{|c|}{ Not enforced } & (MTO 2012) \\
\hline & & $\begin{array}{l}\text { a. Annual average daily traffic excluding } \\
\text { trucks (i.e. cars) }\end{array}$ & & & \\
\hline & & b. Non-truck linear traffic growth rate $(\%)$ & & & \\
\hline & & c. Highway facility type & & & \\
\hline & & d. Highway terrain type & & & \\
\hline & & e. Rural or urban highway environment & & & \\
\hline & & f. User-Specified capacity Limit & & & \\
\hline \multirow{6}{*}{5.} & \multirow{6}{*}{$\begin{array}{c}\text { Axle } \\
\text { Configuration }\end{array}$} & $\begin{array}{ll}\text { i. } & \text { Average axle width }(\mathrm{m})\end{array}$ & 3 & 2.59 & DARWin-ME ${ }^{\mathrm{TM}}$ Default \\
\hline & & ii. $\quad$ Dual tire spacing $(\mathrm{mm})$ & 3 & 305 & DARWin-ME $^{\mathrm{TM}}$ Default \\
\hline & & $\begin{array}{ll}\text { iii. } & \text { Tire pressure }(\mathrm{kPa})\end{array}$ & 3 & 827.4 & DARWin-ME $^{\mathrm{TM}}$ Default \\
\hline & & iv. $\quad$ Tandem axle spacing $(\mathrm{m})$ & 2 & 1.45 & (MTO 2012) \\
\hline & & v. $\quad$ Tridem axle spacing $(\mathrm{m})$ & 2 & 1.68 & (MTO 2012) \\
\hline & & vi. $\quad$ Quad axle spacing $(\mathrm{m})$ & 2 & 1.32 & (MTO 2012) \\
\hline \multirow{3}{*}{6.} & \multirow{3}{*}{$\begin{array}{c}\text { Lateral } \\
\text { Traffic } \\
\text { Wander }\end{array}$} & i. $\quad$ Mean wheel location $(\mathrm{mm})$ & 3 & 460 & DARWin-ME $^{\mathrm{TM}}$ Default \\
\hline & & ii. $\quad$ Traffic wander standard deviation $(\mathrm{mm})$ & 3 & 254 & DARWin-ME ${ }^{\mathrm{TM}}$ Default \\
\hline & & iii. $\quad$ Design lane width $(\mathrm{m})$ & 1 & \multicolumn{2}{|r|}{ MTO Database } \\
\hline & & i. $\quad$ Average spacing of short axles $(\mathrm{m})$ & 2 & 5.1 & (MTO 2012) \\
\hline & & Average spacing of medium axles (m) & 2 & 4.6 & (MTO 2012) \\
\hline & Wheel Base & Average spacing of long axles (m) & 2 & 4.7 & (MTO 2012) \\
\hline 7. & & iv. $\quad$ Percent trucks with short axles (\%) & 3 & 33 & DARWin-ME ${ }^{\mathrm{TM}}$ Default \\
\hline & & v. Percent trucks with medium axles (\%) & 3 & 33 & DARWin-ME ${ }^{\mathrm{TM}}$ Default \\
\hline & & vi. $\quad$ Percent trucks with long axles (\%) & 3 & 34 & DARWin-ME ${ }^{\mathrm{TM}}$ Default \\
\hline
\end{tabular}




\section{APPENDIX B Climate Data for DARWin-ME ${ }^{\mathrm{TM}}$}

Regional climate controls the aging effects in a pavement. Extreme weather conditions such as temperature, precipitation, continuous freeze-thaw cycles and depth of water table play a vital role in producing extreme long term distresses. Local climate is enforced by inputting location parameters (latitude \& longitude), which then indicates location of surrounding weather stations. The DARWin-ME ${ }^{\mathrm{TM}}$ software currently includes a database of 851 weather stations throughout USA and Canada. This database for each weather station contains climatic inputs for multiple years. Each weather station data include hourly data for air temperature, wind speed, sunshine, precipitation and humidity for several months. Several major weather stations have hourly climate data of 60 to 66 months, this is not always the case hence software requires at least 24 months actual weather station data for computational purposes (NCHRP 2004).

The climatic effects on pavement materials, responses and distresses are estimated using the Integrated Climate Model (ICM), which is used to model temperature and moisture within pavement layers and the foundation. Temperature and moisture content are two climatic variables produced by ICM, which affects the pavement layer and subgrade properties. Integrated Climatic Model (ICM) records the initial user specified resilient modulus, $\mathrm{M}_{\mathrm{R}}$, of all unbound layer materials. It estimates the effects of seasonal changes in soil moisture content and freeze-thaw cycles on resilient modulus. Continuously varying $M_{R}$ value with pavement age is used in computations of critical pavement response parameters.

Climatic analysis under ICM requires following input information to start the computation process.

- General information (Base/Subgrade construction time, Existing pavement construction month and year, pavement construction month and year, traffic opening month and year, type of design)

- Weather-related information (Hourly air temperature, hourly precipitation, hourly wind speed, hourly percentage shine, hourly relative humidity)

- Ground water related information (depth) 
- Drainage surface properties (Surface shortwave absorptivity)

- Pavement structure and materials (layer thickness, asphalt, unbound and subgrade material properties)

Climate inputs with level and source used in this study are given in Table B-1 with their level and source. Material information required to run ICM as well as other modules DARWin-ME ${ }^{\mathrm{TM}}$ are described in separate section.

Table B-1: Climate Inputs with level and source used in DARWin-ME ${ }^{\mathrm{TM}}$ projects in Ontario.

\begin{tabular}{|c|c|c|c|}
\hline S.No & Parameter & Level & Source \\
\hline 1 & Longitude & 1 & \multirow{3}{*}{$\begin{array}{l}\text { Site specific longitude, latitude and elevation of } \\
\text { pavement sections were identified from location } \\
\text { of nearest intersection of the section using Google } \\
\text { Maps. }\end{array}$} \\
\hline 2 & Latitude & 1 & \\
\hline 3 & Elevation (m) & 1 & \\
\hline 4 & Depth of Ground Water Table (m) & 3 & Regional default value of $6.1 \mathrm{~m}$ was used. \\
\hline
\end{tabular}

On the basis of these inputs either a single weather station can be used or a set of multiple weather stations can be used to create a virtual weather station. On inputting these location inputs, weather stations are automatically sorted by least distance from the inputted pavement location. It is recommended to select more than one weather station, while creating a virtual weather station. Otherwise, this would lead to missing data and errors. Further, AASHTO (2008) recommends that weather stations with similar elevation should be selected to create a virtual weather station.

On selecting climate station (either single or virtual), software generates a climate summary which gives a mean annual air temperature, mean annual precipitation, mean monthly temperatures (all months), number of wet days, freezing index and average number of freeze/thaw cycles, which gives a general idea of the climate of that region.

Mostly, whether stations from Ontario were used, however weather stations from surrounding states were also used for few pavement sections. Ontario`s 34 whether stations are included in DARWin-ME ${ }^{\mathrm{TM}}$ database. Weather stations of Ontario which are available in default climatic database of DARWin-ME ${ }^{\mathrm{TM}}$ are included in Appendix B. 
Ground Water table (GWT) depth of 6.1m (20 ft) was used in all projects which was level-3 value. Subgrade of most pavement sections are soft (low modulus), the average mode modulus is around 40MPa. Therefore influence of the GWT becomes more as shown in the sensitivity study (Appendix GG-2 of NCHRP (2004)). However, same sensitivity study also recommends that GWT depth less than 5 feet to 7 feet is more critical, while selected GWT depth of $6.1 \mathrm{ft}(20 \mathrm{ft})$ is way above the given values ( 5 feet to 7 feet) which significantly decreases the effects of GWT on modulus of different layers. 


\section{APPENDIX C Pavement Structure Data for DARWin-ME ${ }^{\mathrm{TM}}$}

Typical flexible pavement consists of two types of layers AC layer and unbound (granular and fine) layer. AC layer and unbound layer material inputs are described below.

\section{C.1 Asphalt Concrete Material Inputs}

The properties AC layer mixtures used in DARWin-ME ${ }^{\mathrm{TM}}$ were taken from (Jannat 2012). Following Table C-1 obtained from (Jannat 2012) gives the asphalt concrete mix properties used in analysis of pavement sections.

Table C-1: Asphalt concrete mix properties used for analysing pavement sections.

\begin{tabular}{|c|c|c|c|c|c|c|c|c|c|}
\hline & \multirow{2}{*}{ Asphalt Layer } & \multirow{2}{*}{$\begin{array}{c}\text { Unit } \\
\text { Weight }\end{array}$} & \multirow{2}{*}{$\begin{array}{c}\text { Binder } \\
\text { Content }\end{array}$} & \multirow{2}{*}{$\begin{array}{c}\text { Air } \\
\text { Void }\end{array}$} & $\begin{array}{c}\text { Effective } \\
\text { Binder } \\
\text { Content }\end{array}$ & $\begin{array}{c}\text { Indirect } \\
\text { Tensile } \\
\text { Strength }\end{array}$ & \multicolumn{4}{|c|}{$\begin{array}{c}\mathbf{1 9} \\
\text { mm }\end{array}$} & $\begin{array}{c}\mathbf{9 . 5} \\
\text { mm }\end{array}$ & $\begin{array}{c}\mathbf{4 . 7 5} \\
\text { mm }\end{array}$ & $\begin{array}{c}\mathbf{0 . 0 7 5} \\
\text { mm }\end{array}$ \\
\hline Unit & $\mathrm{Kg} / \mathrm{m}^{3}$ & $\%$ & $\%$ & $\%$ & Mpa & $\%$ & $\%$ & $\%$ & $\%$ \\
\hline HL-1 & 2520 & 5 & 4 & 12.4 & 2.49 & 100 & 82.5 & 55 & 2.5 \\
\hline HL-2 & 2410 & 6 & 5 & 14.2 & 2.51 & 100 & 100 & 92.5 & 5.5 \\
\hline $\begin{array}{c}\text { HL-3, 3M and } \\
\text { SP12.5 }\end{array}$ & 2520 & 5 & 4 & 12.4 & 2.49 & 100 & 82.5 & 55 & 2.5 \\
\hline HL-4B, 4M \& RHL & 2480 & 5 & 4 & 12.2 & 2.52 & 100 & 72 & 53.5 & 3 \\
\hline HL-4S & 2480 & 5 & 4 & 12.2 & 2.52 & 100 & 72 & 53.5 & 3 \\
\hline HL-5 & 2520 & 4.5 & 4 & 10.9 & 2.49 & 97 & 72 & 53.5 & 3 \\
\hline HL-6 & 2460 & 4.5 & 4 & 10.9 & 2.51 & 97 & 72 & 53.5 & 3 \\
\hline HL-8 & 2460 & 4.5 & 4 & 10.9 & 2.69 & 97 & 63 & 42.5 & 3 \\
\hline DFC & 2520 & 5 & 3.5 & 12.4 & 2.56 & 100 & 82.5 & 52.5 & 2.5 \\
\hline HDBC \& HDB & 2460 & 4.5 & 4 & 10.9 & 2.69 & 97 & 63 & 43.5 & 3 \\
\hline MDBC & 2500 & 5 & 4 & 12.3 & 2.69 & 97 & 63 & 40 & 3 \\
\hline RHL & 2480 & 5 & 4 & 12.2 & 2.52 & 100 & 72 & 53.5 & 3 \\
\hline
\end{tabular}

Remaining asphalt concrete layer inputs with level and source used in DARWin-ME ${ }^{\mathrm{TM}}$ projects in Ontario are given in Table C-2. 
Table C-2: Asphalt Concrete Layer Inputs with level and source used in DARWin-ME ${ }^{\mathrm{TM}}$ projects in Ontario.

\begin{tabular}{|c|c|c|c|c|}
\hline Parameter & Input requirement & Level & Values & Source \\
\hline Asphalt Layer & Thickness & 1 & \multicolumn{2}{|c|}{ MTO PMS-2 Database } \\
\hline \multirow{3}{*}{$\begin{array}{c}\text { Mixture } \\
\text { Volumetric }\end{array}$} & Unit weight $\left(\mathrm{Kg} / \mathrm{m}^{3}\right)$ & 2 & Table C-1 & (Jannat 2012) \\
\hline & Effective binder content $(\%)$ & 2 & Table C-1 & (Jannat 2012) \\
\hline & Air voids (\%) & 2 & Table C-1 & (Jannat 2012) \\
\hline \multirow{2}{*}{ Poison's Ratio } & Is Poisson's ratio calculated? & - & False & - \\
\hline & Poison's Ratio & 3 & 0.35 & DARWin-ME ${ }^{\mathrm{TM}}$ Default \\
\hline \multirow{7}{*}{$\begin{array}{l}\text { Mechanical } \\
\text { Properties }\end{array}$} & Dynamic modulus & 3 & & - \\
\hline & - Aggregate Gradation & 2 & Table C-1 & (Jannat 2012) \\
\hline & G Star Predictive Model & 3 & \multicolumn{2}{|c|}{ DARWin-ME ${ }^{\mathrm{TM}}$ Default } \\
\hline & Reference temperature $\left(\mathrm{C}^{\circ}\right)$ & 3 & 21.1 & DARWin-ME ${ }^{\mathrm{TM}}$ Default \\
\hline & Asphalt binder & 2 & \multicolumn{2}{|r|}{ (MTO 2012) } \\
\hline & $\begin{array}{l}\text { Indirect tensile strength at }-10 \mathrm{C}^{\mathrm{o}} \\
(\mathrm{MPa})\end{array}$ & 3 & \multicolumn{2}{|r|}{ Calculated } \\
\hline & Creep compliance (1/GPa) & 3 & \multicolumn{2}{|c|}{ DARWin-ME ${ }^{\mathrm{TM}}$ Default } \\
\hline \multirow{3}{*}{ Thermal } & Thermal conductivity (W/m-K) & 3 & 1.16 & DARWin-ME ${ }^{\mathrm{TM}}$ Default \\
\hline & Heat capacity $(\mathrm{J} / \mathrm{kg}-\mathrm{K})$ & 3 & 963 & DARWin-ME ${ }^{\mathrm{TM}}$ Default \\
\hline & Thermal Contraction & 3 & \multicolumn{2}{|r|}{ Calculated } \\
\hline
\end{tabular}




\section{C.2 Unbound Granular and Fine/Subgrade Material Inputs}

Project specific material properties (level-1) such as gradation, air voids and binder content were not available in database, therefore Ontario region specific material properties (level-2) were used for all materials. These level-2 material properties were obtained from

Table C-3: Unbound Granular Layer Inputs with level and source used in DARWin-ME ${ }^{\mathrm{TM}}$ projects in Ontario.

\begin{tabular}{|c|c|c|c|c|c|c|c|}
\hline \multirow{2}{*}{ Parameter } & \multirow{2}{*}{ Input requirement } & \multicolumn{3}{|c|}{ Unbound Granular Layer } & \multicolumn{3}{|c|}{ Unbound Fine/Subgrade Layer } \\
\hline & & Level & Value & Source & Level & Value & Source \\
\hline \multicolumn{2}{|c|}{ Type of Material } & \multicolumn{3}{|c|}{ MTO PMS-2 Database } & \multicolumn{3}{|c|}{ MTO PMS-2 Database } \\
\hline \multirow{3}{*}{ Unbound } & Layer thickness (mm) & 1 & \multicolumn{2}{|c|}{ MTO PMS-2 Database } & & \multicolumn{2}{|c|}{ Semi-infinite } \\
\hline & Poison's ratio & 3 & 0.35 & Default & 3 & 0.35 & Default \\
\hline & $\begin{array}{l}\text { Coefficient of lateral } \\
\text { earth pressure }\left(k_{\mathrm{o}}\right)\end{array}$ & 3 & 0.5 & Default & 3 & 0.5 & Default \\
\hline Modulus & $\begin{array}{l}\text { Resilient modulus } \\
(\mathrm{MPa})\end{array}$ & 2 & & 2012) & 1 & & $\begin{array}{l}\text { PMS-2 } \\
\text { base }\end{array}$ \\
\hline Sieve & $\begin{array}{l}\text { Gradation \& other } \\
\text { engineering properties }\end{array}$ & 2 & & 2012) & 2 & & 2012) \\
\hline
\end{tabular}

\section{C.3 Rehabilitation Information}

For rehabilitated pavement section surface condition of existing pavement is described in terms of rehabilitation information. MEPDG considers the repairs and milling of the existing pavement layer. Rehabilitated pavements are sensitive to existing conditions of pavements. Milling depth is inputted and pavement repairs taken in account by entering the condition of existing pavement. Pavement ratting among excellent, very good, poor and very poor is selected on the basis of existing pavement. Pavement ratting of Fair (3) was used at the rehabilitation input level-3 on the basis of observed condition of pavement surface in Ontario. Pre-overlay rut is also equally sensitive parameter, which needs to be specified separately for each pavement section. In level-3 
input only total pre-overlay rut is required. The pre-overlay rut for rehabilitated pavements sections was mostly un-available in Ontario historical database. Hence, a comprehensive study was conducted to find a representative pre-overlay rut value for flexible pavement sections in Ontario. The study on evaluation of pre-overlay rut for Ontario is presented in chapter 5. 


\section{REFERENCE LIST}

AASHO (1962). "Rep No. 5." Pavement Research, N. R. Council, ed., National Academy Research, Washington, D.C.

AASHTO (2001). "A Policy on Geometric Design of Highways and Streets."American Association State Highway Transportation Officials

AASHTO (2008). Mechanistic-Empirical Pavement Design Guide: A Manual of Practice, American Association of State Highway and Transportation Officials, Washington DC.

AASHTO (2010). Guide for the Local Calibration of the Mechanical-Empirical Pavement Design Guide, American Association of State Highway and Transportation Officials, Washington DC.

\section{AASHTO (2011). AASHTOWare DARWin-ME SOFTWARE HELP SYSTEM}

Ahmmed, M. A., Kass, S., Hilderman, S., and Tang, W. K. S. (2011). "MEPDG Implementation: Manitoba Experience." Annual Conference of the Trasporataion Association of CanadaEdmonton, Alberta.

Ali, H. A., Tayabji, S. D., and La Torre, F. (1998). "Calibration of mechanistic-empirical rutting model for in-service pavements." Transportation Research Record(1629), 159-168.

Banerjee, A., Aguiar-Moya, J. P., and Prozzi, J. A. (2009). "Calibration of mechanistic-empirical pavement design guide permanent deformation models." Transportation Research Record, (2094), 12-20.

Brown, S. F., Thompson, M. R., and Barenberg, E. J. (2006). "Research Results Digest 307." Research Results Digest, N. C. H. R. PROGRAM, ed.

Caliendo, C. (2012). "Local calibration and implementation of the mechanistic-empirical pavement design guide for flexible pavement design." Journal of Transportation Engineering, 138(3), 348-360.

Cebon, A. C. a. D. (1995). "Modelling Whole-Life Pavement Performance " Journal of Mechanical engineering sciences, 209(6).

Chong, G. J., Phang, W. A., and Wrong, G. A. (1989). "Manual for Condition Rating of Flexible Pavements: Distress Manifestations."Ministry of Transportation Ontario, Research and Development Branch, SP-024.

Corley-Lay, J., Jadoun, F. M., Mastin, J. N., and Kim, Y. R. (2010). "Comparison of Flexible Pavement Distresses Monitored by North Carolina Department of Transportation and Long-Term Pavement Performance Program." Transportation Research Record, (2153), 91-96.

Donahue, J. "Local calibration of the MEPDG for HMA pavements in Missouri." Proc., 2008 Annual Meeting of the Association of Asphalt Paving Technologists, AAPT, April 25, 2008 - April 30, 2008, Association of Asphalt Paving Technologist, 975-984. 
Eisenmann, J., and A. Hilmer. "Influence of Wheel Load and Inflation Pressure on the Rutting Effect at Asphalt-Pavements - Experiments and Theoretical Investigations." Proc., Sixth International Conference on the Structural Design of Asphalt Pavements, 392-403.

Hall, K., Xiao, D., and Wang, K. (2011). "Calibration of the mechanistic-empirical pavement design guide for flexible pavement design in Arkansas." Transportation Research Record, (2226), 135-141.

He, W., Juhasz, M., Crockett, J., Crockett, V., and Lakkavalli, V. (2011). "Evaluation of DARWin-ME Pavement Rutting Prediction Models Using Data from Alberta's Pavement Management System." Annual Conference of the Transportation Association of Canada Edmonton, Alberta.

Hildebrand, G., Busch, C., and Ullidtz, P. "New Danish pavement design guide using simulation to obtain optimum results." Proc., Proceedings of the 1st TRA conference.

Hofstra, A., and A.J.G. Klomp. "Permanent Deformation of Flexible Pavements Under Simulated Road Traffic Conditions." Proc., Third International Conference on tire Stntcttral Design of Asphalt Pavements, 613-621.

Huang, Y. H. (2004). Pavement Analysis and Design, Pearson Prentice Hall, Pearson Prentice Hall Upper Saddle River, NJ 07458.

Institute, A. (2005). "SW-1 Asphalt Pavement Thickness Design Software for Highways, Airports, Heavy Wheel Loads and Other Applications." Asphalt Institute, Inc., P.O. Box 14052, Lexington, KY 40512-4052.

Jadoun, F. M. (2011). "Calibration of the Flexible Pavement Distress Prediction Models in the Mechanistic Empirical Pavement Design Guide (MEPDG) for North Carolina." Doctor of Philosophy, North Carolina State University

Jannat, G. (2012). "Database Development for Ontario's Local Calibration of MechanisticEmpirical Pavement Design Guide (MEPDG) Distress Model." MASc, Ryerson University.

Kang, M., and Adams, T. M. "Local Calibration for Fatigue Cracking Models Used in the Mechanistic Empirical Pavement Design Guide." Proc., Mid-Continent Transportation Research Symposium.

Korkiala-Tanttu, L. "A new material model for permanent deformations in pavements " Proc., Seventh Conference on Bearing Capacity of Roads and Airfields, Ny Media AS, Oslo.

Le, A. T., Lee, H. J., Park, H. M., and Lee, S. Y. (2009). "Development of a permanent deformation model of asphalt mixtures for South Korean pavement design guide." Transportation Research Record(2095), 45-52.

Li, J., Pierce, L. M., and Uhlmeyer, J. (2009). "Calibration of flexible pavement in mechanisticempirical pavement design guide for Washington state." Transportation Research Record, (2095), 73-83.

Li, Q., and Kuai, H. "Regional calibration of asphalt concrete layers permanent deformation model for mechanistic-empirical pavement design guide." Proc., 10th International Conference of Chinese Transportation Professionals - Integrated Transportation 
Systems: Green, Intelligent, Reliable, ICCTP 2010, August 4, 2010 - August 8, 2010, American Society of Civil Engineers, 3628-3636.

Mallela, J., Glover, L. T., and Darter, M. I. (2009). "Guidelines for Implementing NCHRP 1-37A M-E Design Procedures in Ohio: Volume 1- Summary of Findings, Implementation Plan, and Next Steps ", Ohio Department of Transportation, and the U.S. Department of Transportation, Federal Highway Administration, Applied Research Associates, Inc.

MTO, M. E. R. O. (2012). "Ontario's Default Parameters for AASHTOWare Pavement ME Design Interim Report."

NCHRP (2004). "Guide for Mechanistic Empirical Design of New and Rehabilitated Pavement Structures."ARA, Inc., ERES Division 505 West University Avenue Champaign, Illinois 61820.

NCHRP (2004). "HMA Rehabilitation of Existing Pavements."ARA, Inc., ERES Division 505 West University Avenue Champaign, Illinois 61820.

NCHRP (2006). "Research Results Digest 308." Transportation Researh Board, Washington, 24.

Salama, H. K., Chatti, K., and Haider, S. W. "Backcalculation of permanent deformation parameters using time series rut data from in-service pavements." Proc., Pavement Rehabilitation, Strength and Deformation Characteristis, and Surface Properties-Vehicle Interaction 2006, National Research Council, 98-109.

Siraj, N., Mehta, Y. A., Muriel, K. M., and Sauber, R. W. "Verification of MechanisticEmpirical pavement design guide for the state of New Jersey." Proc., 8th International Conference on the Bearing Capacity of Roads, Railways and Airfields, BCR2A'09, June 29, 2009 - July 2, 2009, CRC Press, 921-930.

Souliman, M. I., Mamlouk, M. S., El-Basyouny, M. M., and Zapata, C. E. "Calibration of the AASHTO MEPDG for flexible pavement for Arizona conditions." Proc., 89th Annual Meeting of the Transportation Research Board, Transportation Research Board.

Sousa, J. B., Craus, J., and Monismith, C. L. (1991). "Summary Report on Permanent Deformation in Asphalt Concrete." S. H. R. Program, ed., Institute of Transportation Studies, Washington, D.C.

Terzaghi, K., and Hogentogler, C. A. (1929). "Interrelationship of load, road and subgrade." Public Roads, 37-64.

Ullidtz, P., Harvey, J., Tsai, B.-W., and Monismith, C. L. (2008). "Calibration of mechanisticempirical models for flexible pavements using california heavy vehicle simulators." Transportation Research Record(2087), 20-28.

VonQuintus, H. L., Mallela, J., Bonaquist, R., Schwartz, C. W., and Carvalho, R. L. (2012). "NCHRP REPORT 719 Calibration of Rutting Models for Structural and Mix Design." T. R. BOARD, ed., American Association of State Highway and Transportation WASHINGTON, D.C.

VonQuintus, H. L., and Moulthrop, J. S. (2007). "Mechanistic-Empirical Pavement Design Guide Flexible Pavement Performance Prediction Models.", Montana Department of Transportation, Helena. 
Werkmeister, S. (2002). "Permanent deformation behaviour of unbound granular materials." Ph.D, University of Technology Dresden.

Werkmeister, S., Dawson, A. R., and Wellner, F. (2005). "Permanent Deformation Behaviour of Granular Materials." Road Materials and Pavement Design, 31-51.

White, T. D., and Haddock, J. E. (2002). "NCHRP REPORT 468 Contributions of Pavement Structural Layers to Rutting of Hot Mix Asphalt Pavements." NCHRP REPORT, Transportation Research Board - National Research Council, Washington. D.C.

Williams, D. R. C., and Shaidur, R. (2013). "Mechanistic-Empirical Pavement Design Guide Calibration for Pavement Rehabilitation." SPR 718 Institute for Transportation Iowa State University, 2711 South Loop Drive, Suite 4700 Ames, IA 50010-8664

Zhou, F., and Scullion, T. (2002). "VESYS5 Rutting Model Calibrations with Local Accelerated Pavement Test Data and Associated Implementation." Texas Transportation Institute, 88. 